\title{
LOS CHALCIDOIDEA (HYMENOPTERA) ASOCIADOS CON AGALLAS DE CINÍPIDOS (HYMENOPTERA, CYNIPIDAE) EN LA COMUNIDAD DE MADRID
}

\author{
J. F. Gómez ${ }^{1}$, M. Hernández Nieves ${ }^{1}$, A. M. Garrido Torres, R. R. Askew ${ }^{2}$ \\ y J. L. Nieves-Aldrey ${ }^{1}$
}

\begin{abstract}
RESUMEN
Se compila y actualiza la información existente sobre la comunidad parasitoide de Chalcidoidea, asociada a agallas de cinípidos (Hymenoptera, Cynipidae) en la Comunidad de Madrid. Los datos corresponden a más de 1000 registros, tanto de datos publicados, como inéditos, correspondientes a colectas en 80 localidades de Madrid efectuadas por el equipo investigador a lo largo de 23 años. Se aporta una lista comentada de 121 especies, 19 de las cuales con identificación provisional, de 6 familias de Chalcidoidea: 26 Eurytomidae, 27 Torymidae, 9 Ormyridae, 33 Pteromalidae, 9 Eupelmidae y 17 Eulophidae, inventariadas en la Comunidad de Madrid. Ormyrus rufimanus Mayr, 1904 e Idiomacromerus semiaeneus (Szelenyi, 1957) se citan por primera vez en la Península Ibérica. Para cada familia y género de Chalcidoidea se comentan su biología, diversidad y distribución en la Comunidad de Madrid. Se discute la composición de la comunidad parasitoide asociada a agallas en la Comunidad de Madrid comparándola con la del ámbito íbero-balear y el Paleártico occidental. Se comentan las especies de la comunidad ibérica de parasitoides de Cynipidae ausentes de la región de Madrid, las exclusivas de esta comunidad y las potencialmente presentes. Se incluyen sendos apéndices finales, uno con la lista de especies de Chalcidoidea obtenidas de 74 agallas distintas correspondientes a 71 especies de cinípidos hospedadoras de la Comunidad de Madrid que presentan algún registro de parasitoides, y otro con la relación completa de material estudiado por localidades, con sus coordenadas X e Y, agallas y plantas hospedadoras.
\end{abstract}

Palabras clave: Chalcidoidea, Cynipidae, agallas, parasitoides, comunidad, Madrid, España, nuevas citas

\begin{abstract}
Chalcidoidea (Hymenoptera) associated with galls of Cynipidae (Hymenoptera) in Comunidad de Madrid (Spain)

Information about the chalcid wasp parasitoid community (Hymenoptera, Chalcidoidea) associated with galls of Cynipidae in Madrid (Spain) is compiled and updated. Studied material includes more than 1000 published and unpublished records from samplings in 80 sites in the Madrid region carried out over twenty three years by the research team. A check-list of 121 species, 19 of them provisionally identified, from
\end{abstract} Departamento de Biodiversidad y Biología Evolutiva. Museo Nacional de Ciencias Naturales (CSIC). C/ José Gutiérrez
Abascal, 2. 28006. Madrid, España. E-mail: aldrey@mncn.csic.es, jgomez@mncn.csic.es.

2 5, Beeston Hall Mews, Beeston, Tarpoley, Cheshire, CW6 9TZ England. 
6 families of Chalcidoidea is provided as follows: 26 Eurytomidae, 27 Torymidae, 9 Ormyridae, 33 Pteromalidae, 9 Eupelmidae and 17 Eulophidae. Ormyrus rufimanus Mayr, 1904 and Idiomacromerus semiaeneus (Szelenyi, 1957) are recorded for the first time in the Iberian Peninsula. For each family and genus of Chalcidoidea data are given on biology, diversity and distribution in Comunidad de Madrid. The composition of the chalcid wasp parasitoid community associated with gall wasps in Comunidad de Madrid is discussed and compared to the same community data from the Iberian Peninsula and the Western Palaearctic. Species from the Iberian community of chalcid parasitoids that are missing from Madrid region, exclusive species and potentially present species are also commented upon. Finally two appendices are presented as follows: a list of the Chalcidoidea species reared from 73 different galls made by 71 cynipid species from Madrid with associated parasitoid records, and a final appendix with full record data of all studied material, including information on the sampling localities with X, Y georeferenced coordinates, host galls and host plants.

Key words: Chalcidoidea, Cynipidae, galls, parasitoids, community, Madrid, Spain, new records.

\section{Introducción}

La familia Cynipidae, representada por 140 especies en la Península Ibérica y Baleares (Nieves-Aldrey, 2001; Nieves-Aldrey et al., este volumen), es una de las dos principales dentro de la superfamilia Cynipoidea (Hymenoptera). Se caracteriza por la fitofagia especializada que practican sus especies, cuyo significado es la inducción y formación de agallas en plantas de diferentes familias botánicas. Aunque la formación de agallas vegetales o cecidias no es una particularidad de esta familia de himenópteros dentro del reino animal, las agallas de cinípidos despliegan una morfología y estructura singularmente complejas y varían ampliamente en cuanto a tamaño, forma, ubicación específica sobre la planta hospedadora y órgano vegetal atacado. Por otra parte, las agallas en general, y las de cinípidos en particular, además del interés biológico que en sí mismo representan por el proceso de cecidogénesis, tienen un extraordinario valor ecológico dado que se constituyen como comunidades ecológicas de gran complejidad funcional. En efecto, la entomofauna asociada a las agallas de cinípidos es compleja y diversa hasta el punto que pueden ser consideradas «puntos calientes» ecológicos. En este sentido, albergan una fauna asociada integrada fundamentalmente por tres niveles tróficos: inquilinos, parasitoides y sucesores, con gran cantidad de especies interelacionadas entre sí en complejas redes tróficas (Askew, 1961, 1975a, 1984; Csóka et al., 2005; Hawkins \& Goeden, 1984; Hayward \& Stone, 2005; Memmott \& Godfray, 1992; Price \& Clancy, 1986; Redfern \& Askew, 1992; Shorthouse, 1973; Wiebes-Rijks \&
Shorthouse, 1992). De una simple agalla de la generación ágama de Andricus kollari pueden depender más de 20 especies de artrópodos y las agallas con múltiples cámaras larvales de Biorhiza pallida o Andricus quercusradicis pueden albergar más de un centenar de insectos de múltiples especies (Nieves-Aldrey, 2001; Csóka et al., 2005).

Los parasitoides de agallas de cinípidos pertenecen en su inmensa mayoría a la superfamilia Chalcidoidea (Hymenoptera). La superfamilia Chalcidoidea está compuesta por unas 21.000 especies descritas, en 19 familias (Noyes, 1990; Gibson et al., 1999) aunque estimaciones de algunos autores apuntan a que la riqueza real del grupo oscilaría entre las 60.000 y las 400.000 especies en todo el mundo (Noyes, 2003; Heraty, 2004). El grupo forma, por tanto, una de las superfamilias más amplias dentro del orden Hymenoptera. Mayoritariamente está formada por especies que desarrollan un hábito de vida parasitoide respecto a otros insectos, si bien también la forman otras con diferentes estrategias biológicas como la gallícola o fitófaga.

Entre las diversas comunidades de parasitoides ligadas a agallas de cinípidos, la más estudiada en Europa y, por tanto, la mejor conocida ha sido tradicionalmente la asociada a agallas de especies de la tribu Cynipini, formadas en árboles del género Quercus (Fagaceae). Las comunidades en especies de la tribu Diplolepidini, ligadas a especies de Rosa (Rosaceae) son también relativamente bien conocidas, al igual que la comunidad parasitoide de Pediaspis aceris (Gmelin, 1790) en agallas sobre especies de Acer (Aceraceae) (Askew, 1975b; Pujade-Villar, 1994b). Las comunidades comparati- 
vamente peor estudiadas son las de agallas de cinípidos de la tribu Aylacini formadas en plantas herbáceas de las familias Asteraceae, Papaveraceae, Lamiaceae, Valerianaceae y Rosaceae. La explicación de este hecho puede deberse a que las agallas en plantas herbáceas son un objeto de muestreo más escaso y aleatorio, lo que determina menor número de citas y mayor complicación de estudio. Por esta razón la mayor parte de las novedades, para las listas de parasitoides de agallas de cinípidos de la fauna ibérica y de la Comunidad de Madrid en los últimos años, incluyendo descripciones de géneros y especies nuevas, para la ciencia proceden de las comunidades de agallas de plantas herbáceas.

La obra de conjunto más reciente sobre la fauna europea de parasitoides de agallas de cinípidos fue publicada por Fulmek (1968). En la actualidad están en marcha sendos catálogos de puesta al día de dicho conocimiento; uno sobre la comunidad parasitoide de agallas de cinípidos en especies de Quercus, y el otro del resto de las comunidades ligadas a agallas en plantas herbáceas y arbustos (Askew et al, en prensa; en preparación). De acuerdo a dichos catálogos el listado de Chalcidoidea parasitoides de agallas de Cynipidae en el Paleártico occidental incluye 173 especies identificadas en 35 géneros, a las que habría que añadir 21 más con identificación incierta, quedando un total de 194 especies distribuidas en 38 géneros.

En el ámbito íbero-balear se han citado 133 especies de Chalcidoidea parasitoides de agallas de cinípidos, repartidas en seis familias (Eulophidae, Eupelmidae, Eurytomidae, Ormyridae, Pteromalidae y Torymidae) a las que de igual modo habría que añadir 19 más con identificación incierta (NievesAldrey, 2001; Nieves-Aldrey \& Askew, 2002). Por lo que se refiere a la Comunidad de Madrid, nuestro equipo de trabajo ha venido estudiando intermitentemente desde 1982, las comunidades de parasitoides de Chalcidoidea en agallas de cinípidos, juntamente con las especies de cinípidos hospedantes (véase Nieves-Aldrey et al., este volumen). Como resultado se han publicado a lo largo de estos pasados 23 años distintos artículos sobre la materia, basados al menos en parte en materiales de la Comunidad de Madrid, reseñados cronológicamente: (Nieves-Aldrey \& Martín Chicote, 1986; Nieves-Aldrey \& Askew, 1988; Askew \& Nieves-Aldrey, 1988; Garrido \& Nieves-Aldrey, 1999; Askew \& Nieves-Aldrey, 2000; Nieves-Aldrey \& Askew, 2002; Askew \& Nieves-Aldrey, 2004; Askew et al., 2004; NievesAldrey et al., 2004; Askew \& Nieves-Aldrey, 2005). Faltaba, sin embargo, un trabajo de conjunto, al tiempo que numerosa información adicional en nuestras manos permanecía aún inédita. En consecuencia, el objetivo principal de este trabajo es recopilar y actualizar toda la información disponible, tanto la ya publicada como la inédita, de las especies de la superfamilia Chalcidoidea asociadas a agallas de cinípidos en la Comunidad de Madrid. Este trabajo se realiza en conexión con la realización de la lista anotada y mapas de distribución de los Cynipidae de la Comunidad de Madrid (Nieves-Aldrey et al., este volumen).

\section{Material y métodos}

Los materiales para la elaboración del listado de Chalcidoidea parasitoides de agallas de Cynipidae de la Comunidad de Madrid corresponden a muestreos, efectuados a lo largo de los últimos 23 años dentro de la Comunidad, por el equipo encabezado por el último de los autores. Los muestreos más intensivos fueron realizados desde 1984 a 1987 en la Sierra de Guadarrama y zonas adyacentes; a lo largo de varios años en el Monte de El Pardo y la estación Biogeológica de El Ventorrillo (CSIC), y desde 2002 hasta la actualidad en toda la Comunidad de Madrid. En total se han muestreado 80 localidades distintas repartidas por toda la Comunidad. La relación de localidades muestreadas puede extractarse del Apéndice 2 (véase también Nieves-Aldrey et al., este volumen).

Los muestreos consistieron en la recogida en el campo de agallas de las especies hospedantes que, posteriormente, eran llevadas al laboratorio y depositadas en cajas de emergencia, unas veces en las condiciones del laboratorio otras en las del exterior, hasta la obtención de los adultos. Una fracción de las agallas eran diseccionadas y los contenidos de las cámaras larvales identificados; las larvas o pupas eran en parte guardadas en alcohol para ulteriores estudios de estados inmaduros (morfológicos, moleculares, etc.) y otra parte mantenidas en cápsulas de gelatina hasta la emergencia de los adultos para una mejor identificación.

Otras aportaciones de material estudiado proceden de un proyecto de inventario entomológico de dos areas naturales de la Comunidad de Madrid (Estación Biogeológica de El Ventorillo, situada en la vertiente sur de el Puerto de Navacerrada, en la Sierra de Guadarrama, a unos $60 \mathrm{~km}$ al noroeste de la ciudad de Madrid y Monte de El Pardo en la zona de El Goloso, situada a unos $13 \mathrm{~km}$ al norte de Madrid), llevado a cabo entre los años 1988 a 1992 , en su mayor parte colectados mediante trampas 
Malaise (Garrido-Torres \& Nieves-Aldrey, 1999; Nieves-Aldrey et al., 2003), así como materiales procedentes de muestreos realizados con diversas técnicas, preferentemente red de barrido, por alguno de los autores en la Comunidad de Madrid (Garrido-Torres \& Nieves-Aldrey, 1999).

Todo el material está depositado en las colecciones del MNCN. La relación completa de material estudiado aparece en un Apéndice que se incluye al final del trabajo (Apéndice 2).

\section{Relación de especies}

A continuación se presenta la lista comentada (check list) de los Chalcidoidea parasitoides asociados con agallas de Cynipidae en la Comunidad de Madrid. La lista incluye tanto las especies parasitoides del cinípido inductor como de otros cinípidos inquilinos pobladores de las agallas, e hiperparásitos de otros Chalcidoidea parasitoides primarios. Las especies se listan por familias y géneros, y dentro de éstos en orden alfabético. La lista sigue el orden sistemático de Gauld \& Bolton (1988) para Chalcidoidea y la terminología sigue la nomenclatura más reciente de sendos catálogos paleárticos en marcha de las comunidades de Chalcidoidea parasitoides asociadas con agallas de Cynipidae: el catálogo de la fauna parasitoide primaria ligada a agallas de cinípidos sobre Quercus (Cynipini) (Askew et al., en prensa) y el catálogo de las comunidades parasitoides asociadas a agallas de cinípidos en plantas herbáceas, arbustos y árboles distintos de Quercus (tribus de Cynipidae Aylacini, Diplolepidini y Pediaspidini) (Askew et al., en prep). Junto al nombre válido de algunas especies se incluye el nombre del sinónimo reciente más conocido.

Del total de los taxa listados se han podido identificar un total de 121 especies, repartidas en 30 géneros incluidos en 6 familias. De todas ellas tanto Eurytomidae como Eulophidae se destacan como grupos muy abundantes dentro de Chalcidoidea, de difícil y poco estudiada taxonomía, cuya mayoría de géneros necesitan ser revisados. Ello implica que con mucha frecuencia la identificación del conjunto de especies englobadas en estos géneros, es compleja e insegura. Por esta razón un número considerable de taxa listados no han podido ser asignados a especies conocidas con total seguridad y aparecen bajo los epígrafes "especie cercana a" ( $s p$. $n r$.), "especie del grupo" ( $s p . g r$.) o aparecen identificadas a nivel de especie pero sin nombrar y/ó con un número asignado (por ejemplo, sp. 1) (ver
Apéndice 1). Algo similar ocurre para algunas especies nuevas de Torymidae que se encuentran en estudio en la actualidad y que aparecen así mismo listadas. Todas estas especies no han sido contabilizadas para el cálculo de los porcentajes y proporciones que aparecen en los comentarios específicos de cada uno de los géneros. Gran parte de la información de las citas de presencia en la lista corresponde a datos inéditos de los autores.

\section{EURYTOMIDAE}

EURYTOMA Illiger, 1807

Subg. EURYTOMA Illiger, 1807

1. Eurytoma sp. indet.

2. Eurytoma brunniventris Ratzeburg, 1852

3. Eurytoma infracta Mayr, 1904

4. Eurytoma sp. nr. infracta

5. Eurytoma rosae Nees, 1834

6. Eurytoma sp. gr. rosae

7. Eurytoma sp. nr. rosae

8. Eurytoma rufipes Walker, 1832

9. Eurytoma strigifrons Thomson, 1832

Subg. BRUCHOPHAGUS Ashmead, 1888

10. Eurytoma aspila (Walker, 1836)

11. Eurytoma sp. nr. aspila

12. Eurytoma cynipsea Boheman, 1836

13. Eurytoma sp. nr. cynipsea

14. Eurytoma hybrida Zerova, 1978

15. Eurytoma sp. nr. hypochoeridis

16. Eurytoma sp. nr. jaceae

17. Eurytoma timaspidis Mayr, 1904

18. Eurytoma sp. nr. timaspidis

SYCOPHILA Walker, 1871

Subg. EUDECATOMA Ashmead, 1888

19. Sycophila biguttata (Swederus, 1795)

20. Sycophila binotata (Boyer de Fonscolombe, 1832)

21. Sycophila concinna (Boheman, 1836)

22. Sycophila flavicollis (Walker, 1834)

23. Sycophila iracemae Nieves-Aldrey, 1983

24. Sycophila mayri (Erdös, 1959)

25. Sycophila submutica (Thomson, 1875)

26. Sycophila variegata (Curtis, 1831)

\section{TORYMIDAE}

ADONTOMERUS Nikolskaya, 1955

27. Adontomerus sp. indet.

28. Adontomerus crassipes (Boucek, 1982)

29. Adontomerus impolitus (Askew y Nieves-Aldrey, 1988)

CHALCIMERUS Steffan y Andriescu

30. Chalcimerus borceai Steffan y Andriescu, 1963

GLYPHOMERUS Förster, 1856

31. Glyphomerus stigma (Fabricius, 1793) 
32. Glyphomerus tibialis (Förster, 1859)

IDIOMACROMERUS Crawford, 1914

33. Idiomacromerus sp. indet.

34. Idiomacromerus centaureae (Askew y NievesAldrey, 1988)

35. Idiomacromerus papaveris (Förster, 1856)

36. Idiomacromerus semiaeneus (Szelenyi, 1957)

37. Idiomacromerus silybi Askew, 2004

38. Idiomacromerus urospermi Askew, 2004

MEGASTIGMUS Dalman, 1821

39. Megastigmus dorsalis (Fabricius, 1798)

40. Megastigmus dumicola Boucek, 1982

41. Megastigmus stigmatizans (Fabricius, 1798)

PSEUDOTORYMUS Masi, 1921

42. Pseudotorymus papaveris (Thomson, 1876)

TORYMUS Dalman, 1820

43. Torymus affinis (Boyer de Fonscolombe, 1832)

44. Torymus auratus (Müller, 1764)

Torymus nitens (Walker, 1833)

45. Torymus bedeguaris (Linnaeus, 1758)

46. Torymus chloromerus (Walker, 1833)

47. Torymus cyaneus (Walker, 1847)

48. Torymus erucarum (Schrank, 1781)

49. Torymus fastuosus Boheman, 1834

50. Torymus flavipes (Walker, 1833)

Torymus auratus (Geoffroy in Fourcroy, 1785)

51. Torymus geranii (Walker, 1833)

52. Torymus nobilis Boheman, 1834

53. Torymus notatus (Walker, 1833)

\section{ORMYRIDAE}

ORMYRUS Westwood, 1832

54. Ormyrus capsalis Askew, 1994

55. Ormyrus sp. nr. destefanii (Mayr, 1904)

56. Ormyrus diffinis (Boyer de Fonscolombe, 1832)

57. Ormyrus gratiosus (Förster, 1860)

58. Ormyrus nitidulus (Fabricius, 1804)

Ormyrus tubulosus (Fonscolombe, 1832)

59. Ormyrus papaveris (Perris, 1840)

60. Ormyrus pomaceus (Geoffroy, 1785)

Ormyrus punctiger Westwood, 1832

61. Ormyrus rufimanus Mayr, 1904

62. Ormyrus wachtli (Mayr, 1904)

\section{PTEROMALIDAE}

ARTHROLYTUS Thomson, 1878

63. Arthrolytus nanus Askew y Nieves-Aldrey, 1982

CAENACIS Förster, 1856

64. Caenacis inflexa (Ratzeburg, 1848)

65. Caenacis lauta (Walker, 1835)

CECIDOSTIBA Thomson, 1878

66. Cecidostiba adana Askew, 1961

67. Cecidostiba atra Askew, 1975

68. Cecidostiba fungosa (Geoffroy, 1785)
Cecidostiba hilaris (Walker, 1836)

69. Cecidostiba geganius (Walker, 1848)

70. Cecidostiba ilicina Nieves-Aldrey y Askew, 1988

71. Cecidostiba semifascia (Walker, 1835)

CYRTOPTYX Delucchi, 1956

72. Cyrtoptyx robustus (Masi, 1907)

EUMACEPOLUS Graham, 1957

73. Eumacepolus obscurior Graham, 1961 HOBВYA Delucchi, 1957

74. Hobbya stenonota (Ratzeburg, 1848)

HOMOPORUS Thomson, 1878

75. Homoporus fulviventris (Walker, 1835)

76. Homoporus subniger (Walker, 1835)

MESOPOLOBUS Westwood, 1833

77. Mesopolobus amaenus (Walker, 1834)

78. Mesopolobus dubius (Walker, 1834)

79. Mesopolobus fasciiventris Westwood, 1833

80. Mesopolobus fuscipes (Walker, 1834)

81. Mesopolobus lichtensteini (Mayr, 1903)

82. Mesopolobus mediterraneus (Mayr, 1903)

83. Mesopolobus sericeus (Förster, 1770) Mesopolobus jucundus (Walker, 1834)

84. Mesopolobus tarsatus (Nees, 1834)

Mesopolobus squamifer (Thomson, 1878)

85. Mesopolobus tibialis (Westwood, 1833)

86. Mesopolobus xanthocerus (Thomson, 1878)

ORMOCERUS Walker, 1834

87. Ormocerus latus Walker, 1834

88. Ormocerus vernalis Walker, 1834

PHAENOCYTUS Graham, 1969

89. Phaenocytus sp. indet.

PTEROMALUS Swederus, 1795

90. Pteromalus bedeguaris (Thomson, 1878)

91. Pteromalus sp. $n r$. bedeguaris

92. Pteromalus isarchus Walker, 1839

RIVASIA Askew \& Nieves-Aldrey, 2005

93. Rivasia fumariae Askew \& Nieves-Aldrey, 2005

STINOPLUS Thomson, 1878

94. Stinoplus lapsanae Graham, 1969

TRICHOMALUS Thomson, 1878

95. Trichomalus sp. nr. tenellus (Walker, 1834)

\section{EUPELMIDAE}

CALOSOTA Curtis, 1836

96. Calosota obscura Ruschka, 1921

EUPELMUS Dalman, 1820

Subg. EUPELMUS Dalman, 1820

97. Eupelmus annulatus Nees, 1834

98. Eupelmus cerris Förster, 1860

99. Eupelmus microzonus Förster, 1860

100. Eupelmus urozonus Dalman, 1820

Subg. MACRONEURA Walker, 1837

101. Eupelmus aseculatus (Kalina, 1981)

102. Eupelmus müellneri Ruschka, 1921 
103. Eupelmus seculatus (Ferriere, 1954)

104. Eupelmus vesicularis (Retzius, 1783)

\section{EULOPHIDAE}

APROSTOCETUS Westwood, 1833

105. Aprostocetus aurantiacus (Ratzeburg, 1852)

106. Aprostocetus epicharmus (Walker, 1839)

107. Aprostocetus forsteri (Walker, 1847)

108. Aprostocetus fusificola Graham, 1987

109. Aprostocetus sp. gr. epicharmus

110. Aprostocetus sp. indet. 1

111. Aprostocetus sp. indet. 2

AULOGYMNUS Förster, 1851

112. Aulogymnus arsames (Walker, 1838)

113. Aulogymnus bicolor (Askew, 1973)

114. Aulogymnus gallarum (Linnaeus, 1761)

115. Aulogymnus skianeuros (Ratzeburg, 1844)

116. Aulogymnus trilineatus (Mayr, 1877)

BARYSCAPUS Förster, 1856

117. Baryscapus berhidanus (Erdös, 1954)

118. Baryscapus papaveris Graham, 1991

119. Baryscapus sp. indet.

120. Baryscapus sp. $n r$. diaphantus

PEDIOBIUS Walker, 1846

121. Pediobius rotundatus (Boyer de Fonscolombe, 1832)

Relación comentada de familias y géneros de Chalcidoidea asociados a agallas de cinípidos en la Comunidad de Madrid

\section{FAMilia Eurytomidae}

Amplia familia, con más de 1400 especies en todo el mundo, de calcidoideos con tipos de vida variados, fitófagos, gallícolas, seminívoros, ectoparasitoides o hiperparasitoides de larvas de insectos gallícolas, barrenadores o minadores (NievesAldrey \& Fontal-Cazalla, 1999). En la región pale- ártica se conocen unas 370 especies (Zerova, 1995) de las cuales 25 estarían presentes en el ámbito íbero-balear (Espejo-Noguera \& Pujade-Villar, 2000). Sin embargo esta última cifra se ha incrementado notablemente en los últimos años. Sólo dentro de la comunidad de euritómidos asociada a agallas de cinípidos, se conocen ya 20 especies en dos géneros (de las 31 citadas en la región Paleártica) (Askew et al., en prensa; Askew et al., en prep; Nieves-Aldrey, 2001; Nieves-Aldrey \& Askew, 2002). De ellas, 17 especies están presentes en la Comunidad de Madrid, con lo que en términos comparativos la fauna de euritómidos asociada a agallas de cinípidos en el territorio madrileño representa el $80 \%$ de la la fauna ibérica conocida hasta el momento y aproximadamente el 54\% de las especies paleárticas.

Los trabajos realizados hasta el momento relativos a la familia, en cuanto a las comunidades en agallas de cinípidos en el ámbito íbero-balear, han sido escasos apareciendo datos o reseñas a la familia en algunos trabajos de Nieves-Aldrey (1981; 1984a; 1984b; 2001), Nieves-Aldrey \& Askew (2002) y Pujade-Villar (1992a; 1994a; 1994b).

\section{Eurytoma Illiger, 1807}

Es el género más diverso dentro de la familia y uno de los géneros de Chalcidoidea representado por un mayor número de especies (Fig. 1A). A la comunidad de parasitoides en agallas de cinípidos del Paleártico el género aporta un total de 22 especies (Askew et al., en prensa; Askew et al., en prep), de las cuales 12 han sido citadas en el ámbito íberobalear (Nieves-Aldrey, 2001; Nieves-Aldrey \& Askew, 2002), si bien existen aún 9 especies de identificación incierta que incrementarían dicha cifra. Del mismo modo constituye el grueso de las especies de la familia Eurytomidae en la Comunidad de Madrid, con un total de 9 citadas hasta la fecha, a las que habría que sumar otras 9 de identificación incierta, parasitoides en agallas de distintos géneros y

Fig. 1. - Hembras adultas de especies de Chalcidoidea representativas de la comunidad parasitoide en agallas de cinípidos de la Comunidad de Madrid: A, Eurytoma timaspidis Mayr, 1904 y B, Sycophila mayri (Erdös, 1959) (Eurytomidae); C, Torymus bedeguaris (Linnaeus, 1758) y D, Chalcimerus borceai Steffan \& Andriescu, 1962 (Torymidae, Toryminae); E, Ormyrus nitidulus (Fabricius, 1804) (Ormyridae); F, Megastigmus stigmatizans (Fabricius, 1798) (Torymidae, Megastigminae); G, Eupelmus (Macroneura) vesicularis (Retzius, 1783) (Eupelmidae) y H, Pteromalus bedeguaris (Thomson, 1878) (Pteromalidae).

Fig. 1.- Adult females of representative Chalcidodea species of the parasitoid community in cynipid galls from the Comunidad de Madrid: A, Eurytoma timaspidis Mayr, 1904 and B, Sycophila mayri (Erdös, 1959) (Eurytomidae); C, Torymus bedeguaris (Linnaeus, 1758) and D, Chalcimerus borceai Steffan \& Andriescu, 1962 (Torymidae, Toryminae); E, Ormyrus nitidulus (Fabricius, 1804) (Ormyridae); F, Megastigmus stigmatizans (Fabricius, 1798) (Torymidae, Megastigminae); G, Eupelmus (Macroneura) vesicularis (Retzius, 1783) (Eupelmidae) and H, Pteromalus bedeguaris (Thomson, 1878) (Pteromalidae). 

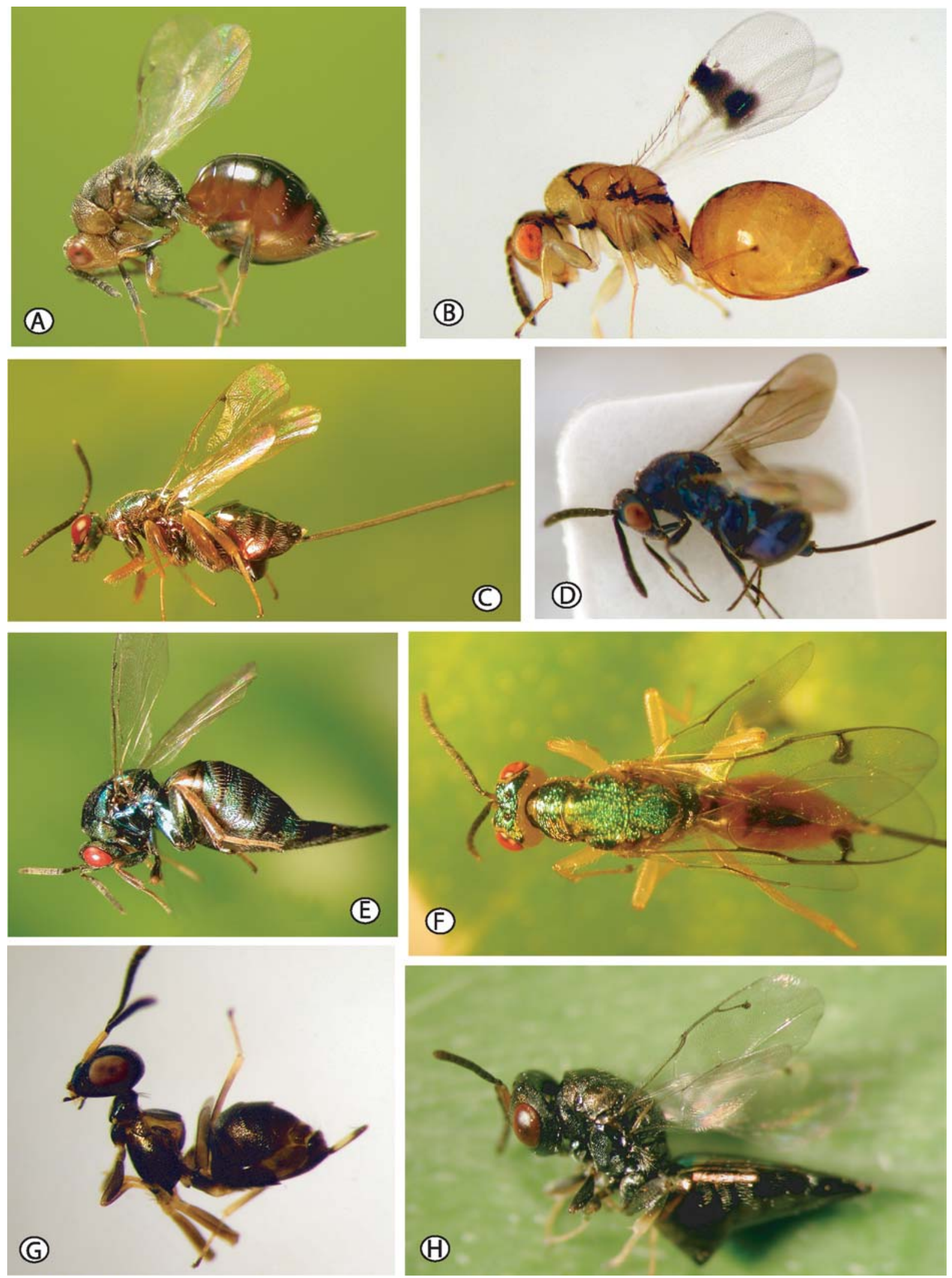
especies (ver Apéndice 1) y variadamente distribuidas por la región (Apéndice 2).

\section{Sycophila Walker, 1871}

En la comunidad de parasitoides de cinípidos en el Paleártico, el género Sycophila está representado por nueve especies de las cuales ocho aparecen citadas en el ámbito íbero-balear (Askew et al., en prensa; Askew et al., en prep; Nieves-Aldrey, 2001; Nieves-Aldrey \& Askew, 2002) (Fig. 1B). La Comunidad de Madrid posee en su calcidofauna las 8 especies citadas en el ámbito íbero-balear, parasitoides en su mayoría de agallas de cinípidos sobre Quercus (Fagaceae), si bien también determinadas especies aparecen citadas sobre agallas en plantas herbáceas de distintas especies (Apéndices 1 y 2).

\section{FAMiLia TORYMidae}

Familia de calcídidos integrada por cerca de 1000 especies en todo el mundo (Grissell, 1995; Noyes, 2003). Sus representantes son fundamentalmente ectoparasitoides de dípteros e himenópteros gallícolas y, en menor medida de algunos ortópteros, coleópteros y lepidópteros. Algunas especies son seminívoras y unas pocas son gallícolas. $\mathrm{La}$ entomofauna de torímidos ligada a agallas de cinípidos es bastante amplia. En el Paleártico está compuesta por 43 especies en 9 géneros (Askew et al., en prensa; Askew et al., en prep), mientras que en el ámbito íbero-balear, sumando las aportaciones del presente trabajo a lo conocido hasta la fecha (Nieves-Aldrey, 2001; Nieves-Aldrey \& Askew, 2002) nos encontramos 30 especies en 8 géneros. En la Comunidad de Madrid está representada aproximadamente el $83 \%$ de la fauna de torímidos íbero-balear con 25 especies en 7 géneros.

Las publicaciones sobre torímidos en España y Comunidad de Madrid han sido muy escasas y esporádicas: Nieves-Aldrey (1984c), Nieves-Aldrey \& Martín Chicote (1986), Askew \& Nieves-Aldrey (1988), Pujade-Villar (1993), Nieves-Aldrey \& Askew (2002), Askew et al., (2004).

\section{Chalcimerus Steffan y Andriescu, 1962}

Género monoespecífico que alberga la especie Chalcimerus borceai parasitoide de agallas del cinípido Barbotinia oraniensis (Barbotin, 1964) en cápsulas de distintas especies de Papaver (Papaveraceae) (Fig. 1D). Su distribución se extiende por el Paleártico siendo su presencia habitual en la Península Iberica (Askew et al., en prep.; Nieves-Aldrey \& Askew, 2002). En la comunidad de Madrid se encuentra bien representada en el sureste de la región (Apéndices 1 y 2).

\section{Idiomacromerus Crawford, 1914}

Género amplio, en el que se engloban parte de las especies conocidas de parasitoides de cinípidos de la tribu Aylacini, gallícolas en plantas herbáceas de la familia Asteraceae (Apéndice 1). Dentro de dicha comunidad hay citadas, hasta la fecha, cinco especies en el área Paleártica, las mismas que para el ámbito íbero-balear (Askew et al., 2004; Askew et al., en prep.; Nieves-Aldrey \& Askew, 2002). y la Comunidad de Madrid. Aparece aparte una especie más que está en proceso de estudio actualmente, lo cúal incrementaría el total de especies citadas a seis dentro del género en la región. En la Comunidad de Madrid su distribución es amplia apareciendo citada en numerosas localidades de distintas áreas (Apéndice 2).

\section{Adontomerus Nikolskaya, 1955}

Género de escasa representación en las comunidades gallícolas, formado en su caso, por especies parasitoides en agallas de Aylacini sobre compuestas (Asteraceae). Tan sólo incluye dos especies conocidas dentro de la comunidad en el Paleártico y el ámbito íbero-balear, $A$. crassipes y A. impolitus (Askew et al., 2004; Askew et al., en prep.; NievesAldrey y Askew, 2002), las cuales se encuentran bien representadas en la Comunidad de Madrid, principalmente en la zona del sureste de la región, donde son abundantes sus agallas hospedadoras (apendices I y II), si bien una especie recientemente encontrada en la Comunidad de Madrid se encuentra en estudio, lo cual incrementaría el número de especies conocidas a tres.

\section{Glyphomerus Förster, 1856}

Género pequeño formado por ocho especies en el Paleártico (Stojanova, 2005), la mayor parte de las cuales son parasitoides de agallas de cinípidos. Su representación hasta la fecha es escasa tanto en el ámbito íbero-balear (Nieves-Aldrey, 2001; Nieves-Aldrey y Askew, 2002) como en la Comunidad de Madrid. Se trata de especies parasitoides de agallas de cinípidos sobre arbustos y herbáceas de diferentes familias. Hasta la fecha de las cuatro especies citadas en el Paleártico (Stojanova, 2005), tan sólo se ha confirmado la presencia en España de dos de ellas (G. stigma y G. tibialis). En la Comunidad de Madrid tienen representación las dos especies (apendices I y II). Previamente citada en la Península únicamente de agallas de Aulacidea subterminalis Niblett, 1946 (Nieves-Aldrey \& 
Askew, 2002), cabe destacar las citas que aquí hacemos de dos nuevas agallas hospedadoras: Barbotinia oraniensis (Barbotin) sobre cápsulas del género Papaver (Papaveraceae), y de Phanacis hypochoeridis (Kieffer, 1887) en plantas del género Hypochoeris (Asteraceae).

\section{Megastigmus Dalman, 1820}

El amplio género Megastigmus, con 126 especies en todo el mundo (Grissell, 1995), dentro de la comunidad de parasitoides de agallas de cinípidos de la región Paleártica incluye cinco especies (Askew et al., en prensa), tres de las cuales tienen representación en el ámbito íbero-balear (Nieves-Aldrey, 1984c; Nieves-Aldrey, 2001) y aparecen también en la Comunidad de Madrid. Las tres son parasitoides primarios de diferentes especies de cinípidos inductores de agallas e inquilinos en fagáceas del género Quercus. Las tres especies son abundantes y están ampliamente distribuidas en la región; dos de ellas, M. dorsalis y M. stigmatizans (Fig. $1 \mathrm{~F}$ ) asociadas a agallas de cinípidos que crecen en robles y quejigos, mientras que la tercera especie, $M$. dumicola, ataca agallas de especies de Plagiotrochus en la coscoja (Q. coccifera L.) (Apéndices 1 y 2).

\section{Pseudotorymus Masi, 1921}

Con numerosas especies descritas dentro del género, por el momento tan sólo Pseudotorymus papaveris ha sido citada de agallas de cinípidos, de las especies Aylax minor, A. papaveris y B. oraniensis en cápsulas de distintas especies de Papaver. Sin embargo, los hospedadores reales probablemente sean Cecidomyiidae que comparten hábitat con los cinípidos en dichas agallas (Grissell, 1995; Askew et al., en prep.).

\section{Torymus Dalman, 1820}

Género muy amplio que alberga la mayor parte de la especies de la familia, con una biología variada y amplio rango de hospedadores. Graham \& Gijswijt (1998) reconocen 154 especies en Europa en su revisión taxonómica del género. Agrupa la mayor parte de las especies de torímidos conocidas parasitoides en agallas de cinípidos. Las especies de Torymus son parasitoides en agallas de especies pertenecientes a todas las tribus de cinípidos, excepto Pediaspidini, tanto en árboles del género Quercus, como en arbustos y herbáceas de diferentes familias botánicas (Apéndice 1) (Fig. 1C). En el Paleártico el género cuenta con 23 especies catalogadas, de la cuales 15 han sido citadas en el ámbito íbero-balear (Askew et al., en prensa; Askew et al., en prep.; Nieves-Aldrey, 1984c; Nieves-Aldrey, 2001; Nieves-Aldrey \& Askew, 2002).

En la Comunidad de Madrid citamos prácticamente el 75\% de las especies de Torymus conocidas del ámbito íbero-balear de donde se han citado hasta la fecha 11 especies. Dada su diversidad de hospedadores, la distribución del género en la región es bastante amplia (Apéndice 2).

\section{Familia Ormyridae}

Pequeña familia de calcidoideos representada por 2 géneros y 74 especies en todo el mundo (Noyes, 2003), de las cuales entre 13 y 15 especies, todas incluidas en el género Ormyrus Westwood, 1832, se encuentran en el Paleártico (Askew et al., en prensa; Askew et al., en prep). En el ámbito íbéro-balear hasta la fecha se han citado 12 especies (Nieves-Aldrey, 1984d; Askew, 1994; NievesAldrey, 2001; Nieves-Aldrey \& Askew, 2002; Pujade-Villar, 1989a) pertenecientes todas al género Ormyrus. Las especies ibéricas son parasitoides de insectos gallícolas, fundamentalmente de cinípidos, con excepción de dos especies parasitoides de Diptera Tephritidae en cabezuelas de compuestas de los géneros Centaurea e Inula y de Diptera Cecidomyiidae en agallas de Salsola, y otra de Eurytomidae gallícolas en Ephedra (Ephedraceae) (Askew \& Blasco-Zumeta, 1998). Los ormíridos parasitoides de agallas de cinípidos parasitan preferentemente especies de las tribus Aylacini y Cynipini, tanto en fagaceas del género Quercus como en herbáceas de las familias Asteraceae, Papaveraceae y Lamiaceae. La comunidad de ormíridos parasitoides de agallas de cinípidos de la Comunidad de Madrid cuenta con nueve especies, que representan la totalidad de los ormíridos ibéricos en dicha comunidad parasitoide, con excepción de O. salmanticus Nieves-Aldrey, 1984. Se cita aquí una nueva especie, a añadir a la lista de los ormíridos ibéricos, Ormyrus rufimanus, parasitoide en agallas de Xestophanes potentillae (Retzius, 1783) sobre Potentilla reptans (Rosaceae).

\section{Familia Pteromalidae}

Amplísima e hiperdiversa familia de calcidoideos con más de 31 subfamilias y alrededor de 4200 especies descritas (Noyes, 2003). La riqueza de la familia en el ámbito íbero-balear se estima en más de 700 especies (Nieves-Aldrey \& FontalCazalla, 1999; Garrido-Torres \& Nieves-Aldrey, 
1990, 1999), si bien sólo unas 325 especies han sido citadas de España. La calcidofauna parasitoide de pteromálidos ligada a agallas de cinípidos en el Paleártico es amplia y se cifra en 43 especies repartidas en 15 géneros (Askew et al., en prensa; Askew et al., en prep), de las cuales en el ámbito íbero-balear se han citado 40 especies en 14 géneros (Nieves-Aldrey, 2001; Nieves-Aldrey \& Askew, 2002; Askew \& Nieves-Aldrey, 2005). En la Comunidad de Madrid se han catalogado por el momento 33 especies en 14 géneros, lo que supone casi la práctica totalidad de las especies íberobaleares.

Las obras de referencia para el estudio de este grupo en Europa siguen siendo la revisión de Graham (1969) y el trabajo de Boucek \& Rasplus (1991). En el ámbito de la comunidad de Madrid destaca el catálogo publicado por Garrido Torres y Nieves-Aldrey (1999) que lista 268 especies. Las publicaciones relativas a especies de pteromálidos asociadas a agallas de cinípidos en el ámbito íbero-balear son relativamente numerosas (Nieves-Aldrey, 1981, 1982a, 1982b, 1983a, 1983b, 1988; Nieves-Aldrey \& Martín-Chicote, 1986; Garrido-Torres y Nieves-Aldrey, 1990; 1999; Pujade-Villar, 1985, 1992b, 1994c, 1994d; Nieves-Aldrey \& Askew, 2002; Askew \& NievesAldrey, 2005).

\section{Arthrolytus Thomson, 1878}

Se trata de un género con nueve especies en Europa, parasitoide de especies de Diptera, Coleoptera e Hymenoptera (Boucek \& Rasplus 1991), de las cuales cuatro forman parte de la comunidad de parasitoides de agallas de cinípidos del Paleártico (Askew et al., en prensa), y han sido citadas también en el ámbito íbero-balear (NievesAldrey, 2001). En la Comunidad de Madrid hasta la fecha sólo ha sido citada una especie dentro de este género ( $A$. nanus) (Garrido-Torres \& NievesAldrey, 1999), parasitando agallas del cinípido Andricus quercusradicis (Fabricius, 1798) sobre Quercus pyrenaica L., en localidades del norte de la región (Apéndices 1 y 2). Arthrolytus ocellus Walker, 1834 y A. glandium Boucek, 1967, que atacan agallas de Callirhytis en glandes de frutos de $Q$. suber y $Q$. ilex, han sido citadas de las provincias cercanas de Salamanca y Ciudad Real (Askew \& Nieves-Aldrey, 1982; Garrido-Torres \& NievesAldrey, 1990). Dado que estos hospedadores se encuentran también en la Comunidad de Madrid, no es descartable que las mencionadas especies de Arthrolytus formen parte de la calcidofauna madrileña y acaben siendo encontradas.

\section{Caenacis Förster, 1859}

Género con dos especies (C. inflexa y C. lauta) ampliamente distribuidas por todo el Paleártico (Boucek \& Rasplus 1991), ambas parasitoides en agallas de cinípidos y citadas para el ámbito íberobalear y la Comunidad de Madrid (Nieves-Aldrey, 1982b; Nieves-Aldrey, 2001; Garrido-Torres y Nieves-Aldrey, 1990, 1999). Caenacis inflexa es parasitoide en agallas de Diplolepis sobre arbustos del género Rosa mientras que $C$. lauta lo es de agallas de especies de Andricus sobre fagáceas del género Quercus. En la Comunidad de Madrid $C$. lauta es relativamente rara habiéndose encontrado únicamente en agallas de $A$. hispanicus mientras que $C$. inflexa aparece mejor representada en la submitad norte de la región (Apéndices 1 y 2).

\section{Cecidostiba Thomson, 1878}

Género que cuenta con ocho especies distribuidas exclusivamente en la región paleártica, todas ellas integrantes de la comunidad de parasitoides de agallas de cinípidos (Nieves-Aldrey \& Askew, 1988). En el ámbito íbero-balear están representadas las siete especies conocidas en el paleártico occidental (Nieves-Aldrey, 1982b; Pujade-Villar, 1994b; Nieves-Aldrey, 2001; Garrido-Torres \& Nieves-Aldrey, 1990, 1999) mientras que en la Comunidad de Madrid están citadas todas excepto C. jucundus (Förster) especie parasitoide en agallas de Pediaspis aceris en especies de Acer, un cinípido hospedador que no está presente en la región de Madrid. Las especies madrileñas son parasitoides de distintas agallas sobre árboles del género Quercus y en general están abundante y ampliamente distribuidas por la región (Apéndices 1 y 2).

\section{Cyrtopyx Delucchi, 1956}

Genero pequeño con 3 especies de amplia distribución en países mediterráneos dentro del Paleártico (Boucek \& Rasplus 1991). Sus especies presentan un alto grado de polifagia y por tanto una gran variedad de hospedadores. Tan sólo una especie, C. robustus, aparece asociada a la comunidad de parasitoides de agallas de cinípidos en el Paleártico, la cual ha sido también citada del ámbito íbero-balear y la Comunidad de Madrid (Nieves-Aldrey, 1982b; Nieves-Aldrey, 2001; Garrido-Torres \& Nieves-Aldrey, 1990, 1999). En la región la especie está presente como parasitoide de los cinípidos Andricus hispanicus Hartig y Cynips disticha Hartig sobre Quercus faginea, Cynips quercus (Fourcroy) sobre Quercus pyrenaica y Plagiotrochus australis (Mayr) sobre Quercus ilex, preferentemente en la submitad norte de la Comunidad (Apéndices 1 y 2). 


\section{Eumacepolus Graham, 1957}

Género del Paleártico occidental con 3 especies habitualmente parasitoides de agallas de cecidómidos (Diptera, Cecidomyiidae) (Boucek \& Rasplus 1991). La especie Eumacepolus obscurior Graham, se ha citado también de agallas de cinípidos en el ámbito íbero-balear (Nieves-Aldrey \& Askew, 1988; Garrido-Torres \& Nieves-Aldrey, 1990; Nieves-Aldrey, 2001) y forma parte de la fauna de la Comunidad de Madrid donde ha sido citada con anterioridad (Garrido-Torres \& Nieves-Aldrey, 1999). En la región se encuentra como parasitoide no habitual de agallas de Andricus hispanicus sobre Quercus faginea (Apéndices 1 y 2).

\section{Hobbya Delucchi, 1957}

Género monoespecífico de amplia distribución en el Paleártico (Boucek \& Rasplus 1991). Incluye la especie H. stenonota, catalogada en el ámbito íbero-balear y la Comunidad de Madrid con anterioridad (Garrido-Torres \& Nieves Aldrey, 1990, 1999; Nieves-Aldrey, 1982b; 2001). En la región aparece como parasitoide en agallas de diferentes especies de cinípidos sobre árboles del género Quercus principalmente distribuida en las vertientes norte y noroeste (Apéndices 1 y 2).

\section{Homoporus Thomson, 1878}

Género ampliamente distribuido con gran número de especies; en el Paleártico occidental cuenta con al menos 28 especies (Boucek, 1988; Boucek \& Rasplus 1991) de las cuales tan sólo dos han sido catalogadas como pertenecientes a la comunidad de parasitoides de agallas de cinípidos (Askew et al. en prep). Ambas especies (H. fulviventris y $H$. subniger) son parasitoides de agallas de cinípidos de varias especies de la tribu Aylacini sobre herbáceas de la familia Asteraceae y están citadas en el ámbito íbero-balear (Garrido-Torres \& Nieves-Aldrey, 1990; Nieves-Aldrey, 2001; Nieves-Aldrey \& Askew, 2002) al igual que en la Comunidad de Madrid (Garrido-Torres \& NievesAldrey, 1999), de donde se aportan nuevos datos de distribución y hospedadores. Ambas especies se distribuyen diferencialmente por zonas del norte y sureste de la Comunidad (Apéndices 1 y 2).

\section{Mesopolobus Westwood, 1833}

Género cosmopolita ampliamente distribuido por el Paleártico occidental donde cuenta con 40 especies conocidas (Boucek , 1988; Boucek \& Rasplus, 1991). Las especies del género presentan una biología muy variada, incluyendo especies que atacan agallas de cinípidos, fundamentalmente aga- llas de cinípidos sobre Quercus. Se han citado un total de 17 especies de Mesopolobus integrantes de la comunidad parasitoide de agallas de cinípidos en el Paleártico (Askew et al., en prensa) y 10 en el ámbito íbero-balear (Garrido-Torres \& NievesAldrey, 1990; Nieves-Aldrey, 1983b, 2001). En la Comunidad de Madrid están representadas la totalidad de las especies citadas para el ámbito íberobalear. Todas las especies son parasitoides en agallas de diversas especies en árboles del género Quercus por lo que su distribución en la Comunidad de Madrid es bastante amplia en todo el territorio (Apéndices 1 y 2).

\section{Ormocerus Walker, 1834}

Género con unicamente dos especies de amplia distribución en el Paleártico occidental (Boucek \& Rasplus, 1991). Ambas (O. latus y O. vernalis) están incluidas en la comunidad de parasitoides en agallas de cinípidos, habiéndose citado en el ámbito íberobalear (Garrido-Torres \& Nieves-Aldrey, 1990; Nieves-Aldrey, 1982a, 2001). En la Comunidad de Madrid han sido citadas ambas (Garrido-Torres \& Nieves-Aldrey, 1999), presentando una buena representación y amplia distribución como parásitas de especies de Andricus y Plagiotrochus sobre Quercus faginea, $Q$. ilex y $Q$. suber (Apéndices 1 y 2).

\section{Phaenocytus Graham, 1969}

Género monoespecífico de amplia distribución en el Paleártico pero muy localizado (Boucek \& Rasplus, 1991), cuya única especie, $P$. glechomae, se encuentra en agallas de Aylacini del género Liposthenes sobre diferentes especies de labiadas. En el ámbito ibero-balear su estatus es dudoso habiendo sido encontrados algunos ejemplares en Cantabria que no han podido ser asimilados con seguridad a esta especie (Garrido \& Nieves-Aldrey, 1992; Garrido-Torres \& Nieves-Aldrey, 1999). En la Comunidad de Madrid hay registros dudosos de esta especie en agallas de la única especie de Liposthenes presente, L. kerneri (Wachtl, 1891) sobre Nepeta latifolia en la Sierra de Guadarrama (Apéndices 1 y 2).

\section{Pteromalus Swederus, 1795}

Género cosmopolita con aproximadamente 100 especies descritas (Boucek \& Rasplus, 1991) de las cuales cuatro han sido identificadas como parasitoides de agallas de cinípidos en el Paleártico (Askew et al., en prensa; Askew et al., en prep.), concretamente sobre especies gallícolas en plantas herbáceas y en arbustos de la familia Rosaceae (Fig. 1H). En la comunidad de parasitoides de aga- 
llas del ámbito ibero-balear se han citado cuatro especies (Garrido-Torres y Nieves-Aldrey, 1990, 1999; Nieves-Aldrey, 2001; Nieves-Aldrey y Askew, 2002) una de ellas de identificación dudosa. Las 3 especies citadas en la Comunidad de Madrid, se distribuyen irregularmente por toda la región (Apéndices 1 y 2).

\section{Rivasia Askew \& Nieves-Aldrey, 2005}

Género monoespecífico descrito recientemente a partir de ejemplares de la Comunidad de Madrid (Askew \& Nieves-Aldrey, 2005). Incluye la especie Rivasia fumariae, obtenida de agallas del cinípido Neaylax versicolor (Nieves-Aldrey, 1985) sobre Fumaria officinalis L. (Papaveraceae), hasta la fecha tan sólo en Rivas-Vaciamadrid (Apéndices 1 y 2). Estos datos constituyen el único registro mundial del género y especie.

\section{Stinoplus Thomson, 1878}

Género pequeño que probablemente cuenta con cuatro especies en el Paleártico occidental (Boucek \& Rasplus, 1991; Askew et al., en prep.). Por lo que se conoce hasta la fecha, se trata de un género compuesto por especies parásitas exclusivas de agallas de diferentes especies de cinípidos de la tribu Aylacini sobre herbáceas de la familia Asteraceae. En el ámbito íbero-balear hasta la fecha han sido catalogadas dos especies (Garrido-Torres, 1990; Nieves-Aldrey \& Askew, 2002) de las cuales sólo una, S. lapsanae, está presente en la Comunidad de Madrid, obtenida de agallas de Timaspis lampsanae (Perris, 1873) sobre la compuesta Lampsana comunis en El Escorial (Apéndices 1 y 2).

\section{Trichomalus Thomson, 1878}

Género amplio con al menos 40 especies descritas en el Paleártico occidental (Boucek \& Rasplus, 1991) de las cuales tan sólo una hasta la fecha ha sido citada dentro de la comunidad de parasitoides de agallas de cinípidos. La especie, identificada provisionalmente como cercana a Trichomalus tenellus, se ha citado como integrante de la comunidad de agallas de Iraella luteipes (Thomson) en tallos de Papaver somniferum, únicamente en la Comunidad de Madrid (Garrido-Torres \& NievesAldrey, 1999; Nieves-Aldrey \& Askew, 2002). Un estudio más detallado de la especie, actualmente en marcha, indica que puede tratarse de una especie nueva para la ciencia. La especie es frecuente en Valdemorillo y otras localidades del Sur y Sureste de la región donde prolifera la adormidera ( $P$. somniferum), planta anfitriona de su cinípido hospedador (Apéndices 1 y 2).

\section{FAMILIA Eupelmidae}

Familia de Chalcidoidea que agrupa unas 900 especies de parasitoides de himenópteros, coleópteros, lepidópteros y otros órdenes de Insecta y Araneae (Nieves-Aldrey \& Fontal-Cazalla, 1999). En el Paleártico los eupélmidos parasitoides de agallas de cinípidos están representados por 14 especies en dos géneros (Askew et al., en prensa; Askew et al., en prep), mientras que en el ámbito íbero-balear se han citado por el momento 11 especies en dos géneros (Askew y Nieves-Aldrey, 2000, 2004; Nieves-Aldrey, 2001; Nieves-Aldrey \& Askew, 2002; Pujade-Villar, 1989b). En relación a la Comunidad de Madrid, hasta la fecha se han catalogado nueve especies en dos géneros, lo cual supone el $75 \%$ de las especies íbero-baleares.

Los trabajos de Askew \& Nieves-Aldrey (2000, 2004), efectúan una puesta al día del estatus de la familia en la Península Ibérica y Canarias, incluyendo claves de identificación de las especies, a la vez que recopilan las citas anteriores y la información existente de la comunidad de eupelmidos parasitoide en agallas de cinípidos en el ámbito íbero-balear y Comunidad de Madrid.

\section{Calosota Curtis, 1836}

Género amplio en el Paleártico que cuenta con una única especie (C. obscura) de inclusión dudosa asociada a la comunidad de parasitoides en agallas de cinípidos (Askew et al., en prep.). Obtenida de agallas de varias especies de Aylacini en asteráceas y papaveráceas se piensa que puede ser un elemento ajeno a la comunidad y que se encontraría parasitando fauna secundaria asociada a las muestras de agallas, como algunas especies de coleópteros o dípteros. En cualquier caso, dado que es una especie registrada de muestras de agallas y de la que por el momento no se tiene certeza de su biología se incluye en el inventario. En la Comunidad de Madrid ha sido citada fundamentalmente del sureste de la región (Apéndices 1 y 2).

\section{Eupelmus Dalman, 1820}

El género más amplio de la familia, con aproximadamente 265 especies en todo el mundo (Gibson, 1995), incluye en el Paleártico 13 especies de parasitoides, generalmente polífagos, que también forman parte de la comunidad parasitoide asociada a agallas de cinípidos (Askew \& Nieves-Aldrey, 2000; Askew et al., en prensa, Askew et al., en prep.) (Fig. 1G). En el ámbito íbero-balear cuenta con 10 especies, que atacan tanto agallas de árboles del género Quercus y Acer, como las formadas 
sobre plantas herbáceas y arbustos de otras familias botánicas (Nieves-Aldrey, 1982c, 2001; NievesAldrey y Askew, 2002). Debido a su gran polifagia las especies de Eupelmus están presentes en la mayoría de los complejos parasitarios de las especies de cinípidos ibéricos. En la comunidad de Madrid el género cuenta con ocho especies. Eupelmus urozonus y E. microzonus son las especies más abundantes y están ampliamente distribuidas por la región, dado que son especies generalistas que atacan una amplia variedad de agallas. Otras especies monófagas tienen una distribución más restringida, como es el caso de E. cerris, cuya distribución sigue limitada a la de su agalla y planta hospedadora específicas, Synophrus politus Hartig, 1843 en $Q$. suber L. (Apéndices 1 y 2).

\section{FAmilia Eulophidae}

Amplia familia de calcidoideos integrada por unas 3900 especies (Noyes, 2003), en su gran mayoría parasitoides de larvas minadoras y gallícolas de himenópteros, dípteros, coleópteros y lepidópteros (Nieves-Aldrey \& Fontal-Cazalla, 1999). La comunidad de Eulophidae ligada a agallas de cinípidos en el paleártico está formada por al menos 36 especies incluidas en 8 géneros (Askew et al., en prensa; Askew et al., en prep). En el ámbito íbero-balear hasta la fecha se han catalogado 25 especies en 5 géneros (Nieves-Aldrey, 2001; Nieves-Aldrey \& Martín-Chicote, 1986; Nieves-Aldrey \& Askew, 2002; Pujade-Villar, 1992c; 1994b), si bien dada la dificultad taxonómica de la familia es posible que haya muchas más especies. En cuanto a la Comunidad de Madrid y contemplando las mismas dificultades, hasta la fecha se han citado 12 especies en 4 géneros, lo que supone cerca del $48 \%$ de la fauna íbero-balear de eulófidos.

Las especies de las subfamilias Eulophinae y Entedontinae, representadas por los géneros Aulogymnus y Pediobius, respectivamente, que atacan exclusivamente la comunidad de agallas de cinípidos en especies arbóreas de Quercus, han sido comparativamente más estudiadas y son mejor conocidas que las especies que atacan especies de plantas herbáceas y arbustos, casi todas pertenecientes a la subfamilia Tetrastichinae. A pesar de las monografías de Graham (1987; 1991), el conocimiento a día de hoy es aún escaso, debido a la complejidad de su estudio taxonómico, motivado por su enorme diversidad y su gran uniformidad morfológica.

\section{Aprostocetus Westwood, 1833}

Uno de los géneros más amplios dentro de la familia con cerca de 650 especies de hábito parasitoide, sobre una amplia variedad de hospedadores. La comunidad de Aprostocetus asociada a agallas de cinípidos en el paleártico está compuesta por unas nueve especies (Askew et al., en prensa; Askew et al., en prep) si bien, y debido a la dificultad de identificación y a su confusión, muchas veces con el género similar Baryscapus, puede que este número cambie. De hecho en muchos complejos parasitarios de especies de cinípidos aparecen algunas especies de Aprotocetus identificadas unicamente a nivel génerico. En el ámbito íbero-balear por el momento hay citadas ocho especies dentro de la comunidad parasitoide en agallas de cinípidos (Nieves-Aldrey, 2001; Nieves-Aldrey \& Askew, 2002), de las cuales cuatro se encuentran representadas en la fauna de la Comunidad de Madrid ( $A$. aurantiacus, A. epicharmus, A. forsteri y A. fusificola), aunque existen algunas otras que por el momento permanecen a nivel de género o con identificación incierta a falta de un estudio más detallado y profundo. Exceptuando A. epicharmus que posee una distribución más amplia en la región, el resto han sido citadas preferentemente en la zona norte y noroeste de la región (Apéndices 1 y 2)

\section{Aulogymnus Förster, 1851}

Género con 9 especies en el paleártico, todas parasitoides especialistas de agallas de cinípidos sobre Quercus, excepto A. aceris Förster que ataca agallas de Pediaspis en Acer. Todas las especies han sido citadas también en el ámbito íbero-balear (Askew et al., en prensa; Nieves-Aldrey, 1983c, 2001). En la Comunidad de Madrid se han citado hasta la fecha cinco especies, lo cual supone más de la mitad de la fauna íbero-balear del género. Son parasitoides exclusivos, casi siempre monófagos o estenófagos, de agallas de cinípidos en fagáceas del género Quercus, mayoritariamente en agallas de especies de Andricus, Biorhiza y Plagiotrochus. La mayor parte de las especies están ampliamente distribuidas en el territorio de la Comunidad de Madrid (Apéndices 1 y 2).

\section{Baryscapus Förster, 1856}

Junto con Aprostocetus es uno de los géneros más amplios dentro de la familia con 109 especies descritas hasta la fecha (Graham, 1987). Engloba un grupo de especies de dificil identificación de tal manera que muchas especies se han identificado unicamente a nivel de género o incluso son de adscripción genérica dudosa. Hasta la fecha en el 
Paleártico hay citadas cinco especies parásitas de agallas de cinípidos de las cuales cuatro han sido catalogadas para el ámbito íbero-balear (Askew et al., en prensa; Askew et al., en prep.; NievesAldrey, 1983c, 2001; Nieves-Aldrey y Askew, 2002). En la Comunidad de Madrid se han encontrado dos de esas especies (B. berhidanus y $B$. papaveris); la primera parasita agallas en árboles del género Quercus, mientras la segunda aparece asociada a agallas de tres especies de cínipidos ligadas a cápsulas de Papaver (A. minor, A. papaveris y $B$. oraniensis). Aunque no son muy abundantes, se pueden encontrar en cualquier área de la región (Apéndices 1 y 2).

\section{Pediobius Walker, 1846}

Amplio género de eulófidos (220 especies) con algunas especies parásitas de agallas de cinípidos. En el Paleártico se han citado seis especies de dicha comunidad parasitoide (Askew et al., en prensa), mientras que para el ámbito íbero-balear han sido citadas hasta la fecha únicamente tres (NievesAldrey, 1983c, 2001). En cuanto a la Comunidad de Madrid sólo se ha encontrado P. rotundatus. Se trata de una especie común, que aparece a asociada a agallas de distintas especies de Plagiotrochus sobre $Q$. ilex y Q. coccifera, especies perennifolias del género Quercus, distribuidas preferentemente en áreas del Centro y Sur de la región (Apéndices 1 y 2).

\section{Discusión}

La lista de calcidoideos parasitoides en agallas de cinípidos en la Comunidad de Madrid está compuesta por 102 especies identificadas, a las que hay que añadir otras 19 de identificación provisional o incierta, la mayoría en el género Eurytoma, o que representan nuevas especies para la ciencia aún sin publicar (géneros Idiomacromerus y Trichomalus). Contabilizando estos últimos taxa, el total de especies de dicha comunidad en Madrid se acercaría por tanto a las 121 especies. De todas ellas y excluyendo tres especies de Eupelmidae que aparecen en más de un subgrupo, 55 especies se encuentran en agallas de Cynipini, 52 en Aylacini y 11 en Diplolepidini. Es de resaltar la alta cifra de especies de Chalcidoidea parasitoides en agallas de cinípidos dentro de la Comunidad de Madrid en comparación con el número de especies de la misma comunidad parasitoide en los ámbitos íbero-balear y Paleártico occidental. Así, las especies citadas en la Comunidad de Madrid representan aproximadamente el $76.6 \%$ del total citado en el ámbito íbero- balear, y un $58.9 \%$ de las especies conocidas en el Paleártico occidental (Tabla 1). Esta cifra está en relación directa con el número de especies de cinípidos presentes en la Comunidad de Madrid (el $73 \%$ del total íbero-balear, Nieves-Aldrey et al., este volumen). La diversidad de cinípidos hospedantes, a su vez, se explica por la variedad y riqueza ambiental de la Comunidad de Madrid donde están representados una amplia variedad de hábitat y ecosistemas ibéricos, y un número elevado de las especies botánicas anfitrionas.

\section{Composición de la calcidofauna asociada a agallas de cinípidos en la comunidad de Madrid}

La composición por familias de la comunidad de Chalcidoidea parasitoides de agallas de cinípidos en la Comunidad de Madrid, comparada con la del conjunto íbero-balear y el Paleártico occidental se refleja en la Tabla 1. La familia de Chalcidoidea más numerosa en especies de dicha comunidad, en el territorio de Madrid es Pteromalidae, con 33 especies repartidas en 14 géneros. Con respecto a los grupos de cinípidos hospedadores, Pteromalidae está mejor representada en la comunidad parasitoide de agallas de cinípidos en Quercus, con 11 géneros y 24 especies, mientras que cuenta con relativamente pocas especies asociadas a agallas de Aylacini y Diplolepidini, seis del primer caso y tres del segundo.

La familia Torymidae es la segunda mejor representada dentro de la comunidad parasitoide de agallas de cinípidos en la Comunidad de Madrid; mientras que el subgrupo de parasitoides de agallas de especies de Cynipini (12) está dominado por especies de Torymus (nueve frente a las dos para Diplolepidini) y Megastigmus (3), siendo estas últimas en esta comunidad ecológica parásitas exclusivas de cinípidos ligados a Quercus. El subgrupo en agallas de Aylacini consta de cinco géneros y 12 especies mientras que el vinculado a agallas de Diplolepidini está integrado por una especie de Glyphomerus y dos de Torymus.

Eurytomidae, con 26 especies repartidas en dos géneros es la siguiente familia con mayor representación. Se trata de una familia mucho más abundante en agallas de Aylacini (16 especies) que en Cynipini (8 especies) y en Diplolepidini (2 especies). La mayor parte de las especies son monófagas especialistas en un tipo de agalla determinado, mientras que en agallas sobre Quercus se encuentran algunas especies polífagas. El hecho de que se trate de una familia cuyas especies en algunos 
Tabla 1.- Comparación de cifras de riqueza ( $\mathrm{n}^{\circ}$ de especies) de Chalcidoidea, desglosadas por familias y géneros, de la Comunidad de Madrid (CM), ámbito Ibero-Balear (AIB) y Paleártico Occidental (PO); * el número exluye 9 especies de Eurytomidae de dudosa identificación, 3 de Eulophidae no identificadas a nivel específico y otras 2 de dudosa identificación en la misma familia, 3 de Torymidae que se encuentran en estudio y 3 de Pteromalidae no identificadas de dudosa identificación a nivel específico en los tres ámbitos considerados, además de otra especie de Pteromalidae y una de Eupelmidae sin identificar citadas en el Paleártico pero no presentes en el ámbito Ibero-Balear y Comunidad de Madrid.

Table 1.- Comparison of species richness of Chalcidoidea, separated by families and genera from Comunidad de Madrid (CM), Iberian Peninsula and Balearic Islands area (AIB) and Western Palaearctic (PO); not included in total numbers: 8 uncertain species of Eurytomidae, 4 under revision of Torymidae and 2 not identified at specific level of Pteromalidae as well as one more not identified of Pteromalidae and one of Eupelmidae not present in Iberian Península and Balearic Islands and Comunidad de Madrid.

\begin{tabular}{|c|c|c|c|}
\hline & CM & AIB & PO \\
\hline EURYTOMIDAE & 17 & 20 & 31 \\
\hline Eurytoma & 9 & 12 & 22 \\
\hline Sycophila & 8 & 8 & 9 \\
\hline TORYMIDAE & 23 & 30 & 43 \\
\hline Adontomerus & 2 & 2 & 2 \\
\hline Chalcimerus & 1 & 1 & 1 \\
\hline Diomorus & - & 1 & 1 \\
\hline Glyphomerus & 2 & 2 & 4 \\
\hline Idiomacromerus & 5 & 5 & 5 \\
\hline Megastigmus & 3 & 3 & 5 \\
\hline Pseudotorymus & 1 & 1 & 1 \\
\hline Thaumatorymus & - & - & 1 \\
\hline Torymus & 11 & 15 & 23 \\
\hline ORMYRIDAE & 9 & 10 & 10 \\
\hline Ormyrus & 9 & 10 & 10 \\
\hline PTEROMALIDAE & 31 & 37 & 40 \\
\hline Arthrolytus & 1 & 4 & 4 \\
\hline Caenacis & 2 & 2 & 2 \\
\hline Cecidostiba & 6 & 7 & 7 \\
\hline Cecidolampa & - & 1 & 1 \\
\hline Cyrtoptyx & 1 & 1 & 1 \\
\hline Eumacepolus & 1 & 1 & 1 \\
\hline Hobbya & 1 & 1 & 1 \\
\hline Homoporus & 2 & 2 & 2 \\
\hline Mesopolobus & 10 & 10 & 12 \\
\hline Ormocerus & 2 & 2 & 2 \\
\hline Phaenocytus & 1 & 1 & 1 \\
\hline Pteromalus & 2 & 3 & 4 \\
\hline Rivasia & 1 & 1 & 1 \\
\hline Stinoplus & 1 & 2 & 2 \\
\hline EUPELMIDAE & 9 & 11 & 13 \\
\hline Calosota & 1 & 1 & 1 \\
\hline Eupelmus & 8 & 10 & 12 \\
\hline EULOPHIDAE & 10 & 25 & 36 \\
\hline Aprostocetus & 4 & 8 & 11 \\
\hline Aulogymnus & 5 & 9 & 9 \\
\hline Baryscapus & 2 & 4 & 5 \\
\hline Cirrospilus & - & - & 2 \\
\hline Dichatomus & - & 1 & 1 \\
\hline Closterocerus & - & - & 1 \\
\hline Minotetrastichus & - & - & 1 \\
\hline Pediobius & 1 & 3 & 6 \\
\hline TOTAL & $102 *$ & $133 *$ & $173 *$ \\
\hline
\end{tabular}

casos presentan gran dificultad de identificación, puede hacer que varíe el número de especies registradas a medida que se vaya profundizando en el conocimiento de la comunidad.

Las especies de Eulophidae parasitoides de agallas de cinípidos poseen una buena representación en la Comunidad de Madrid (17 especies). El grupo de eulófidos asociado a agallas de Cynipini sobre Quercus, cuenta con un género específico Aulogymnus, con cinco especies, una especie de Aprostocetus, una de Baryscapus y otra de Pediobius. Asociadas a especies de la tribu Aylacini hay citadas dos especies y otras dos a Diplolepidini, si bien otras muchas de los géneros Aprostocetus y Baryscapus permanecen sin identificar o con identificación dudosa, dada la dificultad taxonómica del grupo, poniendo de relieve que posiblemente la representación del conjunto de los eulófidos en la región es mayor que lo que indican las listados de las especies identificadas.

Los Ormyridae están representados en agallas de Cynipini por nueve especies en la Comunidad de Madrid, de las cuales dos aparecen en agallas de Cynipini (las especies polífagas $O$. pomaceus y $O$. nitidulus) (Fig. 1E), mientras que en agallas de Aylacini se han catalogado siete, todas ellas monófagas o estenófagas. Por último, y en relación al grupo de calcidoideos de la comunidad parasitoide en agallas de cinípidos de la familia Eupelmidae, cabe destacar el alto grado de polifagia de muchas especies. Así, especies como E. seculatus y E. vesicularis pueden parasitar especies de cinípidos pertenecientes a tribus distintas, además de insectos de otros órdenes. En agallas de Cynipini de la Comunidad de Madrid se han catalogado cinco especies, cuatro en las de Aylacini y dos en las de Diplolepidini, con algunas especies como E. urozonus y E. vesicularis que pueden atacar indistintamente especies de tribus de cinípidos distintas.

\section{Especies de la comunidad ibérica de Chalcidoidea, asociada a agallas de cinípidos, ausentes de la Comunidad de Madrid y especies potencialmente presentes}

Treinta y una especies de la lista de Chalcidoidea ibéricos, del complejo parasitoide de agallas de cinípidos, no han sido citadas en la Comunidad de Madrid. De esta lista, un cierto número de especies está potencialmente excluido de este territorio, dado que falta el elemento fundamental en la cadena trófica que es la especie de planta anfitriona de la agalla y el cinípido hospedador. Por tanto, en estos 
casos no creemos probable que un mayor esfuerzo de muestreo incremente la probabilidad de añadir alguna de estas especies a la lista de Madrid. Es el caso, por ejemplo, de Eurytoma pediaspisi PujadeVillar, 1994, Cecidostiba docimus (Walker, 1839), Eupelmus splendens Giraud, 1871, Dichatomus acerinus Förster, 1878 y Aulogymnus aceris Förster, 1851, todas ellas especies parasitoides específicas de agallas de Pediaspis aceris (Gmelin, 1790) sobre especies de Acer; de Torymus rubi (Schrank, 1781) parásito de Diastrophus rubi (Bouché, 1834); de Torymus cingulatus Nees, 1834, parásita de Liposthenes glechomae (Linnaeus, 1758) y algunas otras. Por el contrario, algunas especies ibéricas de Chalcidoidea parasitoides de agallas de cinípidos, cuyas agallas hospedadoras son de la entomofauna madrileña, o han sido encontradas en localidades de la zona centro de España no lejanas a Madrid, presentan alta probabilidad de ser encontradas. En este caso pueden estar por ejemplo las siguientes: Ormyrus salmanticus Nieves-Aldrey, 1984, parásita de Aulacidea subterminalis Niblett, 1946; Pteromalus hieracii (Thomson, 1878) parasitoide de agallas de varias especies de Aulacidea en plantas herbáceas de la familia Asteraceae; Torymus formosus (Walker, 1833), parasitoide de agallas de la generación ágama de Andricus quercuscorticis (Linnaeus, 1761); Arthrolytus glandium Boucek y A. ocellus Walker, parásitas de agallas de las generaciones ágamas de Callirhytis glandium (Giraud, 1859) y C. rufescens (Mayr, 1882); y Pediobius lysis (Walker, 1839) y Pediobius clita (Walker, 1839), parásitas de distintas agallas de la generación agama de especies de Neuroterus en diferentes especies de Quercus.

\section{Especies exclusivas o singulares}

La Comunidad de Madrid es la región de España con mayor riqueza conocida de Chalcidoidea de la comunidad asociada a agallas de cinípidos. Es también una de las que ha sido más intensamente estudiada, en lo que se refiere al conjunto de dicha comunidad parasitoide, y con toda seguridad la más estudiada en el caso de la comunidad ligada a agallas de Aylacini. Como reflejo de estos hechos varias especies de Chalcidoidea de dicha comunidad parasitoide se han descrito por primera vez con material de la Comunidad de Madrid. Estas especies son Adontomerus impolitus (Askew \& Nieves-Aldrey, 1988), Idiomacromerus silybi Askew, 2004, Idiomacromerus centaureae (Askew \& NievesAldrey, 1988) y Rivasia fumariae Askew \& Nieves-
Aldrey, 2005. Otras especies tienen hasta ahora las únicas citas ibéricas conocidas dentro del territorio de Madrid. En este caso están las siguientes: Eurytoma infracta Mayr, 1904, Ormyrus wachtly Mayr, 1904, O. rufimanus, Mayr, 1904, Stinoplus lapsanae Gram., 1969 y Phaenocytus glechomae (Förster, 1841), esta última especie identificada con dudas.

\section{Distribución y riqueza de Chalcidoidea asociados a agallas de cinípidos en la Comunidad de Madrid}

La riqueza y la presencia/ausencia de determinada especie de Chalcidoidea parasitoide de agallas de cinípidos, depende directamente de la presencia de su hospedador, de tal modo que sus distribuciones van a estar estrechamente ligadas, salvo en el caso de las especies con alto grado de polifagia que sean capaces de pasar a otros hospedadores. En este volumen se presentan los mapas de distribución en la Comunidad de Madrid de todas las especies de cinípidos hospedadores, las cuales representan también el área potencial de distribución de sus especies parasitoides y deben, por tanto, consultarse a este respecto (Nieves-Aldrey et al., este volumen). Actualmente los factores que afectan a la riqueza de especies de las comunidades de parasitoides en agallas de cinípidos en el ámbito íbero-balear se encuentran en estudio por parte de los autores, aunque factores que puedan ser determinantes probablemente sean el subgrupo hospedador (tribu de cinípido), la planta que abergue la agalla y la distribución del propio hospedador.

Del análisis de nuestros resultados y teniendo en cuenta las consideraciones expuestas en la discusión se puede concluir que las 121 especies de calcidoideos parasitoides listadas en la Comunidad de Madrid se corresponden a una imagen cercana a la real de la comunidad de parasitoides en agallas de cinípidos de Madrid. Sin embargo el número final de especies puede aún incrementarse con especies potencialmente presentes en la Comunidad aún no encontradas. Por otra parte, consideramos que pueden quedan aún especies parasitoides nuevas por encontrar y describir, especialmente en la comunidad parasitoide asociada a agallas en plantas herbáceas de especies de cinípidos de la tribu Aylacini, como demuestran los descubrimientos recientes de varias especies (Askew et al., 2004; Askew \& NievesAldrey, 2005). Entre las comunidades a investigar podemos mencionar las de las agallas de Aulacidea laurae Nieves-Aldrey, 1992 en Scorzonera laciniata, de Iraella luteipes (Thomson, 1877) en Papaver 
somniferum, de Ceconia valerianellae (Thomson, 1877) en especies de Valerianella, de Isocolus fitchi (Kieffer, 1898) en Centaurea scabiosa, de Timaspis lusitanica Tavares, 1904 en Barckausia taraxacifolia y de Timaspis rufipes Ionescu \& Roman, 1959 en Crepis pulchra. A medida que se puedan colectar más agallas de estas especies escasas o raras cabe esperar que se obtengan nuevos calcidoideos parasitoides específicos y se incremente la lista conocida de especies de esta taxocenosis en la Comunidad de Madrid.

\section{AGRADECIMIENTOS}

El trabajo ha sido financiado parcialmente con fondos de los proyectos de la Consejería de Educación de la Comunidad de Madrid (07M/0080/2002 y GR/AMB/0750/2004) y del Ministerio de Ciencia y Tecnología (REN2002-03518/GLO).

\section{Referencias}

ASKEW, R. R., 1961. On the biology of the inhabitants of oak galls of Cynipidae (Hymenoptera) in Britain. Transactions of the Society for British Entomology, 14: 237-268.

ASKEW, R. R., 1975a. The organisation of Chalcid-dominated parasitoid communities centered upon endophytic hosts. In: P. W. Price (ed.). Evolutionary strategies of parasitic insects and mites. Plenum Press. New York: 130-153.

Askew, R. R., 1975b. Descriptions of a new genus and two new species of Pteromalidae (Hym., Chalcidoidea) reared from cynipids (Hymenoptera) galls, with notes on some other species. Bulletin $d u$ museum National d'Historie Naturelle, 202: 405-412

Askew, R. R., 1984. The biology of gall wasps. In: T. N. Ananthakrishnan (ed.). Biology of gall Insects. Oxford \& IBH. New Delhi: 223-271.

AsKew, R. R., 1994. Two new European species of Ormyrus (Hym., Ormyridae). Entomologist's monthly Magazine, 130: 87-93.

Askew, R. R. \& Blasco-ZumetA, J., 1998. Insects associated with galls of a new species of Eurytomidae (Hymenoptera: Chalcidoidea) on Ephedra nebrodensis in Spain. Journal of Natural History, 32: 805-821.

Askew, R. R., Gómez, J. F. \& Nieves-Aldrey, J. L., 2004. Species of Microdontomerini (Hymenoptera: Chalcidoidea: Torymidae) associated with galls of Cynipidae (Hymenoptera) in Europe. Journal of Hymenoptera Research, 13(2): 214-222.

Askew, R. R. \& Nieves-Aldrey, J. L., 1982. European species of Arthrolytus Thomson (Hym., Pteromalidae) reared from cynipid oak galls with descriptions of two new species. Entomologica Scandinavica, 13: 414-418.
Askew, R. R. \& Nieves-Aldrey, J. L., 1988. Some Monodontomerinae and Megastigminae (Torymidae) associated with Cynipidae in Spain (Hymenoptera). Entomologica Scandinavica, 18: 355-359.

Askew, R. R. \& Nieves-Aldrey, J. L., 2000. The genus Eupelmus Dalman, 1820 (Hymenoptera, Chalcidoidea, Eupelmidae) in peninsular Spain and the Canary Islands, with taxonomic notes and descriptions of new species. Graellsia, 56: 49-61.

AsKew, R. R. \& NiEves-AldREy, J. L., 2004. Further observations on Eupelminae (Hymenoptera, Chalcidoidea, Eupelmidae) in the Iberian Peninsula and Canary Islands, including descriptions of new species. Graellsia, 60(1): 27-39.

Askew R. R. \& Nieves-Aldrey, J. L., 2005. A new genus and species of Pteromalidae (Hymenoptera, Chalcidoidea) from Spain, parasitic in cynipid galls on Fumaria. Journal of natural History, 39(25): 2331-2338.

Askew, R. R., Nieves-Aldrey, J. L., Pujade-Villar, J., Schönrogge, K. \& Thuróczy, C., (en prensa). The oak gall communities. In: G. N. Stone, G. Melika \& Gy. Csóka (eds.). The Oak Cynipids of the Western Palaeartic. The Ray Society. London.

BouceK, Z., 1988. Australasian Chalcidoidea (Hyme-noptera). C. A. B. International. Wallingford. UK. 832 pp.

BouceK, Z. \& Rasplus, J. Y., 1991. Illustrated key to West-Palearctic genera of Pteromalidae. INRA Editions. Paris. 140 pp.

Csóka, G., Stone, G. N. \& Melika, G., 2005. The biology, ecology and evolution of gall wasps. In: A. Raman, C. W. Schaeffer \& T. M. Withers (eds.). Biology, ecology and evolution of gall-inducing arthropods. Science Publishers Inc. Enfield: 569-636.

Espejo-Noguera, F. \& Pujade-Villar, J., 2000. Situació i noves aportacions al coneixement de la familia Eurytomidae Walker 1833 (Hymenoptera: Chalcidoidea) a la Península Ibérica i a les illes Balears. Sessió d'Entomologia de la Institució Catalana d'Història Natural-Societat Catalana de Lepidopterologia, [1997], 10: 51-62.

FulMEK, L., 1968. Parasiteninsekten der Insecktengallen Europas. Beiträge zur Entomologie, 18: 719-952.

Garrido, A. M. \& Nieves-Aldrey, J. L., 1992. Nuevas citas de Pteromalidae para España (Hymenoptera, Chalcidoidea) colectados con trampas "Malaise". Actas do $V$ Congresso Ibérico de Entomologia. Boletim da Sociedade Portuguesa de entomología, Suplemento, 3: 501-512.

Garrido-Torres, A. M., \& Nieves-Aldrey, J. L., 1990. Catálogo actualizado de los pteromálidos de la Península Ibérica e Islas Baleares (Hym., Chalcidoidea, Pteromalidae). Boletín de la Asociación española de Entomología, 14: 71-87.

Garrido-Torres, A. M. \& Nieves-Aldrey, J. L., 1999. Pteromálidos de la Comunidad de Madrid: 
Faunística y Catálogo (Hymenoptera, Chalcidoidea, Pteromalidae). Graellsia, 55: 9-147.

Gauld, I. \& Bolton, B., 1988. The Hymenoptera. Oxford University Press. Oxford. 332 pp.

GiBson, G. A., 1995. Parasitic wasps of the subfamily Eupelminae: Classification and revision of world genera (Hymenoptera: Chalcidoidea: Eupelmidae). Memoirs on Entomology, Internacional, 5: 1- 421.

Gibson, G. A., Heraty, J. M. \& Woolley, J. B., 1999. Phylogenetics and classification of Chalcidoidea and Mymarommatoidea: A review of current concepts (Hymenoptera, Apocrita). Zoologica Scripta, 28: 87-124.

Graham, M. W. R. DE V., 1969. The Pteromalidae of North-Western Europe (Hymenoptera: Chalcidoidea). Bulletin of the British Museum Natural History. (Entomology) suppl., 16: 1-908.

Graham, M.W.R. DE V., 1987. A reclassification of the European Tetrastichinae (Hymenoptera: Eulophidae), with a revision of certain genera. Bulletin of the British Museum Natural History. (Entomology), 55: 1-392.

Graham, M.W.R. DE V., 1991. A reclassification of the european Tetrastichinae (Hymenoptera: Eulophidae): Revisión of the remaining genera. Memoirs of the American Entomological Institute, 49: 1-322.

Graham, M.W.R. DE V. \& Gijswijt, M. J., 1998. Revision of the European species of Torymus Dalman (s. lat.) (Hymenoptera: Torymidae). Zoologische Verhandelingen, 317: 1-202.

GrisSELL, E. E., 1995. Toryminae (Hymenoptera: Chalcidoidea: Torymidae): A Redefinition, Generic Classification, and Annotated World Catalog of Species. Memoirs on Entomology, Internacional, 2: $1-470$.

Hawkins, B. A. \& Goeden, R. D., 1984. Organization of a parasitoid community associated with a complex of galls on atriplex spp. in southern California. Ecological Entomology, 9: 271-292.

Hayward, A. \& Stone, G. N., 2005. Oak gall wasp communities: Evolution and ecology. Basic and Applied Ecology, 6: 435-443.

Heraty, J., 2004. Molecular Systematics, Chalcidoidea and Biological Control. In: L.E. Ehler, R. Sforza \& T. Mateille (eds). Genetics, Evolution and Biological Control. CAB International. New York: 39-71.

Memmott, J. \& Godfray, H. C. J., 1992. Parasitoids webs. In: J. Lasalle \& I. D. Gauld (eds.). Hymenoptera and biodiversity. $\mathrm{CAB}$ Internacional, Wallingford: 217-234.

Nieves-Aldrey, J. L., 1981. Datos sobre Diplolepis rosae (L.) (Hym., Cynipidae) y sus himenópteros parásitos en Salamanca. Boletín de la Asociación española de Entomología, [1980], 4: 107-113.
NiEves-AldREY, J. L., 1982a. Nuevos datos sobre las especies europeas del género Ormocerus Walker (Hym., Pteromalidae) con descripción del macho de Ormocerus vernalis Walker. Nouvelle Revue d'Entomologie, 12: 183-187.

Nieves-Aldrey, J. L., 1982b. Nuevos datos sobre las especies de los géneros Cyrtoptyx Delucchi, Caenacis Förster, Cecidostiba Thomson Walter y Hobbya Delucchi asociadas con agallas de cinípidos de los robles. Graellsia, 38: 35-42

Nieves-Aldrey, J. L., 1982c. Eupélmidos (Hym., Eupelmidae) que parasitan a los pobladores de las agallas de cinípidos producidas en especies de Quercus en Salamanca. Boletín de la Asociación Española de Entomología, [1981], 5:143-150.

Nieves-Aldrey, J. L., 1983a. Contribución al conocimiento de la fauna de himenópteros inquilinos y parásitos en las agallas de Diplolepis mayri (Schechtendal) y Diplolepis eglanteriae (Hartig) (Hym., Cynipidae). Graellsia, 39: 93-102.

Nieves-Aldrey, J. L., 1983b. Sobre las especies del género Mesopolobus (Hym., Pteromalidae) asociadas con agallas de cinípidos en Quercus spp. en Salamanca. Boletín de la Asociación española de Entomología, 7: 9-18.

Nieves-Aldrey, J. L., 1983c. Contribución al conocimiento de los eulófidos (Hym., Chalcidoidea, Eulophidae) parásitos en las agallas de cinípidos producidas sobre especies de Quercus. Boletín de la Asociación española de Entomología, 7: 43-54.

Nieves-Aldrey, J. L., 1984a. Contribución al conocimiento de la fauna de himenópteros inquilinos $\mathrm{y}$ parásitos en las agallas de Diplolepis mayri (Schlechtendal) y Diplolepis eglanteriae (Hartig) (Hym.,Cynipidae). Graellsia, [1983] 39: 93-102.

Nieves-Aldrey, J. L., 1984b. Sobre las especies de Sycophila Walker, asociadas con agallas de cinípidos en la Península Ibérica, con descripción de una nueva especie (Hym., Eurytomidae). Eos, [1983] 59: 175-187.

NiEves-Aldrey, J. L., 1984c. Observaciones sobre los torímidos (Hym., Chalcidoidea, Torymidae) asociados con agallas de cinípidos (Hym., Cynipidae) sobre Quercus spp. en la zona centro-occidental de España. Boletín de la Asociación española de Entomología, 8: 121-134.

Nieves-Aldrey, J. L., 1984d. Primeros datos sobre los representantes de la familia Ormyridae en España, con descripción de una nueva especie (Hym., Chalcidoidea). Graellsia, 40: 119-127.

Nieves-Aldrey, J. L., 1988. Descripción de una nueva especie de Isocolus Förster con notas de otras especies de Aylaxini nuevas para la Península Ibérica (Hym., Cynipidae). Eos, 64(1): 221-227.

Nieves-Aldrey, J. L., 2001. Familia Cynipidae. Hymenoptera, Cynipidae. In: Ramos, M. A. et al. 
(eds). Fauna Ibérica, vol. 16. Museo Nacional de Ciencias Naturales. CSIC. Madrid. 636 pp.

Nieves-Aldrey, J. L. \& Askew, R. R., 1988. A new species of Cecidostiba Thomson (Hym., Pteromalidae) a key to species of the genus and rearing records of other pteromalidae associated with oak gall wasp (Hym., Cynipidae). Entomologist's Monthly Magazine, 124: 16.

Nieves-Aldrey, J. L. \& Askew, R. R., 2002. Calcidoideos (Hym., Chalcidoidea) asociados a agallas de Aylacini y Diplolepidini (Hym., Cynipidae) en España. Boletín de la Asociación Española de Entomología, 26 (1-2): 11-37.

Nieves-Aldrey, J. L. \& Fontal-Cazalla, F. M., 1999. Filogenia y Evolución del Orden Hymenoptera. In: Melic, A. (ed.). Evolución y Filogenia de Arthropoda. Volumen Monográfico de la SEA, 26: 459-474.

Nieves-Aldrey, J. L., Fontal-Cazalla, F., GarridoTorres, A. M. \& Rey Del Castillo, C., 2003. Inventario de Hymenoptera (Hexapoda) en El Ventorrillo: Un rico enclave de biodiversidad en la sierra de Guadarrama (España central). Graellsia, 59(2-3): 25-43

Nieves-Aldrey, J. L., Gómez, J. F. \& Hernández NiEves, M., 2004. Nuevos datos sobre Aulacidea freesei y Phanacis zwoelferi (Hymenoptera, Cynipidae, Aylacini), inductores de agallas en Silybum marianum (Asteraceae), en la Península ibérica, incluyendo la descripción y comparación de sus larvas terminales y sus agallas. Boletín de la Sociedad entomológica Aragonesa, 34: 85-93.

Nieves-Aldrey, J. L., Gómez, J. F. , Hernández Nieves, M. \& LoBO, J. M., 2006. Los Cynipidae (Hymenoptera) de la Comunidad de Madrid: lista anotada, mapas de distribución, riqueza y estatus de conservación. Graellsia, 62(número extraordinario): 371-402.

Nieves-Aldrey, J. L. \& Martin-Chicote, I., 1986. Nuevas citas de calcídidos parásitos de insectos gallícolas en España. Boletín de la Asociación española de Entomología, 10: 209-213.

Noyes, J. S., 1990. The number of described chalcidoid taxa that are currently regarded as valid. Chalcid Forum, 13: 9-10.

Noyes, J. S., 2003. Universal Chalcidoidea Database. World Wide Web electronic publication. www.nhm.ac.uk/entomology/chalcidoids/index.html [acceso 10-Oct-2005 ]

Price, P. W. \& ClAnCy, K. M., 1986. Interactions among three throphic levels: gall size and parasitoid attack. Ecology, 67 (6): 1593-1600.

Pujade-VILlar, J., 1985. Sobre Plagiotrochus panteli Pujade (Hym., Cynipidae) y sus parásitos (Hym., Chalcidoidea). Actas do II Congresso Ibérico de entomología. Suplemento 1. Boletim da Sociedade Portuguesa de Entomología, 2: 531-539.
PuJADE-VILlaR, J., 1989a. Sobre la variabilitat morfològica d'algunes espècies dels Ormyridae Foerster, una nova família d'himenòpters per a Catalunya (Hymenoptera, Chalcidoidea). Sessió d'Entomologia de la Institució Catalana d'Història Natural-Societat Catalana de Lepidopterologia, 5: 77-90.

Pujade -Villar, J., 1989b. Primeros datos sobre los eupélmidos asociados a agallas en Cataluña (Hym., Chalcidoidea, Eupelmidae) con la descripción del macho de Macroneura seculata (Ferrière, 1954). Orsis, 4: 151-160.

Pujade-Villar, J., 1992a. Sobre la presencia de Diastrophus rubi (Hym., Cynipidae) en el nordeste Ibérico y sobre sus parásitos (Hym., Torymidae, Eurytomidae, Eupelmidae). Boletim da Sociedade portugueza de Entomologia. Supplemento, 3(2): 117-126.

Pujade-VILlar, J., 1992b. Especies asociadas (Hym., Ichneumonidea [sic], Chalcidoidea) a agallas de las distintas especies de Diplolepis Geoffroy (Hym., Cynipoidea) detectadas en el Nordeste Ibérico. Boletim da Sociedade portugueza de Entomologia. Supplemento, 3 (2): 127-136.

Pujade-Villar, J., 1992c. Sobre las especies de Aprostocetus Westwood, 1833, recolectadas en Cataluña en agallas de cinípidos producidas sobre especies del género Rosa y Quercus (Hym., Chalcidoidea, Eulophidae). Orsis, 7: 79-85.

Pujade-VILlar, J., 1993. Sobre els Megastigmus Dalman (Hymenoptera: Chalcidoidea, Torymidae) detectats a Catalunya a partir de la recollecció de cecidis de cinípids produïts sobre Rosa i Quercus. Sessió d'Entomologia de la Institució Catalana d'Història Natural-Societat Catalana de Lepidopterologia, [1991] 7: 53-58.

Pujade-Villar, J., 1994a. Sobre les espècies de Sycophila Walker, 1871 relacionades amb cinipo-cecidis recol.lectats sobre Quercus y Rosa a Catalunya (Hymenoptera: Chalcididae: Eurytomidae). Butlleti Institució Catalana Història Natural secció Zoología, 61: 69-79.

Pujade-Villar, J., 1994b. Sobre el complejo parasitario (Hym.: Eurytomidae, Pteromalidae, Eulophidae y Eupelmidae) de Pediaspis aceris (Gmelin) (Hym.: Cynipidae) en la Península Ibérica. Boletín de la Asociación española de Entomología, 18: 21-30.

Pujade-VILlar, J., 1994c. Sobre las especies de pteromálidos (Hym., Pteromalidae) detectadas en agallas de Diplolepis sp. (Hym., Cynipidae) en Cataluña. Orsis, 9: 107-108.

Pujade-Villar, J., 1994d. Especies de Mesopolobus (Hym., Pteromalidae) asociadas a agallas de Cynipini (Hym., Cynipidae) del nordeste ibérico y notas sobre la validez de $M$. lichtensteini (Mayr, 1903). Eos, [1993] 69: 63-73.

REDFERN, M. y AsKew, R.R., 1992. Plant galls. In: Naturalists'Handbooks, vol. 17. Richmond Publishing Co. Ltd. Slough. 99 pp. 
SHORTHOUSE, J. D., 1973. The insect community associated with rose galls of Diplolepis polita (Cynipidae, Hymenoptera). Quaestiones entomologicae, 9: 55-98.

Stojanova, A. 2005. Glyphomerus aylax sp. $\mathrm{n}$ (Hymenoptera: Torymidae) from Bulgaria. Revue Suisse de Zoologie, 112 (1): 173-182.

Wiebes-RijKs, A. A. \& Shorthouse, J. D., 1992. Ecological relationships of insects inhabiting cynipid galls. In: Shorthouse, J. D. \& Rohfritsch, O. (eds.). Biology of insect-induced galls. Oxford University Press. New York: 238-257.

Zerova, M.D., 1995. Parasitic HymenopteraEurytominae and Eudecatominae of Paleartics. Kiev, Naukova Dumka. 456 pp. 
Apéndice 1.- Relación de las especies de Chalcidoidea obtenidad de cada una de las agallas hospedadoras de las especies de cinípidos de la Comunidad de Madrid.

Appendix 1. - List of Chalcidoidea species reared from each host gall of the cynipid species of Comunidad de Madrid.

\section{AYLACINI}

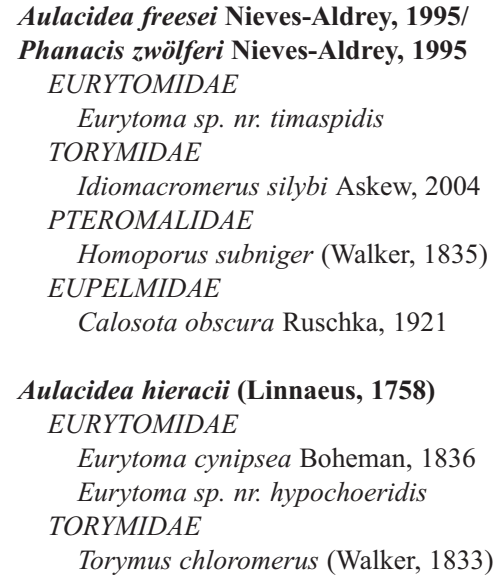

Pseudotorymus papaveris (Thomson, 1876) ORMYRIDAE

Ormyrus capsalis Askew, 1994

Ormyrus papaveris (Perris, 1840)

EULOPHIDAE

Aprostocetus epicharmus (Walker, 1839)

Baryscapus papaveris Graham, 1991

EUPELMIDAE

Eupelmus microzonus Förster, 1860

\section{Aylax papaveris (Perris, 1840) \\ TORYMIDAE}

Idiomacromerus papaveris (Förster, 1856)

Pseudotorymus papaveris (Thomson, 1876) ORMYRIDAE

Ormyrus papaveris (Perris, 1840)

EULOPHIDAE

Baryscapus papaveris Graham, 1991

EUPELMIDAE

Eupelmus vesicularis (Retzius, 1783)

Barbotinia oraniensis (Barbotin, 1964)

EURYTOMIDAE

Eurytoma sp. nr. infracta

TORYMIDAE

Chalcimerus borceai Steffan \& Andriescu, 1962

Glyphomerus tibialis (Förster, 1859)

Idiomacromerus papaveris (Förster, 1856)

Pseudotorymus papaveris (Thomson, 1876)

ORMYRIDAE

Ormyrus capsalis Askew, 1994

Ormyrus papaveris (Perris, 1840)

EULOPHIDAE

Baryscapus sp. indet.

Baryscapus papaveris Graham, 1991

EUPELMIDAE

Eupelmus microzonus Förster, 1860

\section{Iraella luteipes (Thomson, 1877)}

EURYTOMIDAE

Eurytoma cynipsea Boheman, 1836

Eurytoma sp. sp. nr. jaceae

TORYMIDAE

Idiomacromerus sp. indet.

PTEROMALIDAE

Trichomalus sp. $n r$ tenellus

EUPELMIDAE

Calosota obscura Ruschka, 1921

Isocolus leuzeae Nieves-Aldrey \& Parra, 2003 EURYTOMIDAE

Eurytoma strigifrons Thomson, 1876

Sycophila submutica (Thomson, 1876)
Isocolus lichtensteini (Mayr, 1882) EURYTOMIDAE

Eurytoma strigifrons Thomson, 1876

Sycophila submutica (Thomson, 1876)

TORYMIDAE

Adontomerus crassipes Boucek, 1982

ORMYRIDAE

Ormyrus gratiosus (Förster, 1860)

EUPELMIDAE

Eupelmus microzonus Förster, 1860

EULOPHIDAE

Aprostocetus sp. indet. 1

Aprostocetus sp. gr. epicharmus

Isocolus scabiosae (Giraud, 1859) f. rogenhoferi

EURYTOMIDAE

Sycophila mayri (Erdös, 1959)

Sycophila submutica (Thomson, 1876)

ORMYRIDAE

Ormyrus gratiosus (Förster, 1860)

Liposthenes kerneri (Wachtl, 1891)

PTEROMALIDAE

Phaenocytus sp. indet.

ORMYRIDAE

Ormyrus diffinis (Fonscolombe, 1832)

EUPELMIDAE

Eupelmus microzonus Förster, 1860

Eupelmus vesicularis (Retzius, 1783)

EULOPHIDAE

Aprostocetus sp. indet. 1

Neaylax salviae (Giraud, 1859)

EURYTOMIDAE

Eurytoma infracta Mayr, 1904 ORMYRIDAE

Ormyrus wachtli Mayr, 1904

EUPELMIDAE

Eupelmus microzonus Förster, 1860

Neaylax verbenacus (Nieves-Aldrey, 1988)

EURYTOMIDAE

Eurytoma infracta Mayr, 1904

ORMYRIDAE

Ormyrus wachtli Mayr, 1904

Neaylax versicolor (Nieves-Aldrey, 1985)

PTEROMALIDAE

Rivasia fumariae Askew \& Nieves-Aldrey, 2005 
Phanacis centaureae Förster, 1860

EURYTOMIDAE

Eurytoma aspila (Walker, 1836)

Sycophila mayri (Erdös, 1959)

TORYMIDAE

Idiomacromerus centaureae (Askew \&

Nieves Aldrey, 1988)

ORMYRIDAE

Ormyrus sp. nr. destefanii Mayr, 1904

PTEROMALIDAE

Homoporus fulviventris (Walker, 1835)

Homoporus subniger (Walker, 1835)

EUPELMIDAE

Eupelmus microzonus Förster, 1860

Eupelmus vesicularis (Retzius, 1783)

\section{Phanacis hypochoeridis (Kieffer, 1887)}

EURYTOMIDAE

Eurytoma cynipsea Boheman, 1836

TORYMIDAE

Glyphomerus tibialis Förster, 1856

Idiomacromerus urospermi Askew, 2004

PTEROMALIDAE

Homoporus subniger (Walker, 1835)

EUPELMIDAE

Eupelmus vesicularis (Retzius, 1783)

Timaspis cichorii (Kieffer, 1909)

EURYTOMIDAE

Eurytoma aspila (Walker, 1836)

Eurytoma cynipsea Boheman, 1836

Eurytoma sp. $n r$. aspila

Eurytoma sp. nr. cynipsea

TORYMIDAE

Idiomacromerus centaureae (Askew \&

Nieves-Aldrey, 1988)

Idiomacromerus semiaeneus (Szélenyi, 1957)

PTEROMALIDAE

Homoporus fulviventris (Walker, 1835)

Homoporus subniger (Walker, 1835)

EUPELMIDAE

Eupelmus microzonus Förster, 1860

EULOPHIDAE

Baryscapus sp. indet.

Baryscapus sp. nr. diaphantus

Timaspis lampsanae (Perris, 1873)

EURYTOMIDAE

Eurytoma rosae Nees, 1834

Eurytoma sp. nr. rosae

PTEROMALIDAE

Stinoplus lapsanae Graham, 1969

EUPELMIDAE

Eupelmus microzonus Förster, 1860

Timaspis phoenixopodos Mayr, 1882 EURYTOMIDAE

Eurytoma aspila (Walker, 1836)

Eurytoma sp. nr. hypochoeridis

Eurytoma sp. gr. rosae

Eurytoma timaspidis Mayr, 1904
TORYMIDAE

Idiomacromerus papaveris (Förster, 1856)

PTEROMALIDAE

Homoporus fulviventris (Walker, 1835)

Homoporus subniger (Walker, 1835)

EUPELMIDAE

Eupelmus vesicularis (Retzius, 1783)

Xestophanes brevitarsis (Thomson, 1877)

EURYTOMIDAE

Eurytoma rufipes Walker, 1832

Sycophila concinna (Boheman, 1836)

Xestophanes potentillae (Retzius, 1783)

EURYTOMIDAE

Eurytoma sp. indet.

Eurytoma rufipes Walker, 1832

ORMYRIDAE

Ormyrus rufimanus Mayr, 1904

PTEROMALIDAE

Pteromalus isarchus Walker, 1839

EUPELMIDAE

Eupelmus microzonus Förster, 1860

\section{SYNERGINI}

\section{Synophrus politus Hartig, 1843 EUPELMIDAE}

Eupelmus cerris Förster, 1860

\section{DIPLOLEPIDINI}

Diplolepis mayri (Schlechtendal, 1877)

EURYTOMIDAE

Eurytoma rosae Nees, 1834

TORYMIDAE

Glyphomerus stigma (Fabricius, 1793)

Torymus bedeguaris (Linnaeus, 1758)

PTEROMALIDAE

Caenacis inflexa (Ratzeburg, 1848)

Pteromalus bedeguaris (Thomson, 1878)

EUPELMIDAE

Eupelmus urozonus Dalman, 1820

Eupelmus vesicularis (Retzius, 1783)

EULOPHIDAE

Aprostocetus forsteri (Walker, 1847)

Diplolepis nervosa Curtis, 1838

Diplolepis eglanteriae (Hartig, 1840)

EURYTOMIDAE

Eurytoma rosae Nees, 1834

PTEROMALIDAE

Pteromalus sp. $n r$. bedeguaris

EUPELMIDAE

Eupelmus muellneri Ruschka, 1921

Eupelmus urozonus Dalman, 1820

EULOPHIDAE

Aprostocetus sp. indet. 2

Aprostocetus auranticus (Ratzeburg, 1852)

Diplolepis rosae (Linnaeus, 1758)

EURYTOMIDAE

Eurytoma rosae Nees, 1834
TORYMIDAE

Glyphomerus stigma (Fabricius, 1793)

Torymus bedeguaris (Linnaeus, 1758)

PTEROMALIDAE

Pteromalus bedeguaris (Thomson, 1878)

EUPELMIDAE

Eupelmus urozonus Dalman, 1820

EULOPHIDAE

Aprostocetus sp. indet. 2

\section{CYNIPINI}

Andricus burgundus Giraud, $18590^{\circ}$ 우

PTEROMALIDAE

Mesopolobus lichtensteini (Mayr, 1903)

Mesopolobus tibialis (Westwood, 1833)

Andricus coriarius (Hartig, 1843) $\succ$ EURYTOMIDAE

Eurytoma brunniventris Ratzeburg, 1852 Sycophila biguttata (Swederus, 1795)

Sycophila iracemae Nieves Aldrey, 1984 TORYMIDAE

Megastigmus dorsalis (Fabricius, 1798)

Megastigmus stigmatizans (Fabricius, 1798)

ORMYRIDAE

Ormyrus pomaceus (Geoffroy, 1785)

PTEROMALIDAE

Hobbya stenonota (Ratzeburg, 1848)

Mesopolobus amaenus (Walker, 1834)

EUPELMIDAE

Eupelmus annulatus Nees, 1834

Eupelmus urozonus Dalman, 1820

EULOPHIDAE

Aulogymnus trilineatus (Mayr, 1877)

Andricus curvator Hartig, 1840 ○' 우

EURYTOMIDAE

Eurytoma brunniventris Ratzeburg, 1852

Sycophila biguttata (Swederus, 1795)

TORYMIDAE

Torymus flavipes (Walker, 1833)

ORMYRIDAE

Ormyrus pomaceus (Geoffroy, 1785)

PTEROMALIDAE

Cecidostiba fungosa (Geoffroy, 1785)

Mesopolobus fasciiventris Westwood, 1833

Mesopolobus tarsatus (Nees, 1834)

Mesopolobus tibialis (Westwood, 1833)

EULOPHIDAE

Aulogymnus arsames (Walker, 1838)

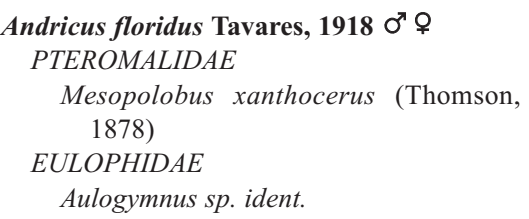

Andricus grossulariae Giraud, $1859 \sigma^{\circ}$ 우

PTEROMALIDAE

Mesopolobus lichtensteini (Mayr, 1903) 


\author{
Andricus grossulariae Giraud, 1859 ช \\ PTEROMALIDAE \\ Hobbya stenonota (Ratzeburg, 1848) \\ Mesopolobus sericeus (Forster, 1770)
}

\section{Andricus hispanicus (Hartig, 1856) $\sigma^{\top}$ 우} PTEROMALIDAE

Mesopolobus xanthocerus (Thomson, 1878)

Ormocerus vernalis (Walker, 1834)

EULOPHIDAE

Aprostocetus sp. indet.

\section{Andricus hispanicus (Hartig, 1856) $\succ$ EURYTOMIDAE \\ Eurytoma brunniventris Ratzeburg, 1852 Sycophila biguttata (Swederus, 1795) Sycophila variegata (Curtis, 1831) TORYMIDAE \\ Megastigmus dorsalis (Fabricius, 1798) Megastigmus stigmatizans (Fabricius, 1798) Torymus auratus (Müller, 1764) ORMYRIDAE \\ Ormyrus nitidulus (Fabricius, 1804) Ormyrus pomaceus (Geoffroy, 1785) \\ PTEROMALIDAE \\ Caenacis lauta (Walter, 1835) \\ Cyrtoptyx robustus (Masi, 1907) \\ Eumacepolus obscurior Graham, 1961 \\ Hobbya stenonota (Ratzeburg, 1848) \\ Mesopolobus sp. indet. \\ EUPELMIDAE \\ Eupelmus annulatus Nees, 1834 \\ Eupelmus urozonus Dalman, 1820 \\ EULOPHIDAE \\ Asprostocetus sp. indet. \\ Baryscapus berhidanus Erdös, 1954}

\section{Andricus legitimus Wiebes-Rijks, $1980 \succ$}

EURYTOMIDAE

Eurytoma brunniventris Ratzeburg, 1852

PTEROMALIDAE

Mesopolobus tibialis (Westwood, 1833)

EUPELMIDAE

Eupelmus annulatus Nees, 1834

\section{Andricus malpighi Adler, $1881 \sigma^{7}$ 우}

PTEROMALIDAE

Mesopolobus tibialis (Westwood, 1833)

Mesopolobus xanthocerus (Thomson, 1878)

Andricus pictus (Hartig, 1856) $\succ$

EURYTOMIDAE

Sycophila biguttata (Swederus, 1795)

ORMYRIDAE

Ormyrus pomaceus (Geoffroy, 1785)

PTEROMALIDAE

Hobbya stenonota (Ratzeburg, 1848)

Mesopolobus amaenus (Walker, 1834)

Mesopolobus sericeus (Forster, 1770)

EUPELMIDAE

Eupelmus annulatus Nees, 1834
Andricus pseudoinflator Tavares, $1902 \sigma^{\circ} \%$ EURYTOMIDAE

Eurytoma brunniventris Ratzeburg, 1852

Sycophila flavicollis (Walter, 1834)

TORYMIDAE

Megastigmus dorsalis (Fabricius, 1798)

ORMYRIDAE

Ormyrus pomaceus (Geoffroy, 1785)

PTEROMALIDAE

Arthrolytus nanus Askew \& Nieves-Aldrey, 1982

Cecidostiba fungosa (Geoffroy, 1785)

Hobbya stenonota (Ratzeburg, 1848)

EUPELMIDAE

Eupelmus aseculatus (Kalina, 1981)

Eupelmus urozonus Dalman, 1820

Eupelmus vesicularis (Retzius, 1783)

Andricus quercusradicis (Fabricius, 1798) $0^{\circ}$ 우

EURYTOMIDAE

Eurytoma brunniventris Ratzeburg, 1852

Sycophila flavicollis (Walker, 1834)

TORYMIDAE

Megastigmus dorsalis (Fabricius, 1798) ORMYRIDAE

Ormyrus pomaceus (Geoffroy, 1785)

PTEROMALIDAE

Arthrolytus nanus Askew \& Nieves-Aldrey, 1982

Cecidostiba fungosa (Geoffroy, 1785)

Hobbya stenonota (Ratzeburg, 1848)

EUPELMIDAE

Eupelmus aseculatus (Kalina, 1981)

Eupelmus urozonus Dalman, 1820

Eupelmus vesicularis (Retzius, 1783)

Andricus quercusradicis (Fabricius, 1798) $\succ$ TORYMIDAE

Torymus erucarum (Schrank, 1781)

PTEROMALIDAE

Cecidostiba geganius (Walker, 1848)

Andricus quercusramuli (Linnaeus, 1761) $\sigma^{\circ}$ 우

EURYTOMIDAE

Sycophila biguttata (Swederus, 1795)

TORYMIDAE

Torymus flavipes (Walker, 1833)

ORMYRIDAE

Ormyrus pomaceus (Geoffroy, 1785)

PTEROMALIDAE

Cecidostiba fungosa (Geoffroy, 1785)

Hobbya stenonota (Ratzeburg, 1848)

Mesopolobus mediterraneus (Mayr, 1903)

Mesopolobus xanthocerus (Thomson, 1878)

Ormocerus latus (Walker, 1834)

EUPELMIDAE

Eupelmus urozonus Dalman, 1820

EULOPHIDAE

Aprostocetus sp. indet.

Aulogymnus gallarum (Linnaeus, 1761)
Andricus quercustozae (Bosc, 1792) $\succ$

EURYTOMIDAE

Eurytoma brunniventris Ratzeburg, 1852

Sycophila biguttata (Swederus, 1795)

Sycophila variegata (Curtis, 1831)

TORYMIDAE

Megastigmus stigmatizans (Fabricius, 1798)

Torymus auratus (Müller, 1764)

ORMYRIDAE

Ormyrus pomaceus (Geoffroy, 1785)

PTEROMALIDAE

Cecidostiba adana Askew, 1961

Hobbya stenonota (Ratzeburg, 1848)

EUPELMIDAE

Eupelmus annulatus Nees, 1834

Andricus solitarius (Boyer de Fonscolombe, 1832) $\succ$

EURYTOMIDAE

Eurytoma brunniventris Ratzeburg, 1852 Sycophila biguttata (Swederus, 1795)

PTEROMALIDAE

Mesopolobus mediterraneus (Mayr, 1903)

Mesopolobus tibialis

\section{Andricus testaceipes Hartig, $1840 \succ$}

EURYTOMIDAE

Eurytoma brunniventris Ratzeburg, 1852 TORYMIDAE

Torymus nobilis Boheman, 1834

Biorhiza pallida (Olivier, 1791) $\sigma^{7}$ 우 EURYTOMIDAE

Eurytoma brunniventris Ratzeburg, 1852 TORYMIDAE

Torymus affinis (Fonscolombe, 1832)

Torymus auratus (Müller, 1764)

Torymus flavipes (Walker, 1833)

ORMYRIDAE

Ormyrus pomaceus (Geoffroy, 1785)

PTEROMALIDAE

Cecidostiba fungosa (Geoffroy, 1785)

Cecidostiba semifascia (Walker, 1835)

Hobbya stenonota (Ratzeburg, 1848)

Mesopolobus sp. indet.

Mesopolobus mediterraneus (Mayr, 1903)

Mesopolobus tibialis (Westwood, 1833)

Mesopolobus xanthocerus (Thomson, 1878)

EUPELMIDAE

Eupelmus urozonus Dalman, 1820

EULOPHIDAE

Aprostocetus sp. indet.

Aulogymnus skianeuros (Ratzeburg, 1844)

\section{Biorhiza pallida (Olivier, 1791) $\succ$} TORYMIDAE

Torymus nobilis Boheman, 1834

PTEROMALIDAE

Cecidostiba fungosa (Walker, 1848) 

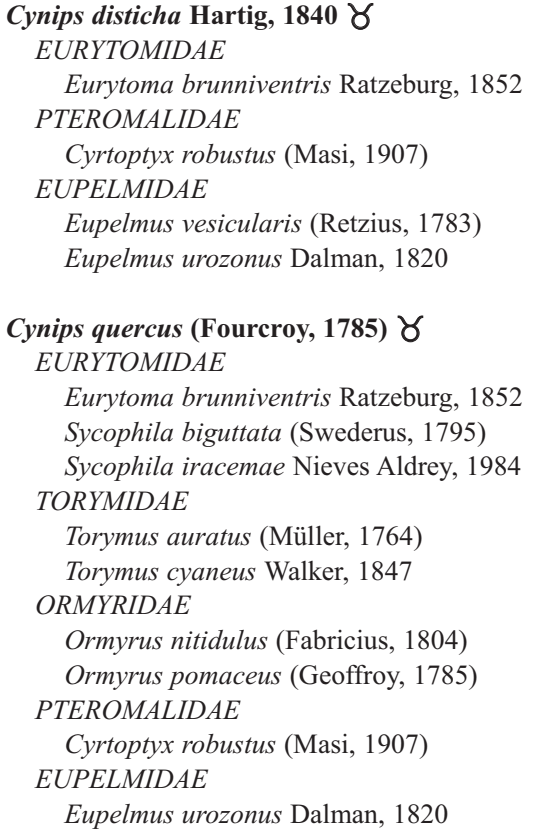
Cynips quercusfolii Linnaeus, $1758 \succ$ TORYMIDAE

Torymus auratus (Müller, 1764)

\section{Neuroterus albipes (Schenck, 1863) 우 우 PTEROMALIDAE \\ Mesopolobus tibialis (Westwood, 1833)}
Neuroterus albipes (Schenck, 1863) $\succ$ EURYTOMIDAE
Sycophila biguttata (Swederus, 1795)
TORYMIDAE
Torymus flavipes (Walker, 1833)

\section{Neuroterus anthracinus (Curtis, 1838) $\succ$ EURYTOMIDAE \\ Eurytoma brunniventris Ratzeburg, 1852 PTEROMALIDAE}

Mesopolobus tibialis (Westwood, 1833)

Mesopolobus xanthocerus (Thomson, 1878)

\section{Neuroterus numismalis (Fourcroy, 1785) $\succ$ EURYTOMIDAE \\ Sycophila biguttata (Swederus, 1795)}

\section{Neuroterus politus Hartig, $1840 \sigma^{7}$ ㅇ ORMYRIDAE \\ Ormyrus pomaceus (Geoffroy, 1785) \\ PTEROMALIDAE \\ Mesopolobus fuscipes (Walker, 1834) \\ Mesopolobus tibialis (Westwood, 1833)}

\section{Neuroterus quercusbaccarum (Linnaeus, 1758) $\sigma^{\pi}$ 우 \\ EURYTOMIDAE}

Eurytoma brunniventris Ratzeburg, 1852 Sycophila biguttata (Swederus, 1795)

\section{TORYMIDAE \\ Torymus flavipes (Walker, 1833) \\ PTEROMALIDAE \\ Mesopolobus tibialis}

Neuroterus saliens (Collar, 1857) $\sigma^{7}$ 우 EURYTOMIDAE

Sycophila variegata (Curtis, 1831)

PTEROMALIDAE

Mesopolobus lichtensteini (Mayr, 1903)

Neuroterus tricolor (Hartig, 1841) $\sigma^{\top}$ ㅇ
PTEROMALIDAE
$\quad$ Mesopolobus tibialis (Westwood, 1833)

Plagiotrochus amenti Kieffer, $1901 \sigma^{7}$ 우 PTEROMALIDAE

Mesopolobus lichtensteini (Mayr, 1903)

Mesopolobus mediterraneus (Mayr, 1903)

Mesopolobus tibialis (Westwood, 1833)

\section{Plagiotrochus australis (Mayr, 1882) $\sigma^{\top}$ 우} EURYTOMIDAE

Eurytoma brunniventris Ratzeburg, 1852 Sycophila biguttata (Swederus, 1795) Sycophila variegata (Curtis, 1831) TORYMIDAE

Torymus notatus (Walker, 1833)

ORMYRIDAE

Ormyrus pomaceus (Geoffroy, 1785)

PTEROMALIDAE

Cecidostiba atra Askew, 1975

Cecidostiba ilicina Nieves Aldrey \& Askew, 1988

Cyrtoptyx robustus (Masi, 1907)

Mesopolobus lichtensteini (Mayr, 1903)

Mesopolobus tibialis (Westwood, 1833)

EUPELMIDAE

Eupelmus seculatus (Ferrière, 1954)

Eupelmus urozonus Dalman, 1820

EULOPHIDAE

Aulogymnus bicolor (Askew, 1975)

Pediobius rotundatus (Fonscolombe, 1832)

\section{Plagiotrochus australis (Mayr, 1882) $\gamma$}

EURYTOMIDAE

Sycophila binotata (Fonscolombe, 1832)

TORYMIDAE

Torymus notatus (Walker, 1833)

Plagiotrochus britaniae Barbotin, 1985 o 우 PTEROMALIDAE

Mesopolobus sp. indet.

Mesopolobus lichtensteini (Mayr, 1903)

Mesopolobus mediterraneus (Mayr, 1903)

\section{Plagiotrochus burnayi Kieffer, $1901 \succ$} EURYTOMIDAE

Eurytoma brunniventris Ratzeburg, 1852
Plagiotrochus cardiguensis (Tavares, 1928) $\sigma^{7}$ 우

PTEROMALIDAE

Mesopolobus lichtensteini (Mayr, 1903) Mesopolobus mediterraneus (Mayr, 1903) Mesopolobus tibialis (Westwood, 1833) EULOPHIDAE

Aprostocetus sp. indet.

Aprostocetus fusificola Graham, 1987

Pediobius rotundatus (Fonscolombe, 1832)

\section{Plagiotrochus coriaceus}

PTEROMALIDAE

Cecidostiba atra Askew, 1975

Mesopolobus sp. indet.

Mesopolobus lichtensteini (Mayr, 1903)

EULOPHIDAE

Pediobius rotundatus (Fonscolombe, 1832)

Plagiotrochus kiefferianus Tavares, $1902 \succ$ EURYTOMIDAE

Sycophila binotata (Fonscolombe, 1832)

Sycophila variegata (Curtis, 1831)

TORYMIDAE

Megastigmus dumicola Boucek, 1982

Plagiotrochus panteli Pujade-Villar, 1985 ơ 우 EURYTOMIDAE

Sycophila variegata (Curtis, 1831)

PTEROMALIDAE

Mesopolobus xanthocerus (Thomson, 1878)

Plagiotrochus quercusilicis (Fabricius, 1798) $0^{7}$ 우

\section{EURYTOMIDAE}

Eurytoma brunniventris Ratzeburg, 1852 Sycophila binotata (Fonscolombe, 1832) Sycophila flavicollis (Walker, 1834) Sycophila variegata (Curtis, 1831) TORYMIDAE

Torymus flavipes (Walker, 1833)

Torymus notatus (Walker, 1833)

ORMYRIDAE

Ormyrus pomaceus (Geoffroy, 1785)

PTEROMALIDAE

Cecidostiba ilicina Nieves Aldrey \& Askew, 1988

Mesopolobus lichtensteini (Mayr, 1903)

Mesopolobus sp. indet.

Mesopolobus lichtensteini (Mayr, 1903)

Mesopolobus mediterraneus (Mayr, 1903)

Mesopolobus tibialis (Westwood, 1833)

Mesopolobus xanthocerus (Thomson, 1878)

EUPELMIDAE

Eupelmus seculatus (Ferrière, 1954)

Eupelmus urozonus Dalman, 1820

EULOPHIDAE

Aprostocetus sp. indet.

Aprostocetus fusificola Graham, 1987

Aulogymnus arsames (Walker, 1838)

Aulogymnus bicolor (Askew, 1975)

Pediobius rotundatus (Fonscolombe, 1832) 


\section{Plagiotrochus razeti Barbotin, $1985 \sigma^{7}$ 우} PTEROMALIDAE

Mesopolobus lichtensteini (Mayr, 1903) Mesopolobus tibialis (Westwood, 1833)

Ormocerus latus Walker, 1834

Trigonaspis brunneicornis Kieffer, $1901 \succ$ EURYTOMIDAE

Sycophila flavicollis (Walker, 1834)

Sycophila variegata (Curtis, 1831)

ORMYRIDAE

Ormyrus pomaceus (Geoffroy, 1785)

EUPELMIDAE

Eupelmus vesicularis (Retzius, 1783)

EULOPHIDAE

Aprostocetus sp. indet.
Trigonaspis mendesi Tavares, $1902 \succ$ EURYTOMIDAE

Sycophila biguttata (Swederus, 1795) ORMYRIDAE

Ormyrus pomaceus (Geoffroy, 1785)

PTEROMALIDAE

Mesopolobus dubius (Walker, 1834) EUPELMIDAE

Eupelmus urozonus Dalman, 1820 EULOPHIDAE

Aulogymnus gallarum (Linnaeus, 1761)

Trigonaspis synaspis (Hartig, 1841) $\sigma^{7}$ 우 TORYMIDAE

Torymus fastuosus Boheman, 1834
Trigonaspis synaspis (Hartig, 1841) $\succ$ EURYTOMIDAE

Eurytoma brunniventris Ratzeburg, 1852 TORYMIDAE

Torymus geranii (Walker, 1833)

ORMYRIDAE

Ormyrus pomaceus (Geoffroy, 1785)

EUPELMIDAE

Eupelmus vesicularis (Retzius, 1783) 


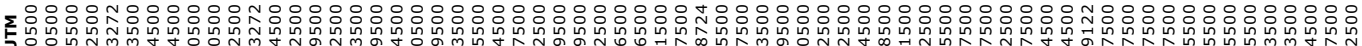

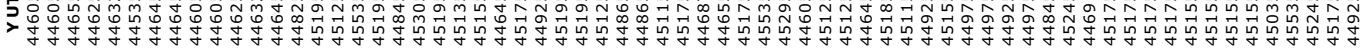

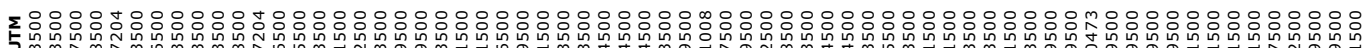

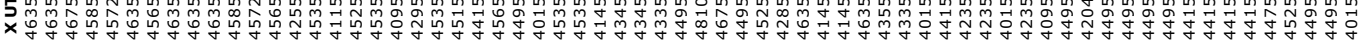

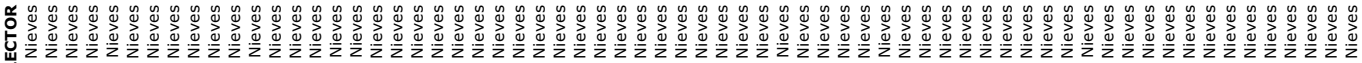

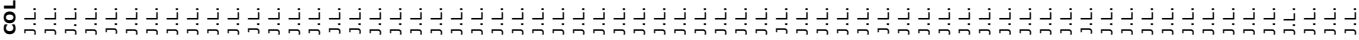

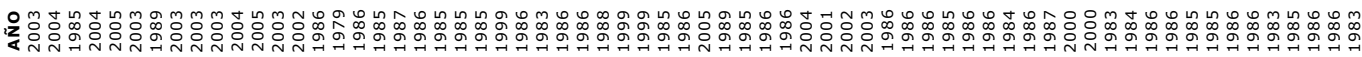

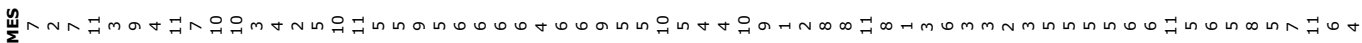

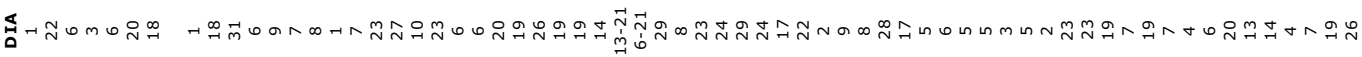<smiles>[CH]=[CH]</smiles>

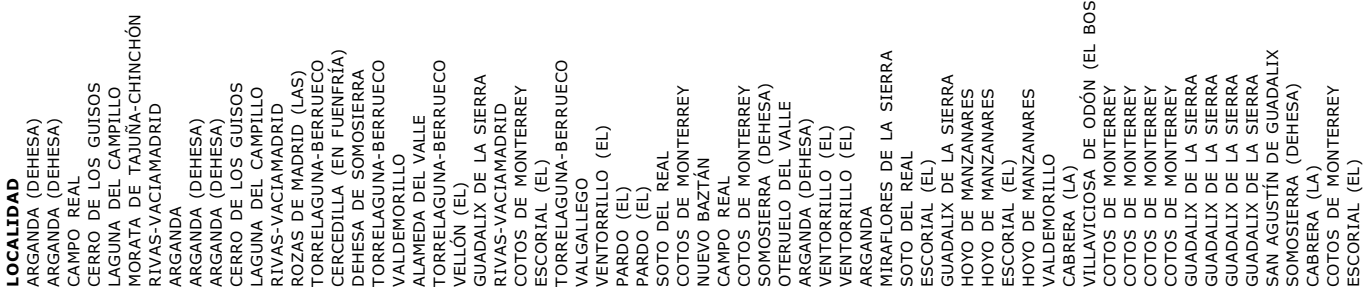

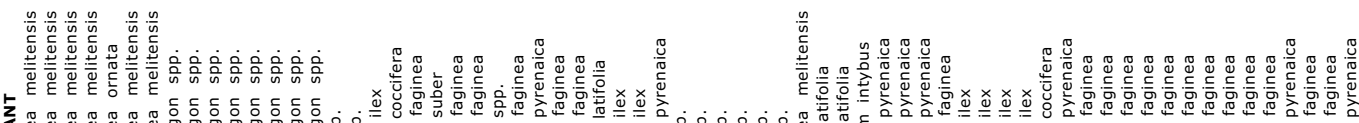

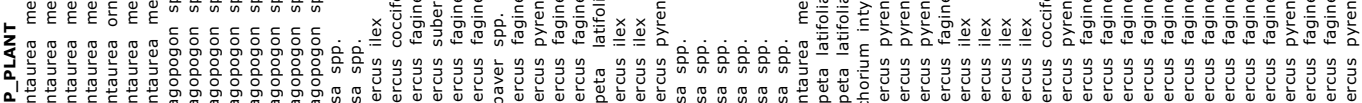

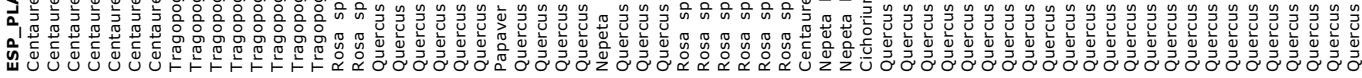

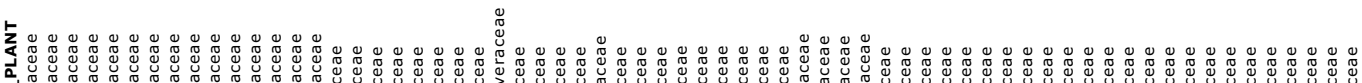

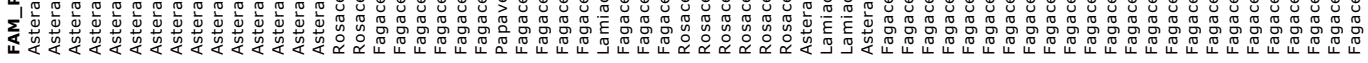




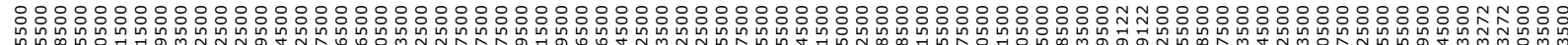

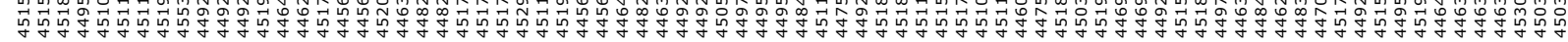

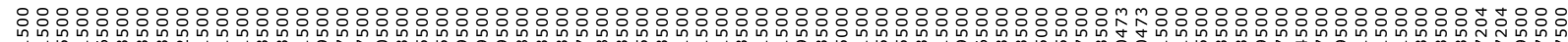

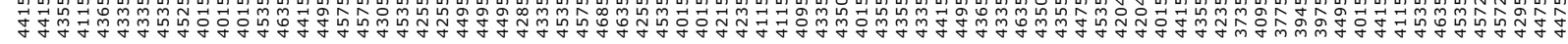

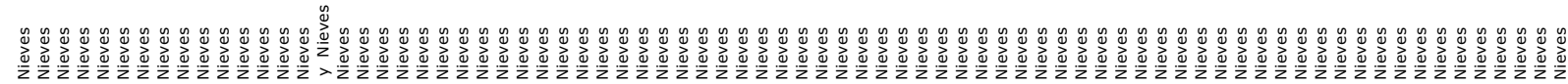
送

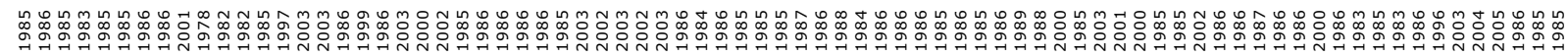

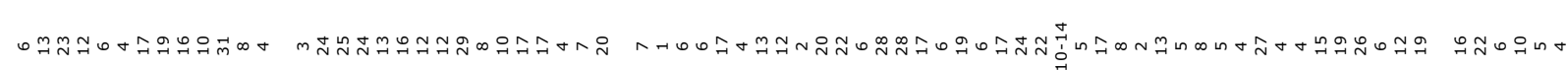

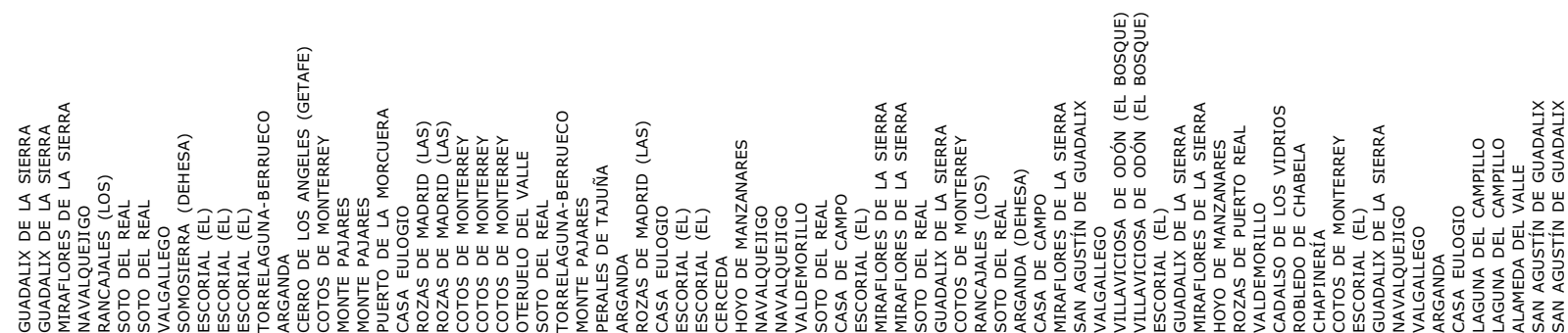

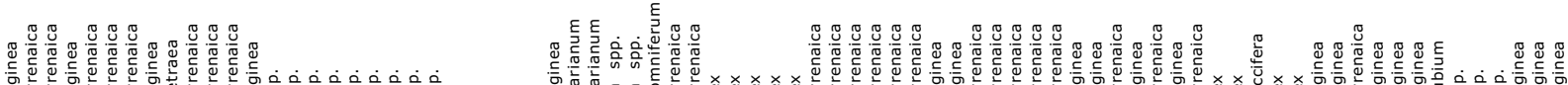

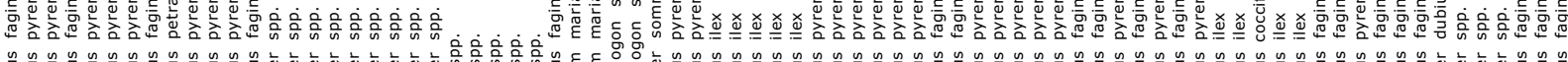

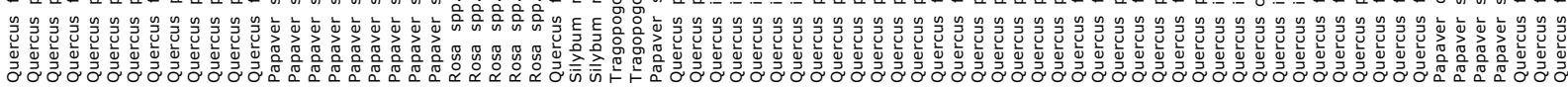

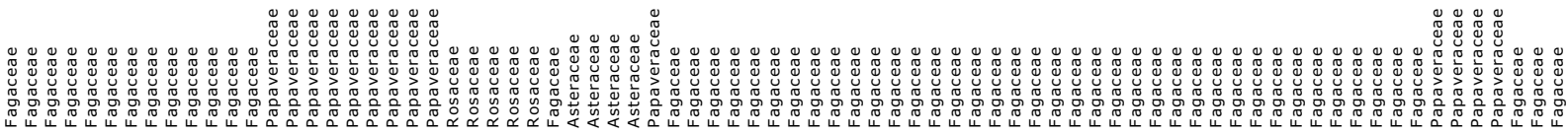

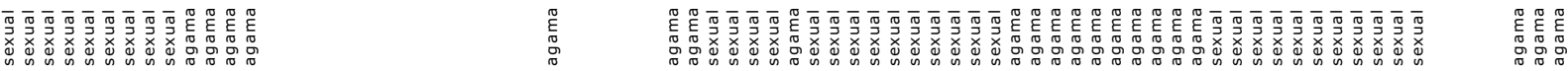
踣 究运

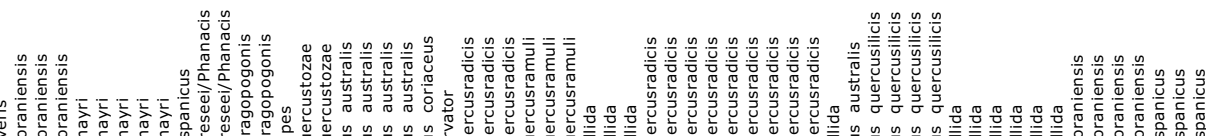

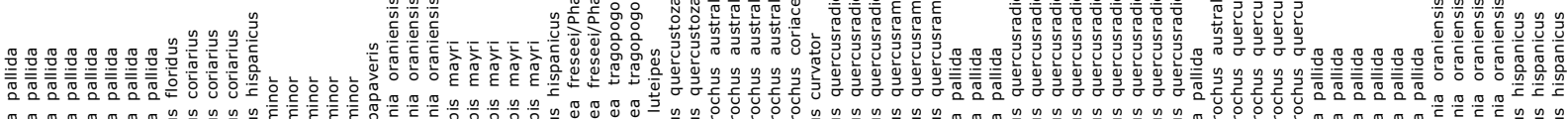

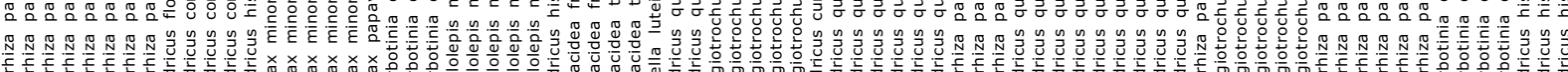

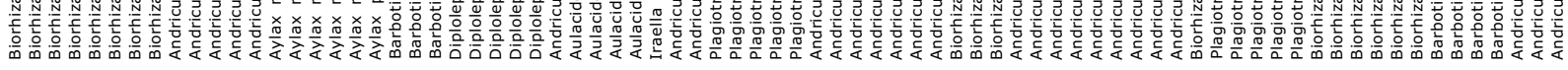

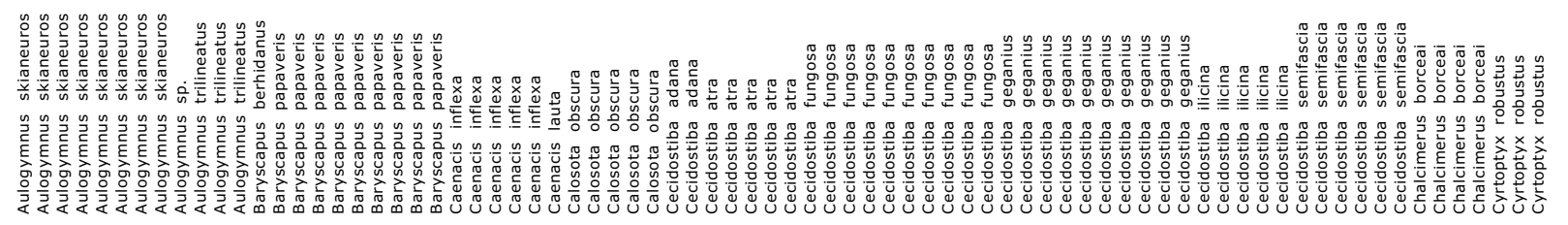




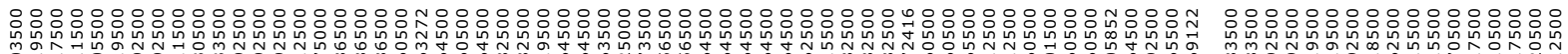

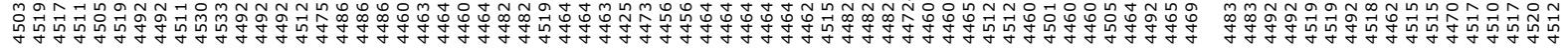

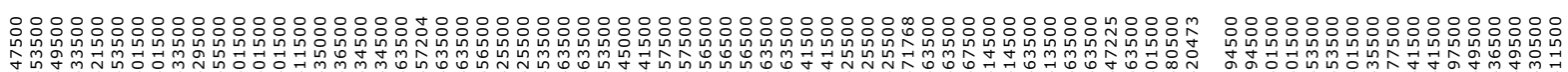

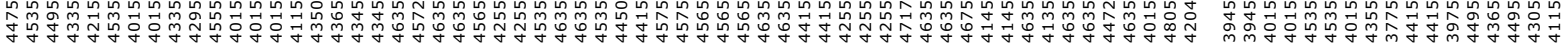

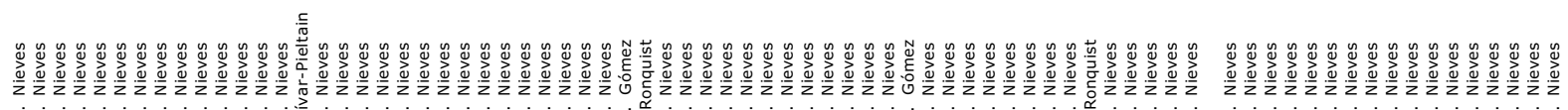

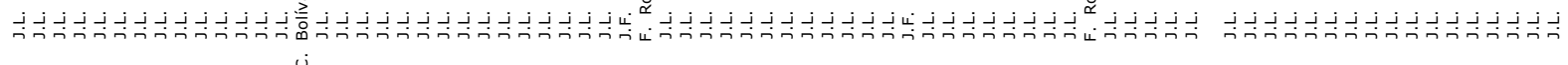

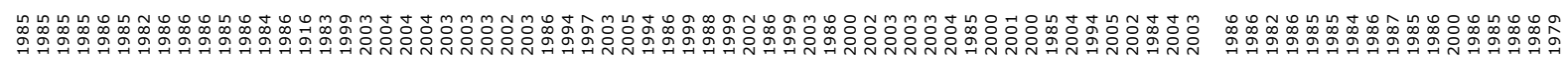

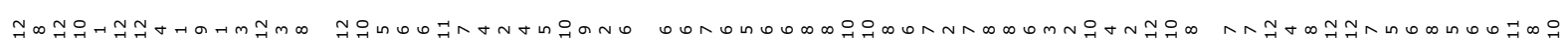

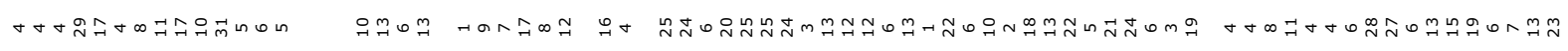

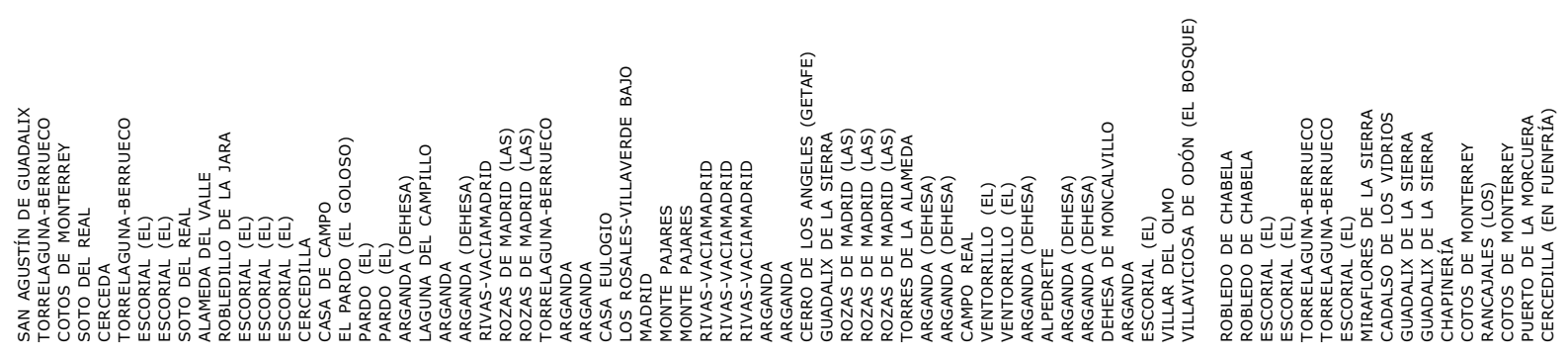

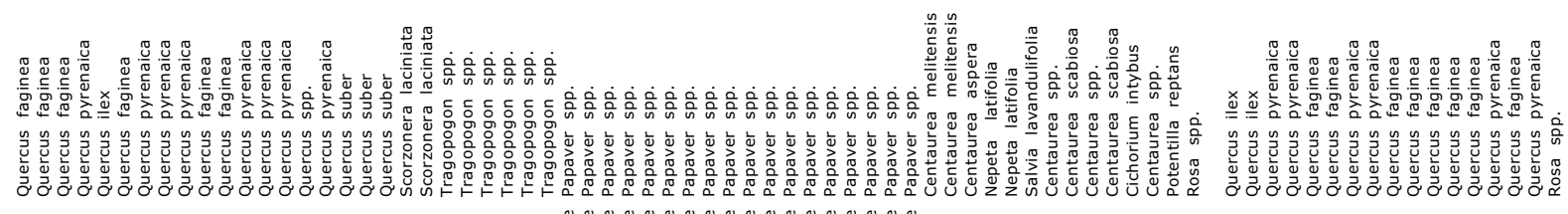

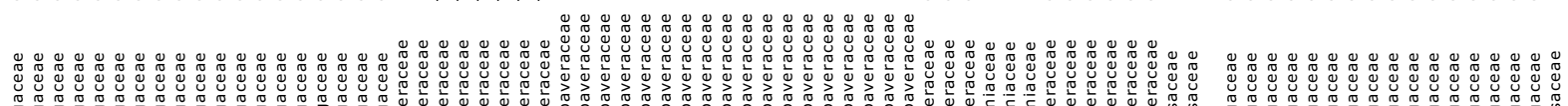

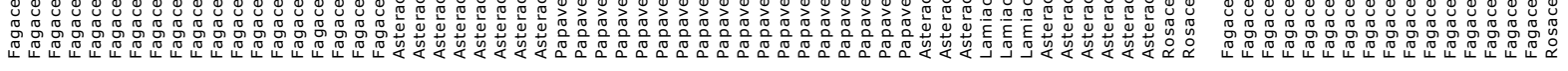

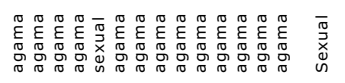

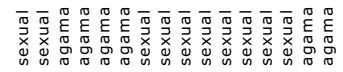
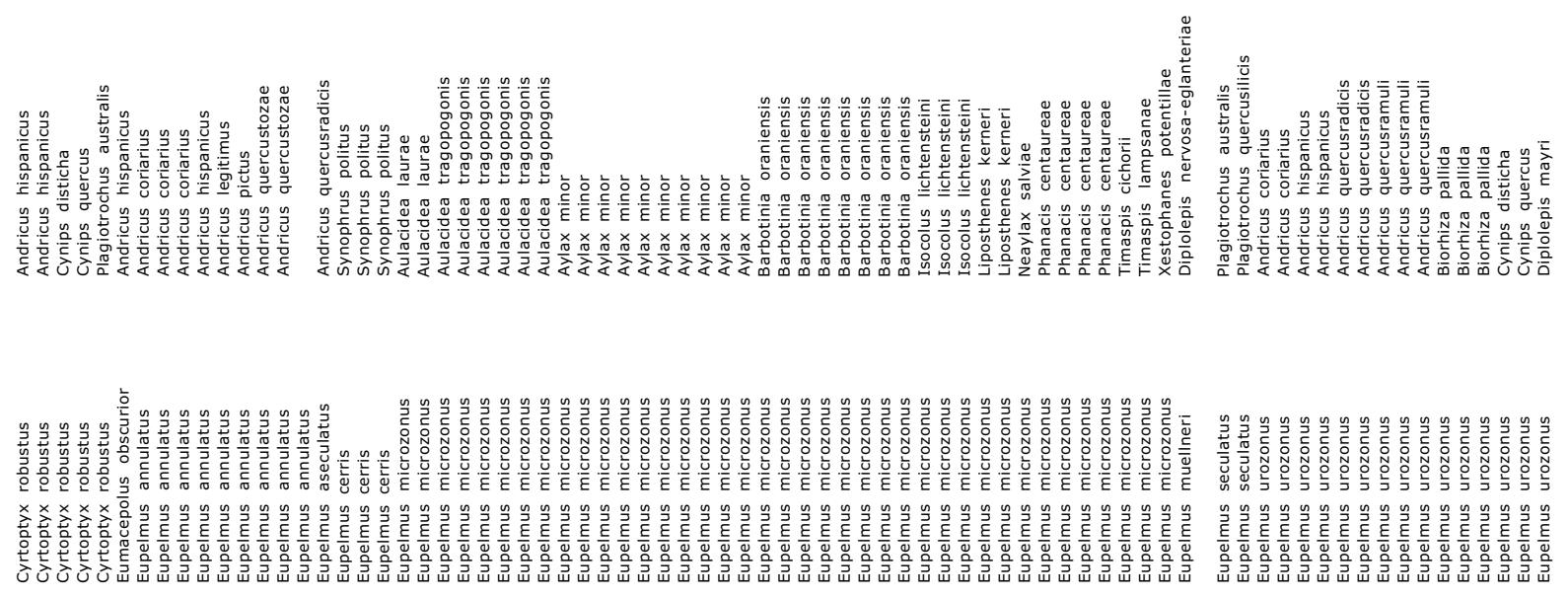


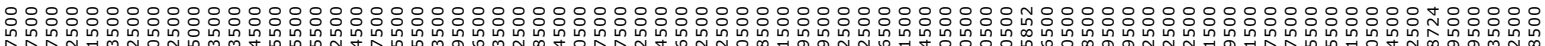

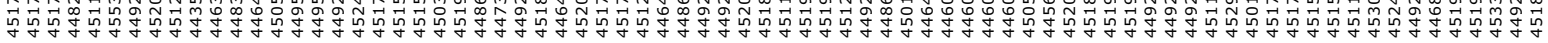

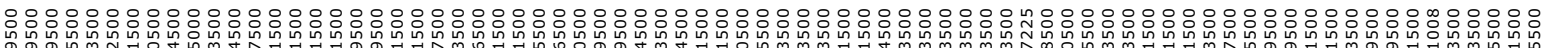

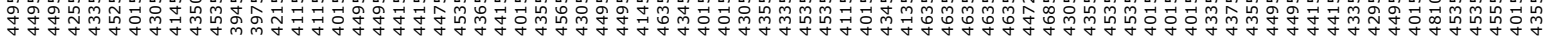

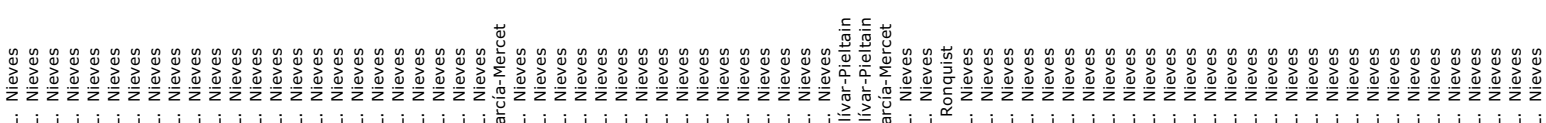

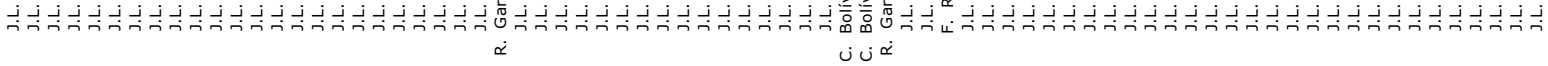

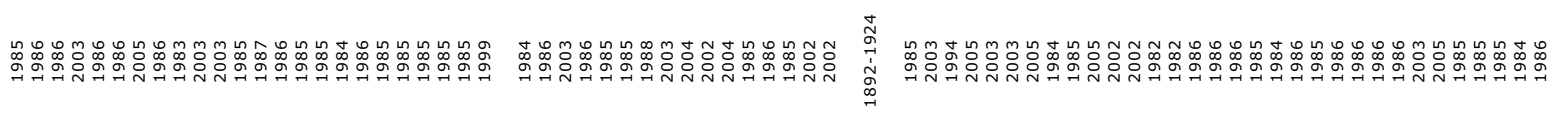

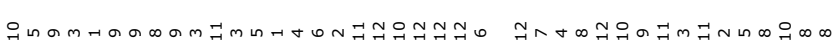
m

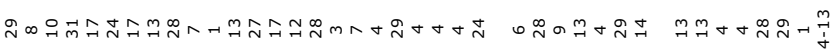

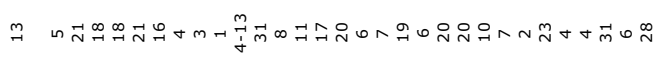

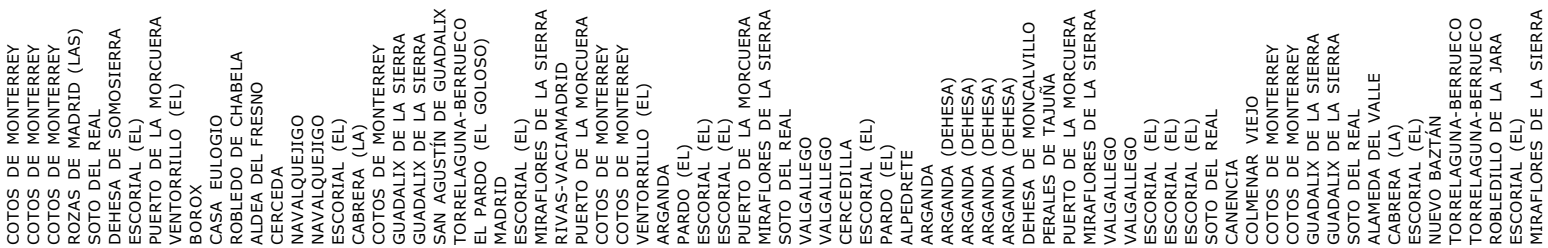

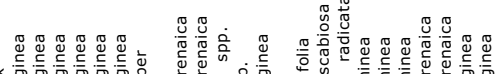

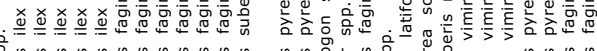

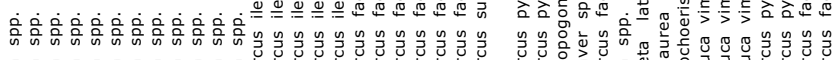

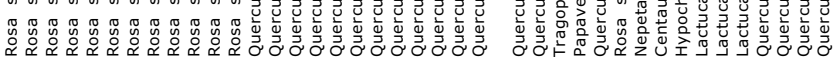

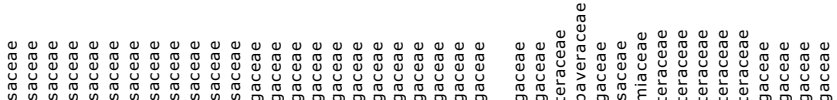

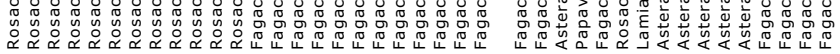

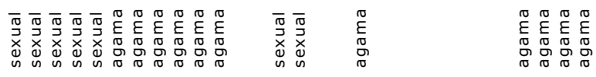

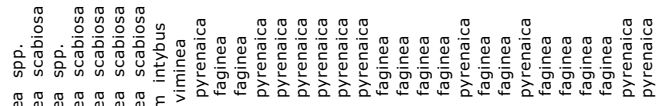

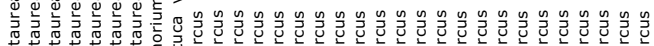

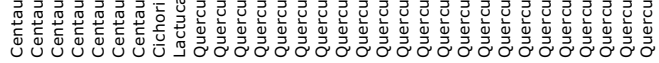

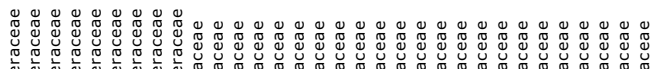

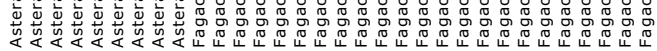

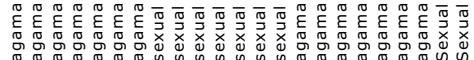
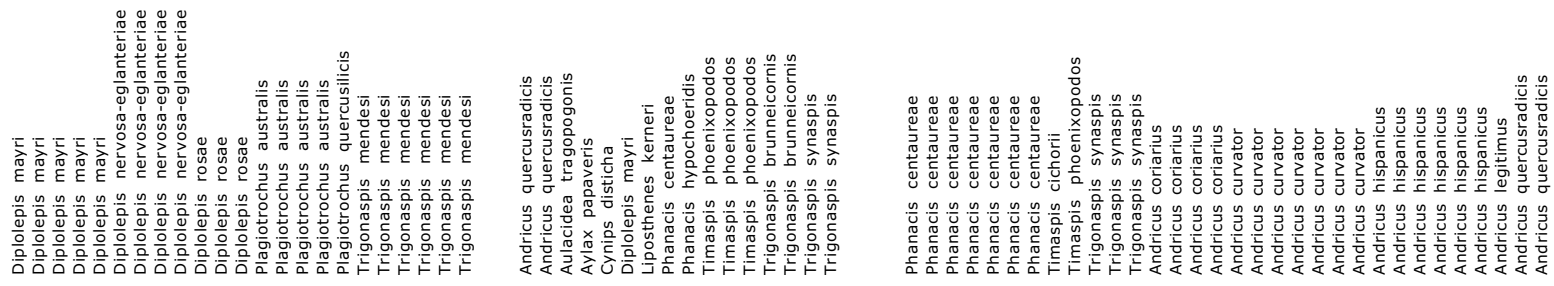

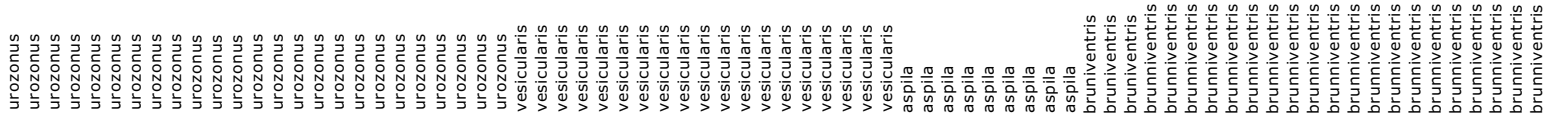

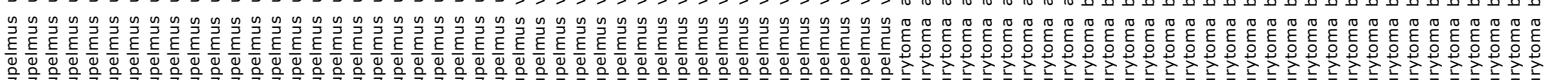




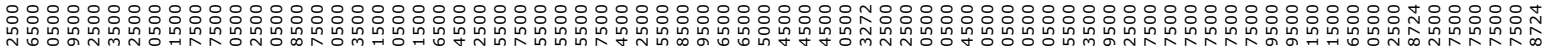

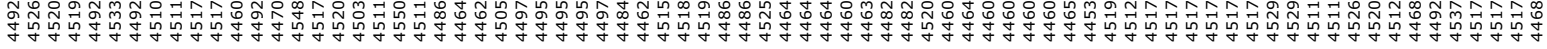

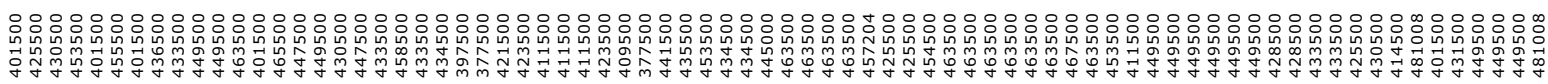

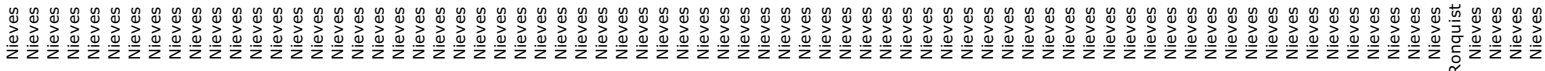

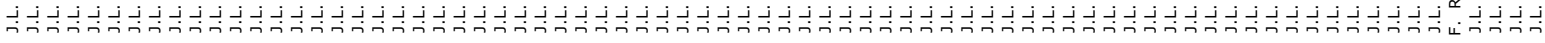

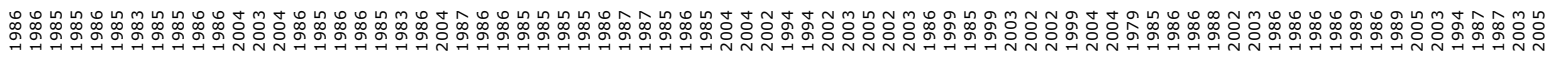

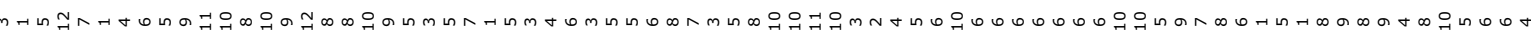

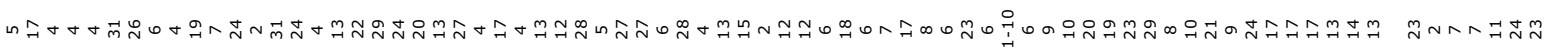

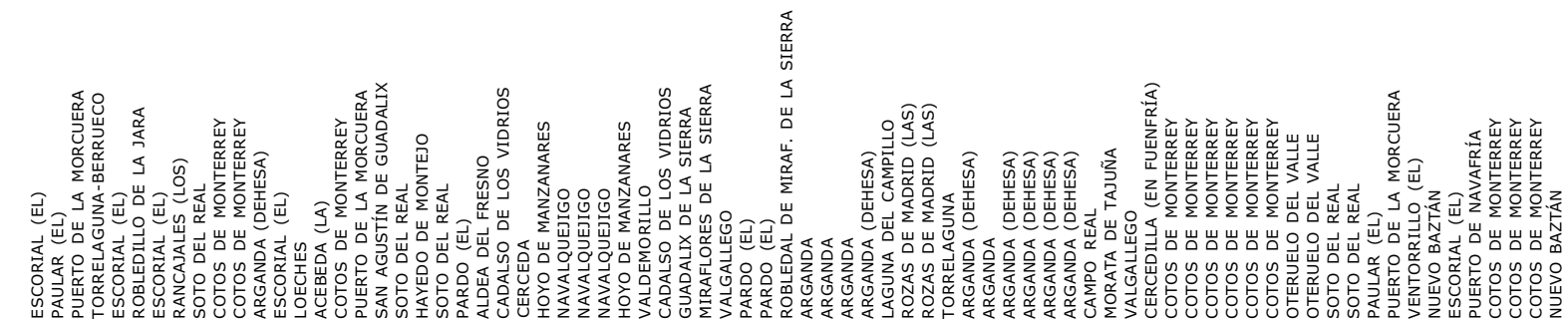

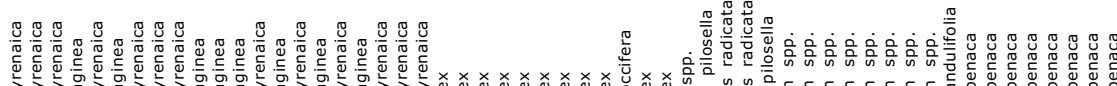
(2)

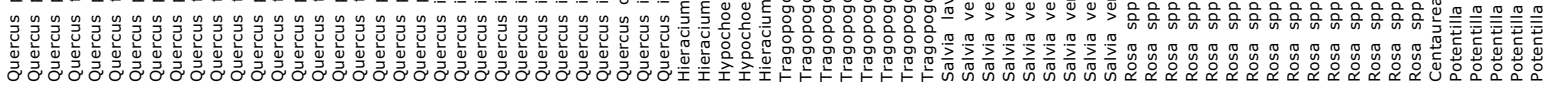

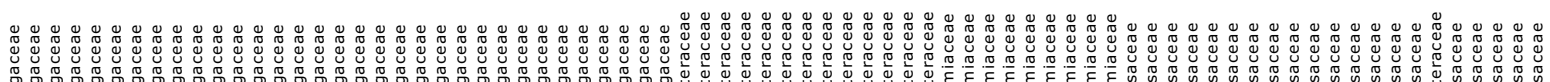

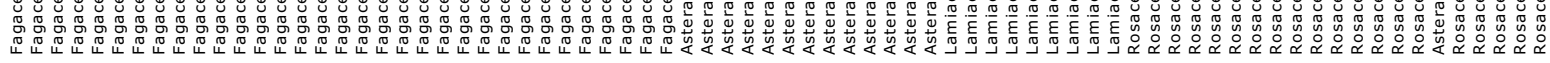

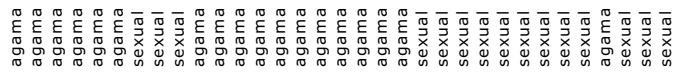

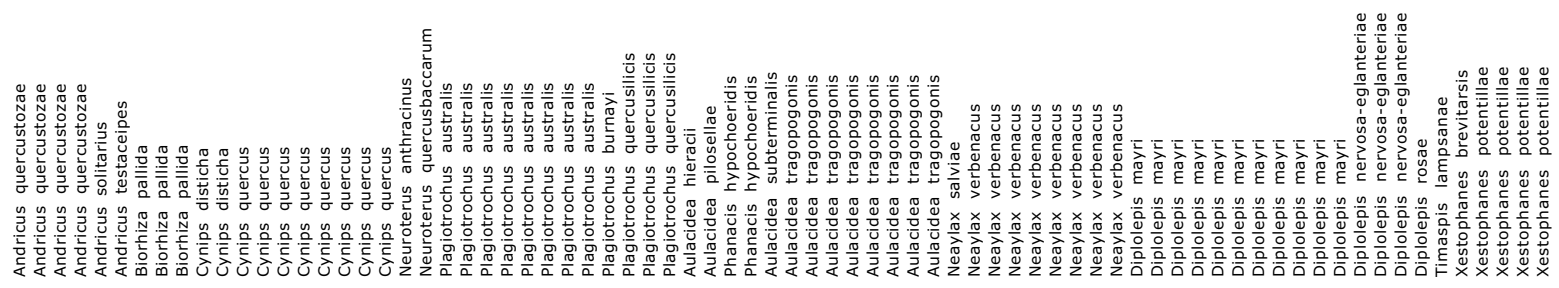

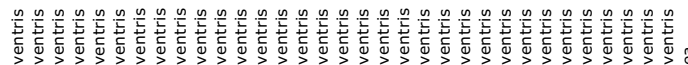

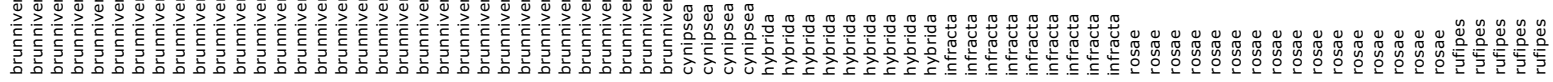

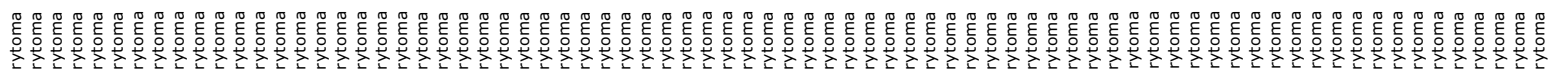

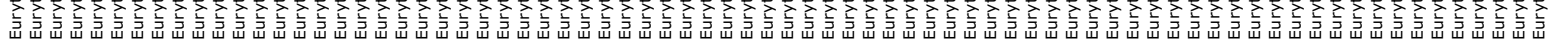




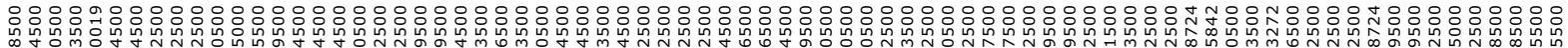

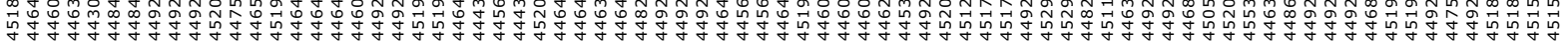

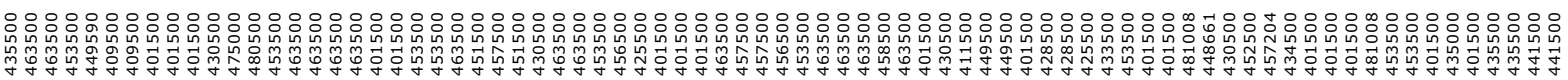

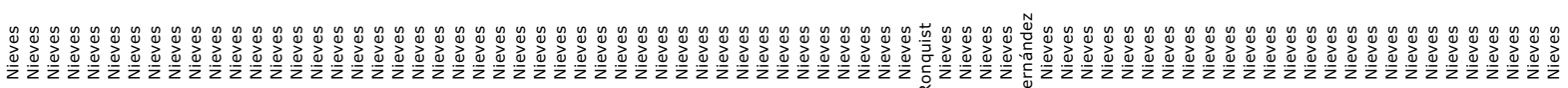

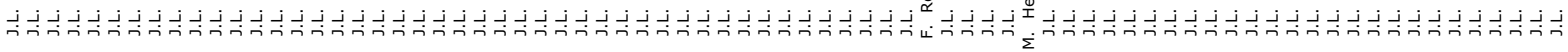

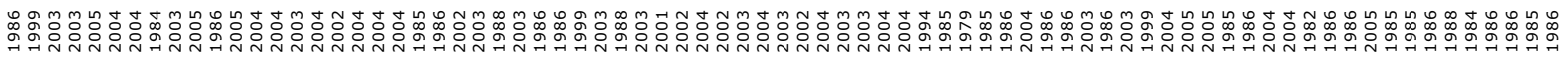

m

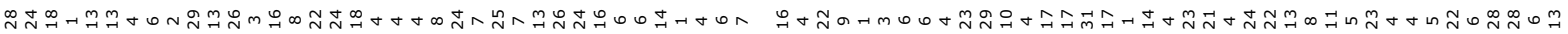

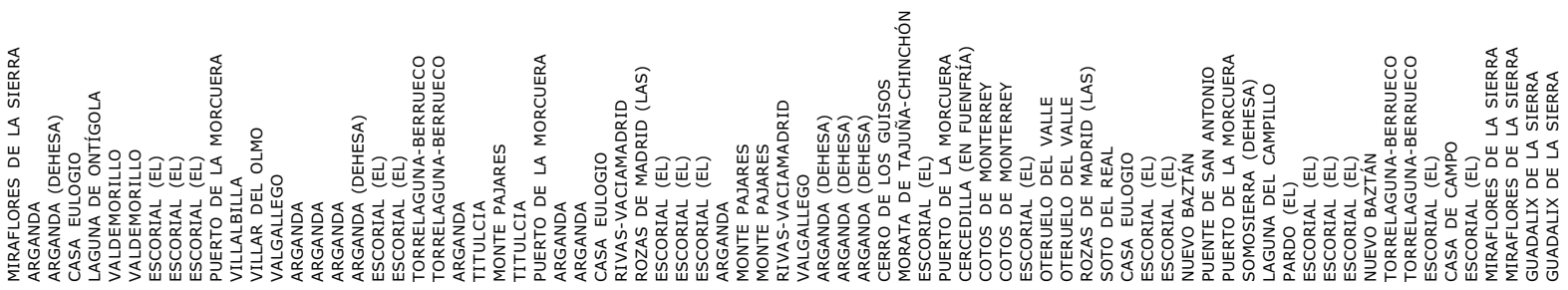

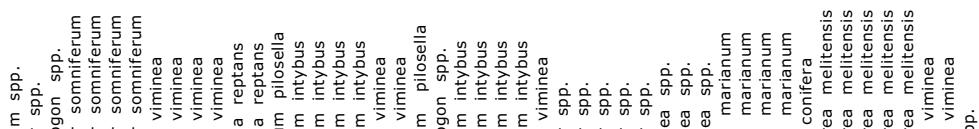

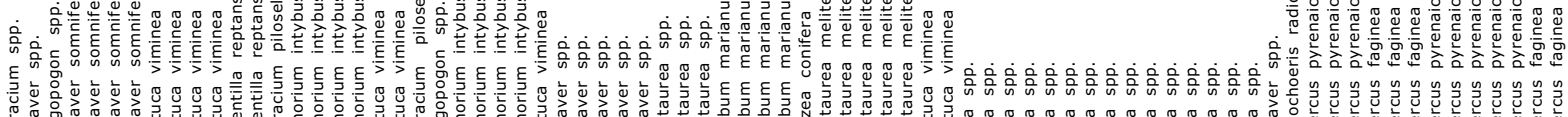
$\begin{array}{lll} & \\ 0 & \end{array}$

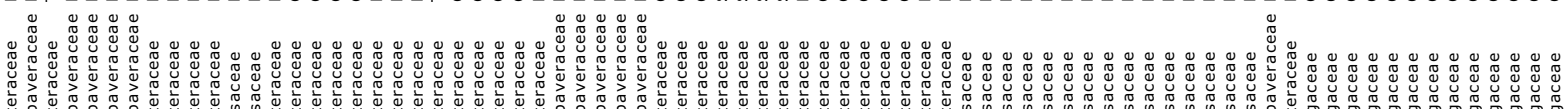
$\begin{array}{llll} & \\ & \end{array}$

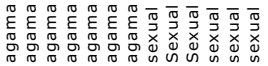

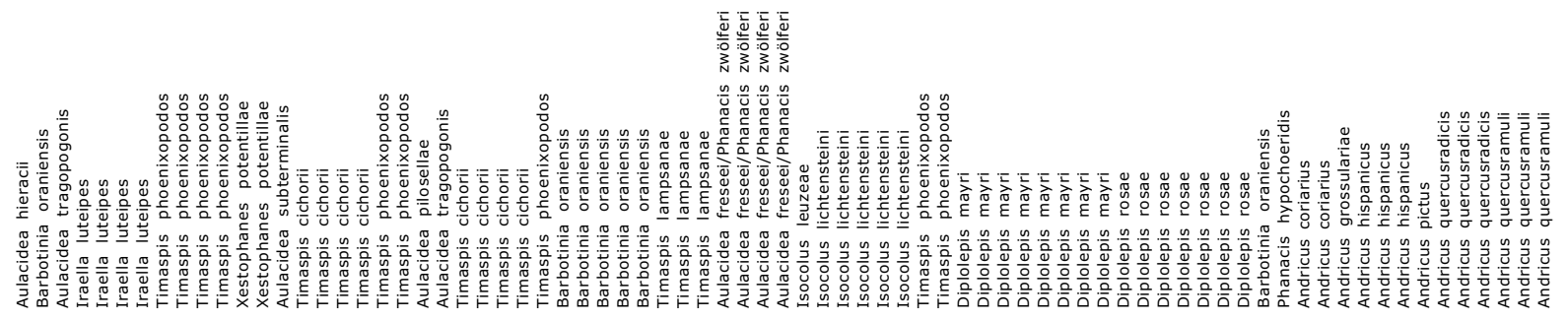

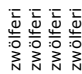

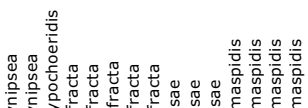

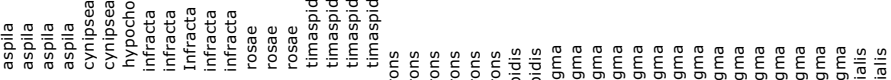

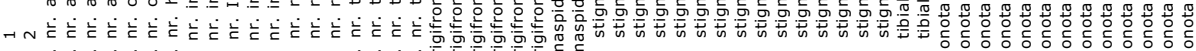

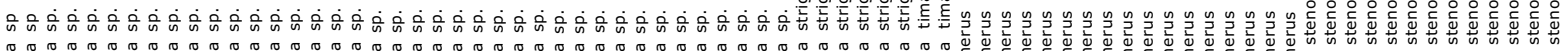
$\begin{array}{llll} & \\ 0\end{array}$

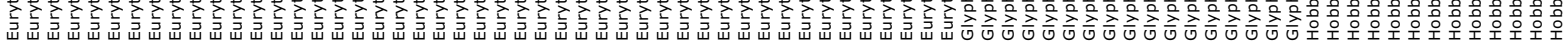




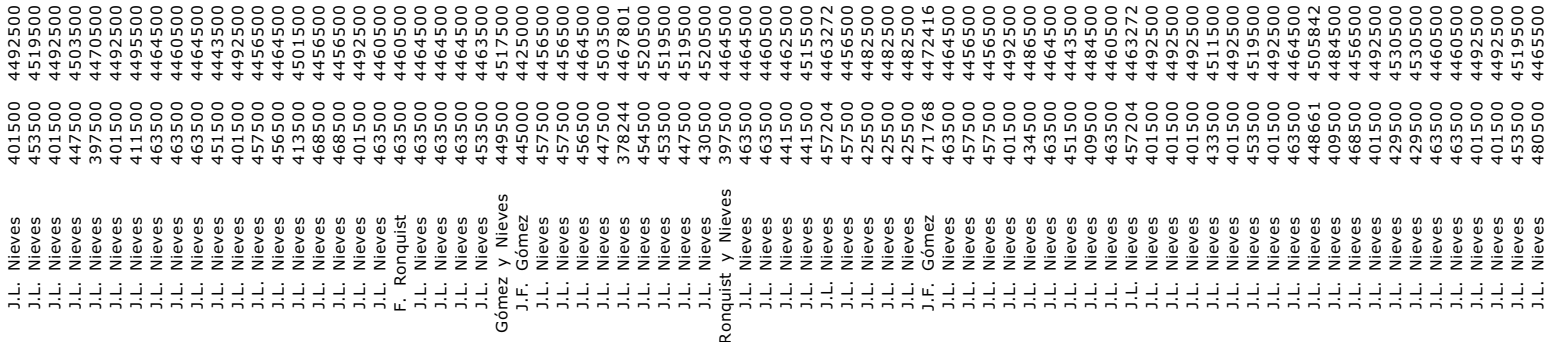

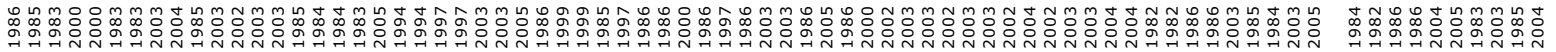

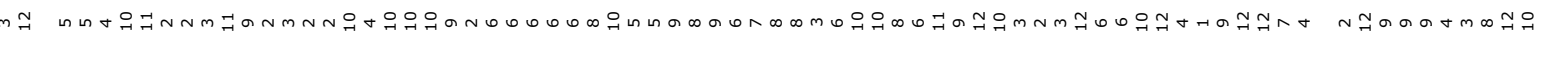

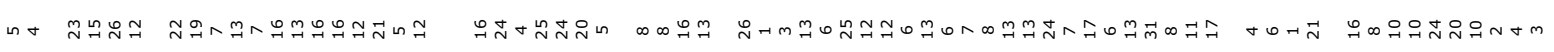
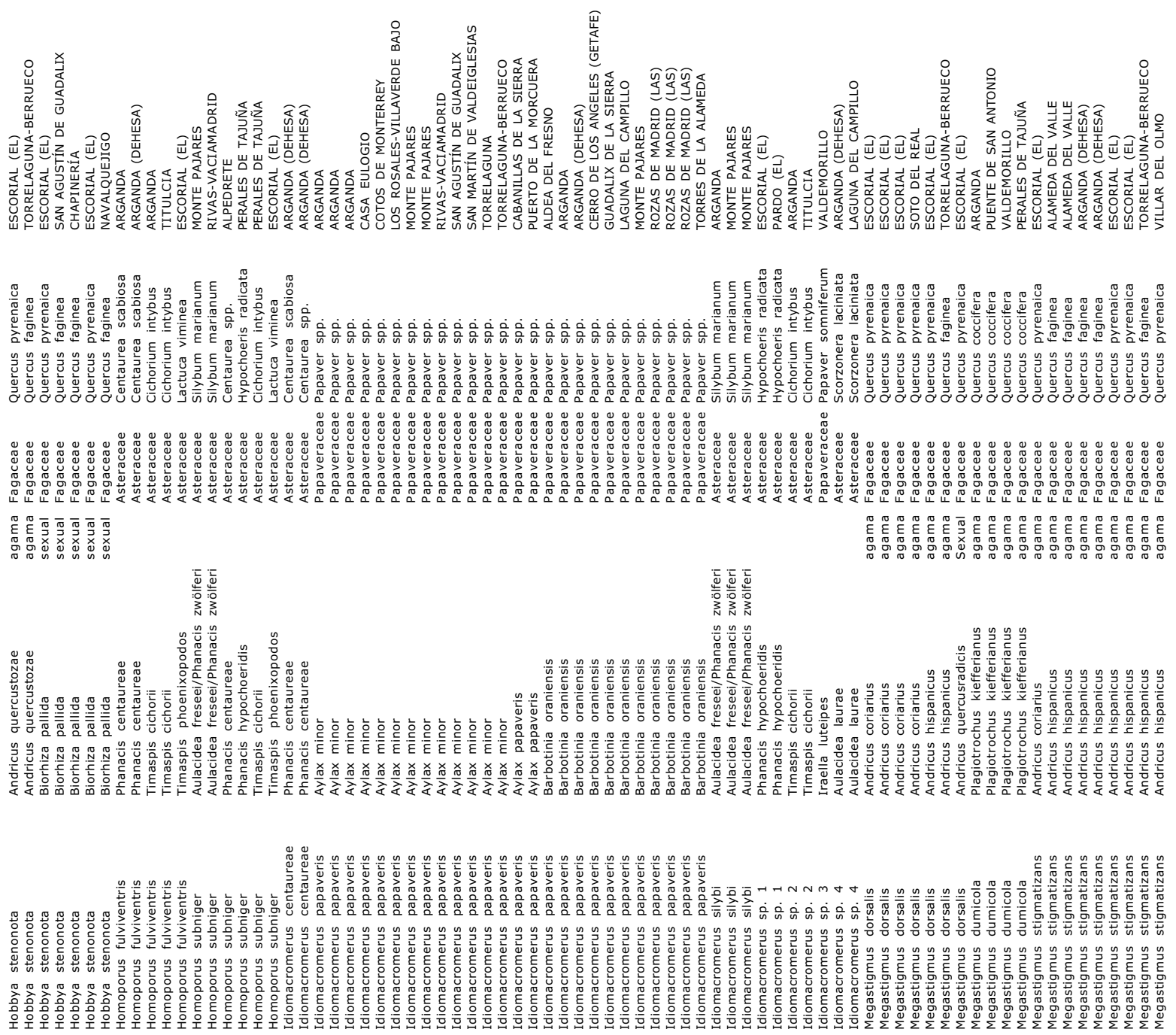


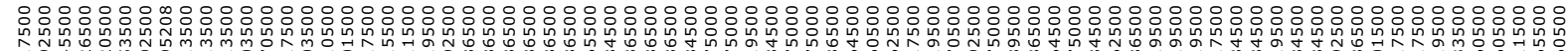

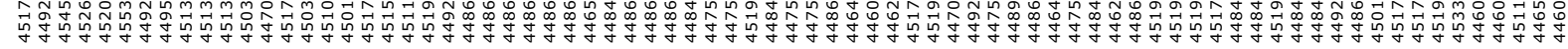

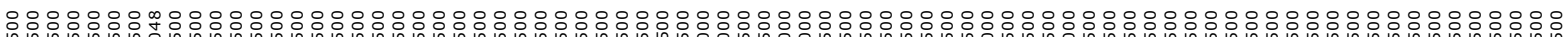

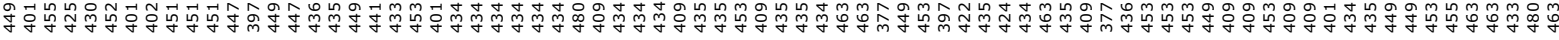

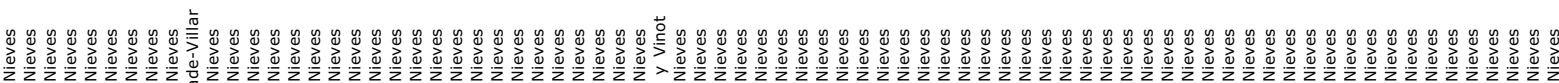
送

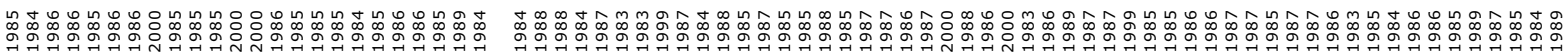

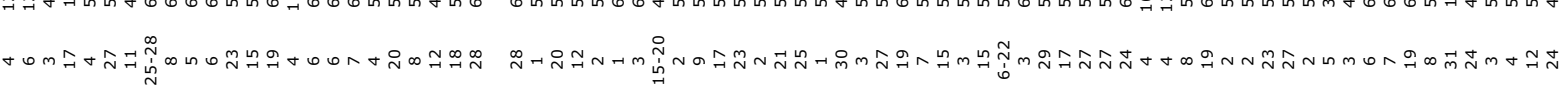

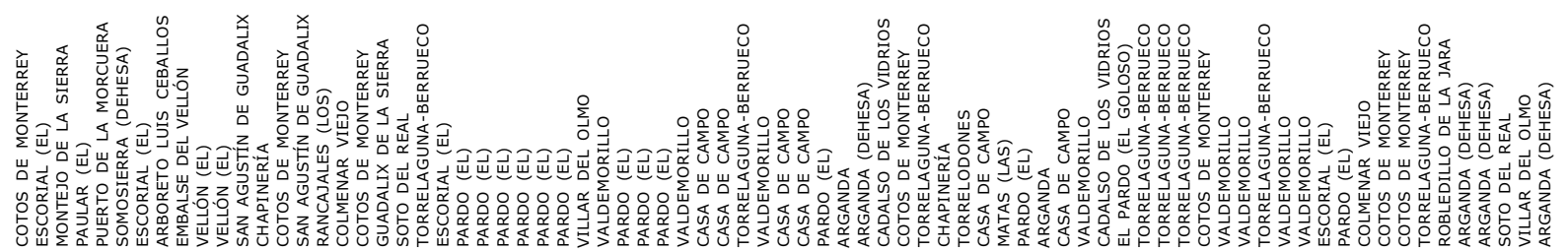

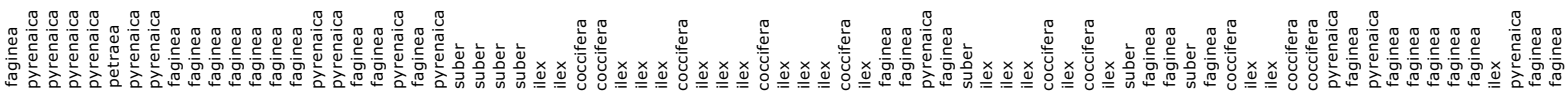

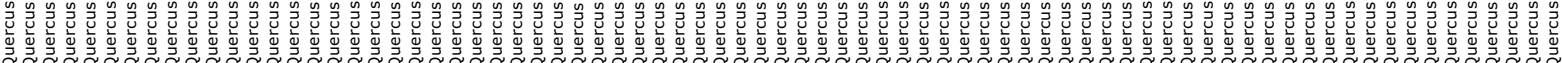

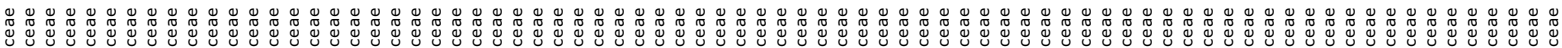
D.
D.

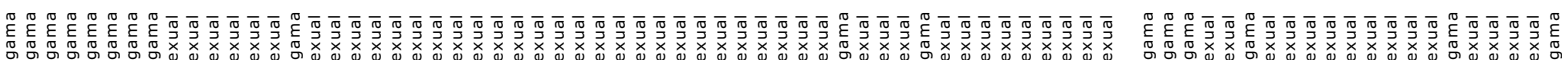

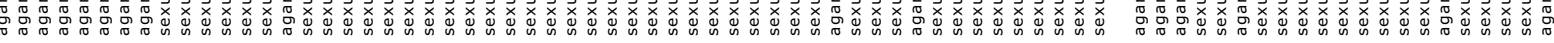
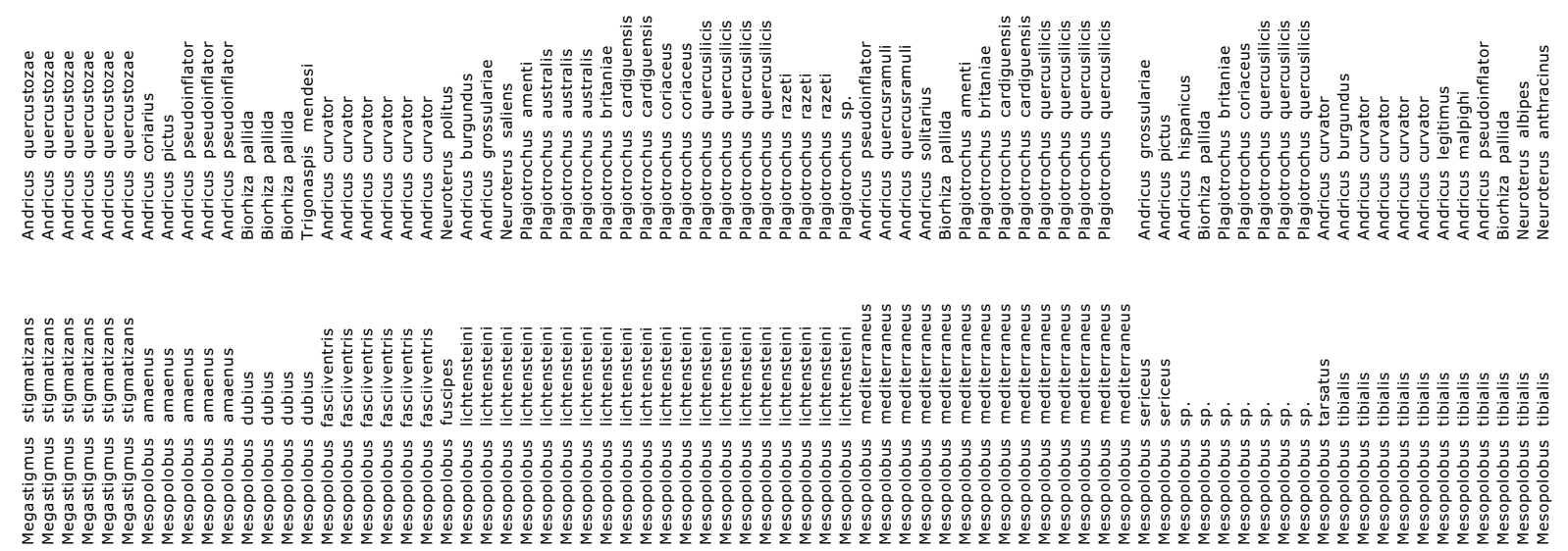


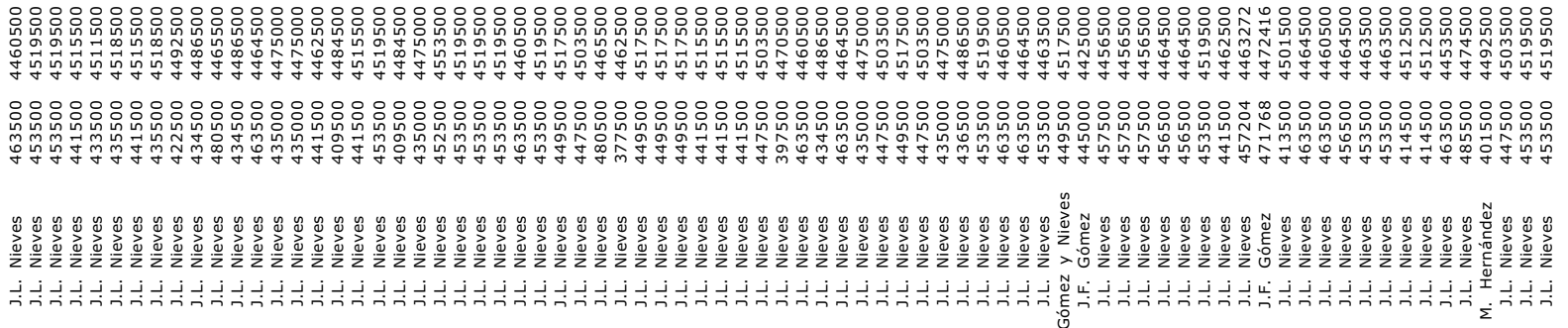

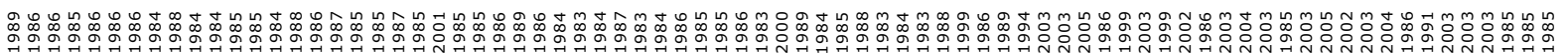

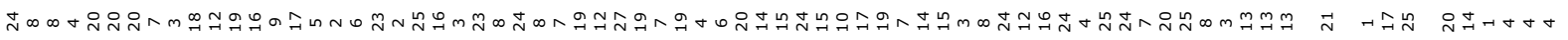

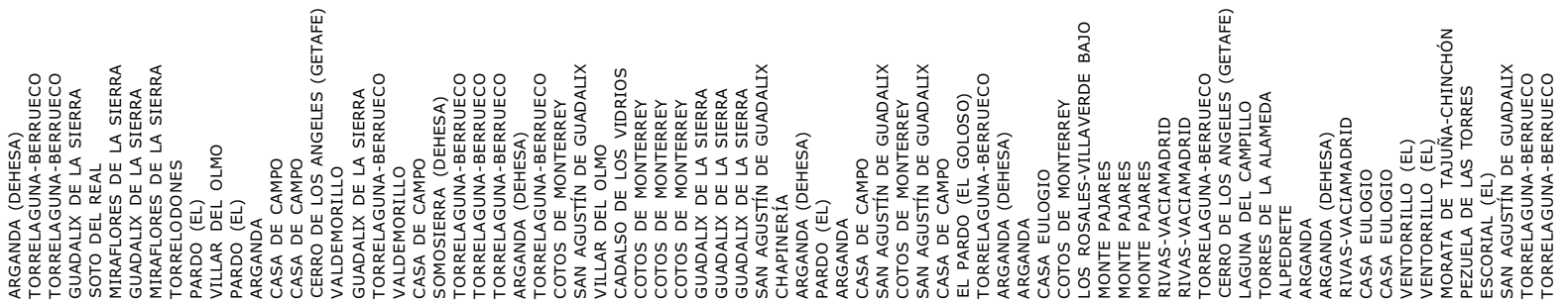

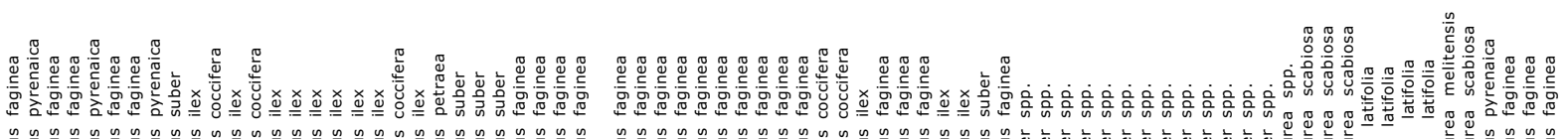

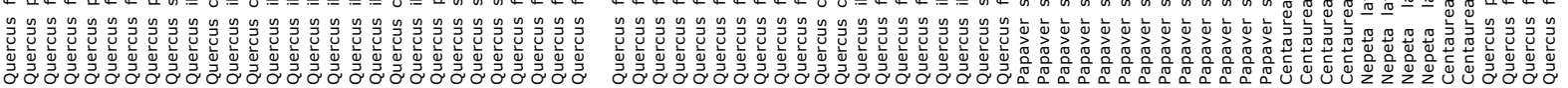

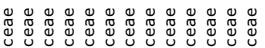

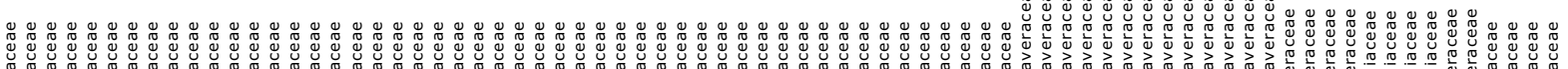

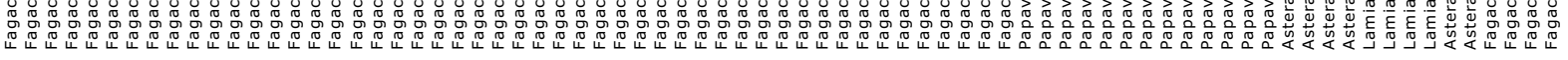

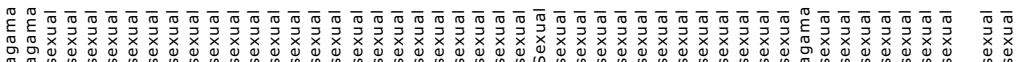

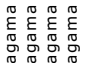
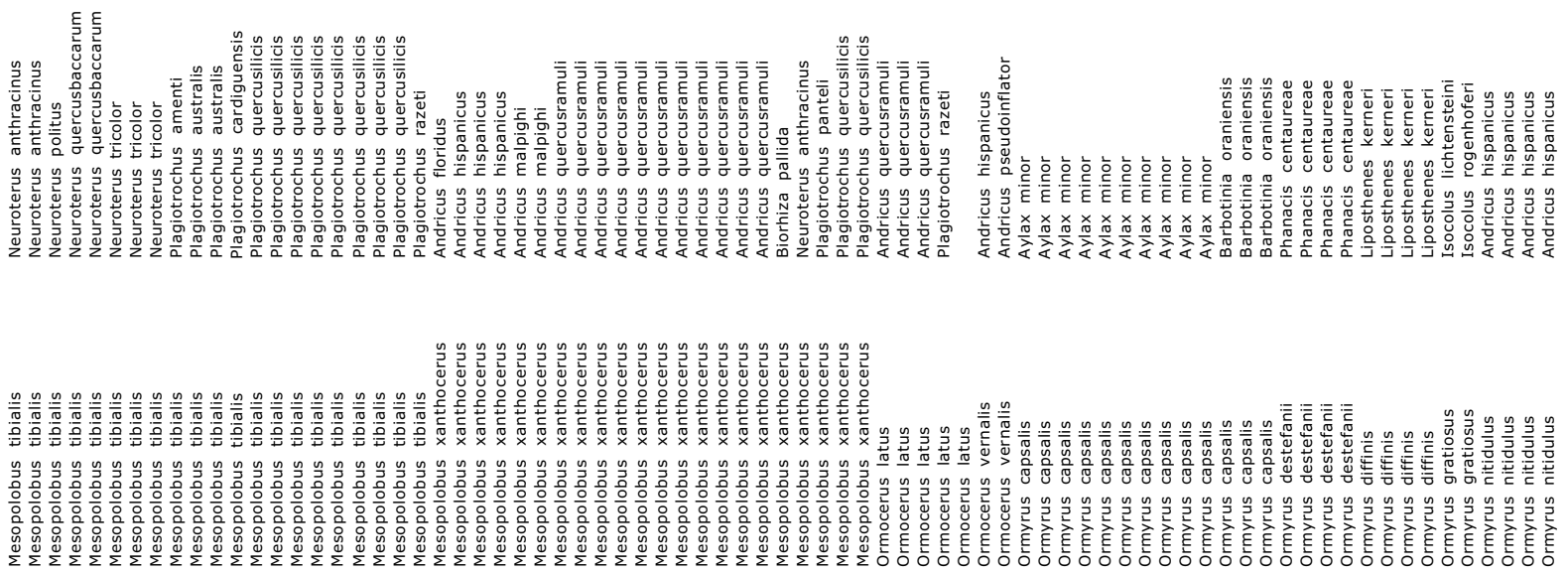


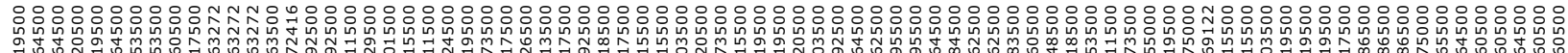

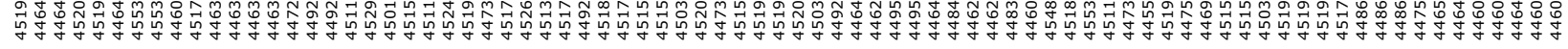

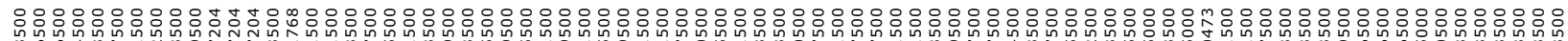

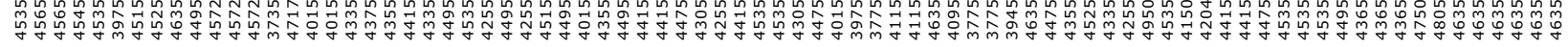

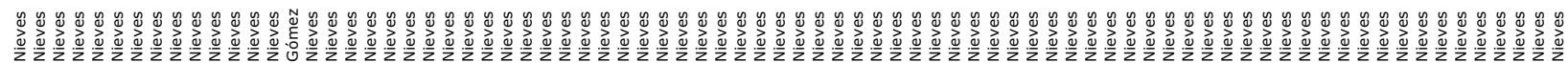

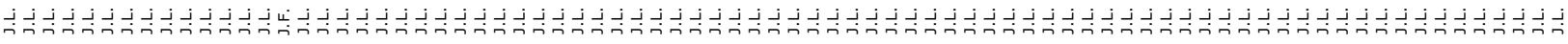

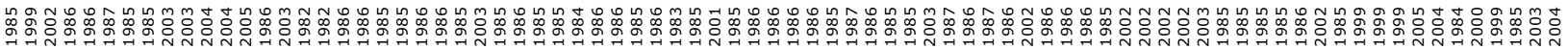

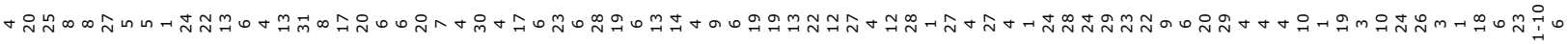

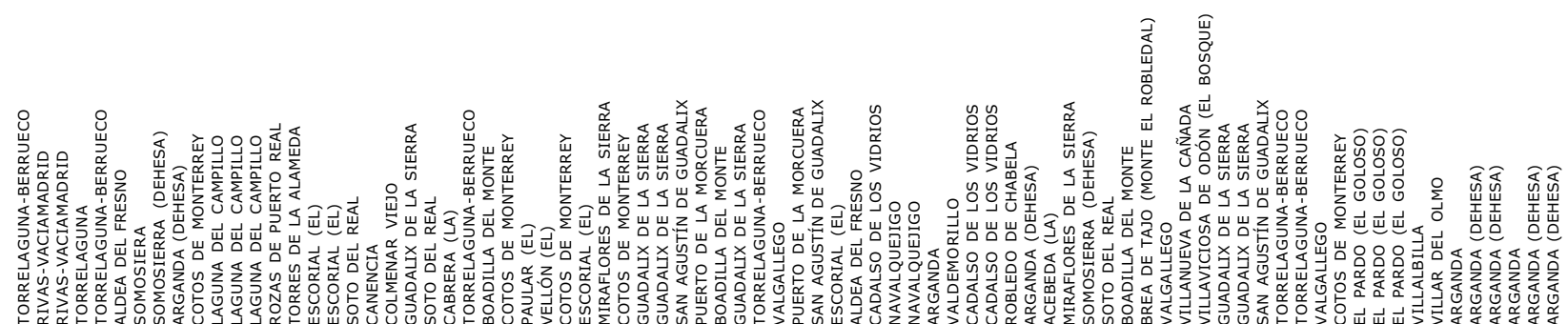

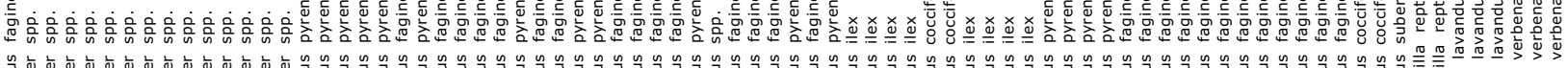

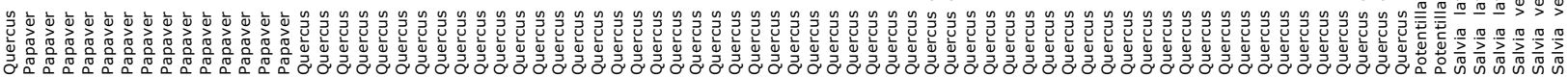

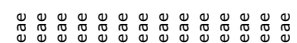

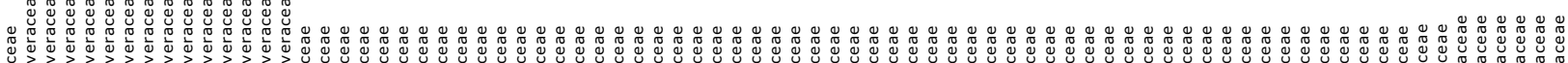

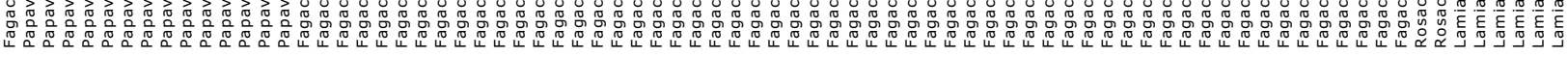
产

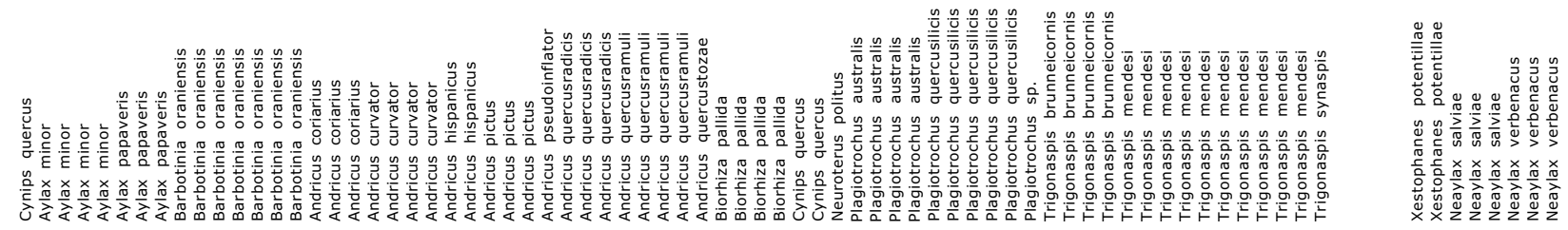

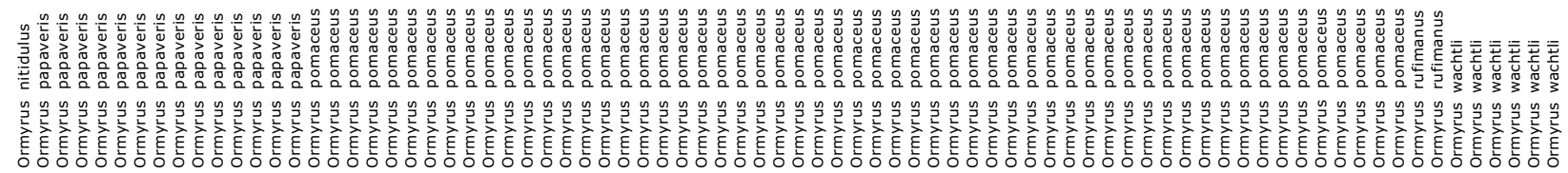




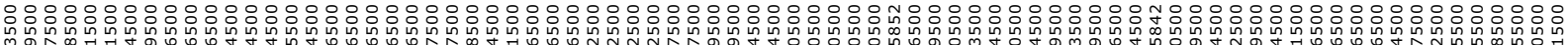

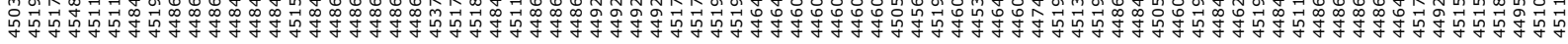

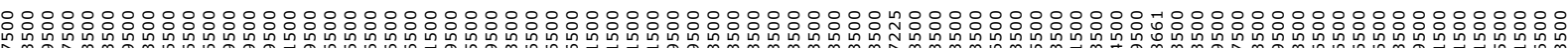

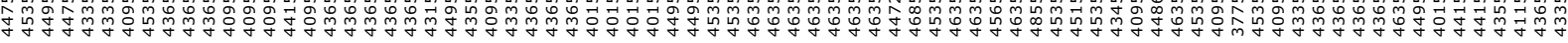

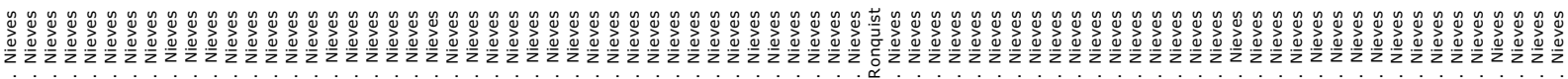

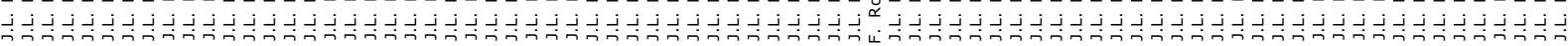

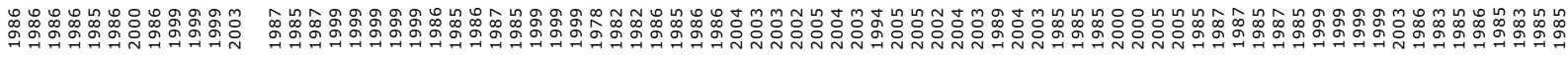

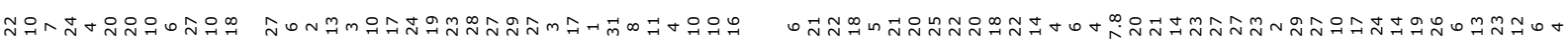

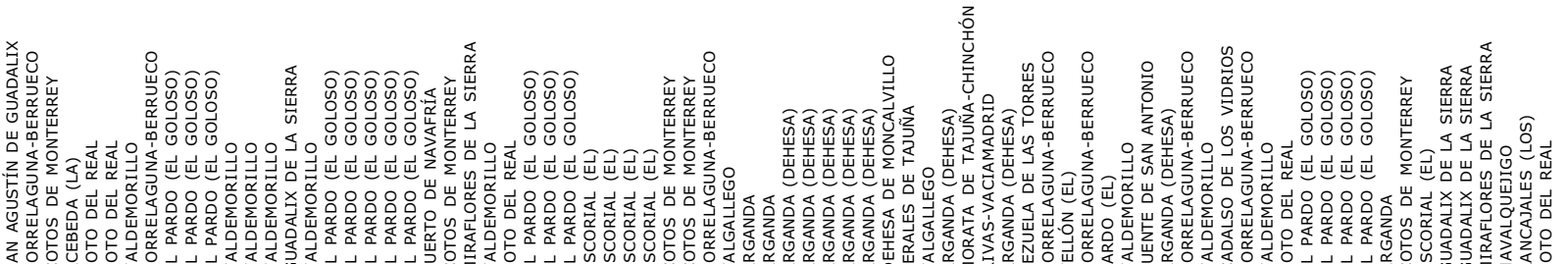

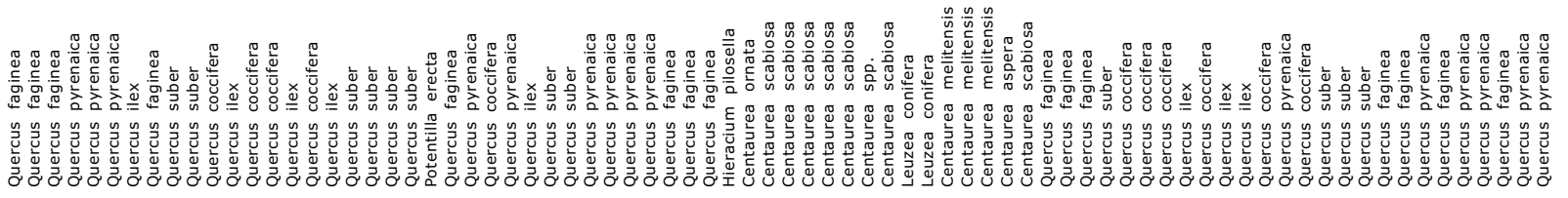

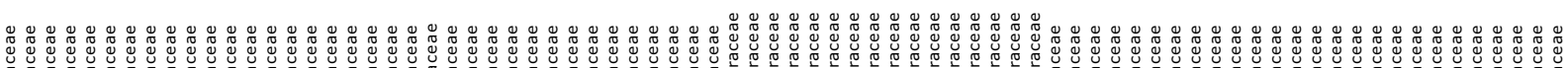

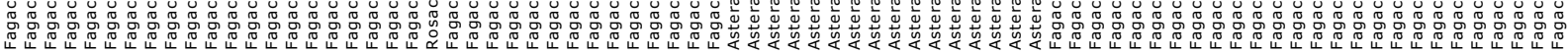

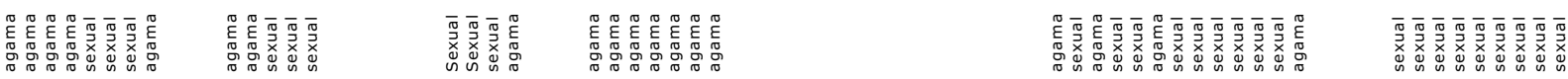

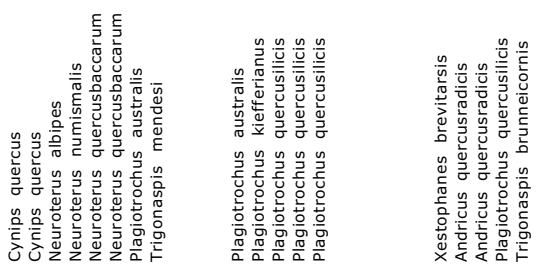

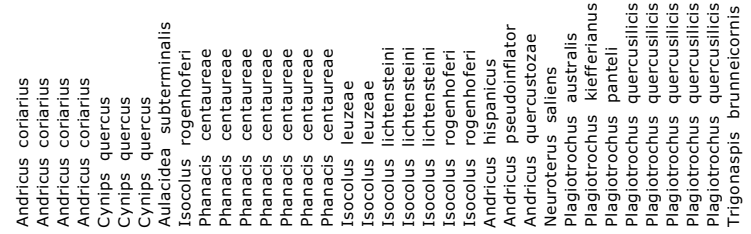

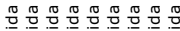

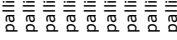

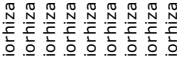

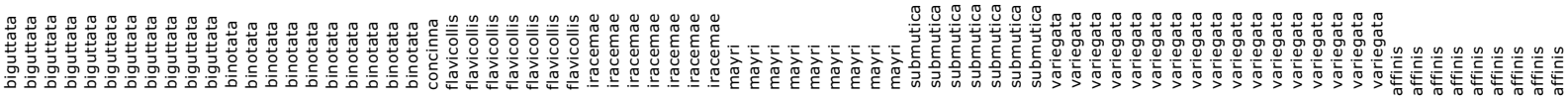

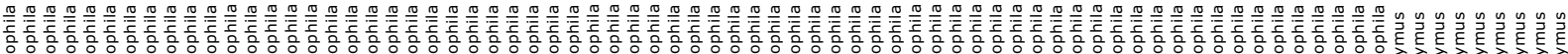

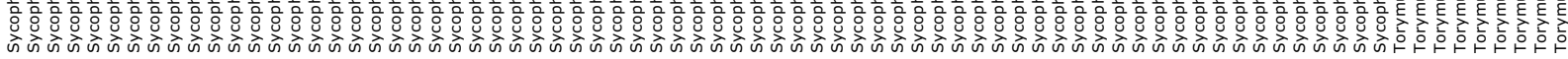




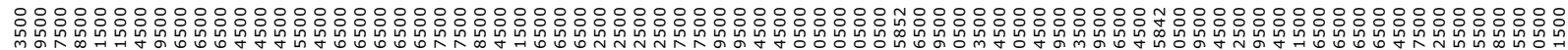

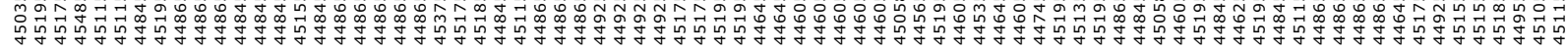

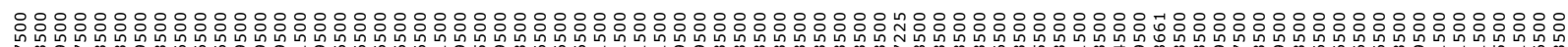

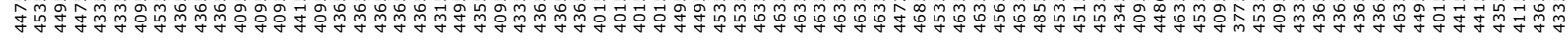

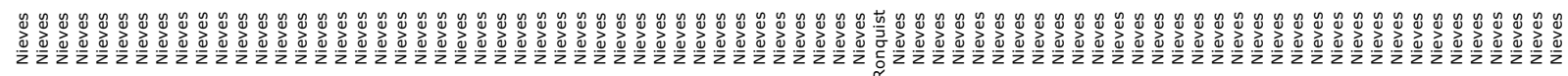

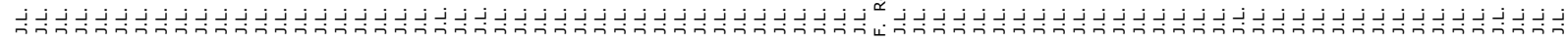

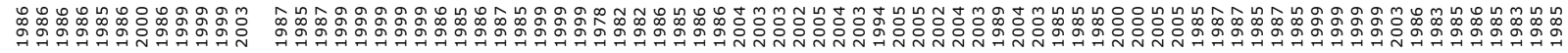

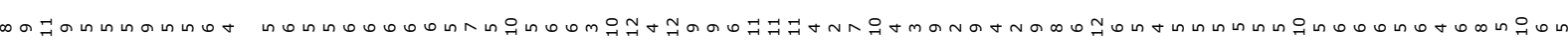

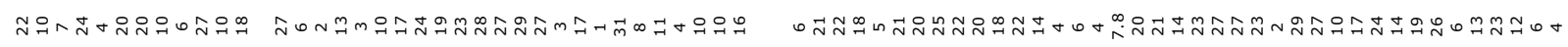

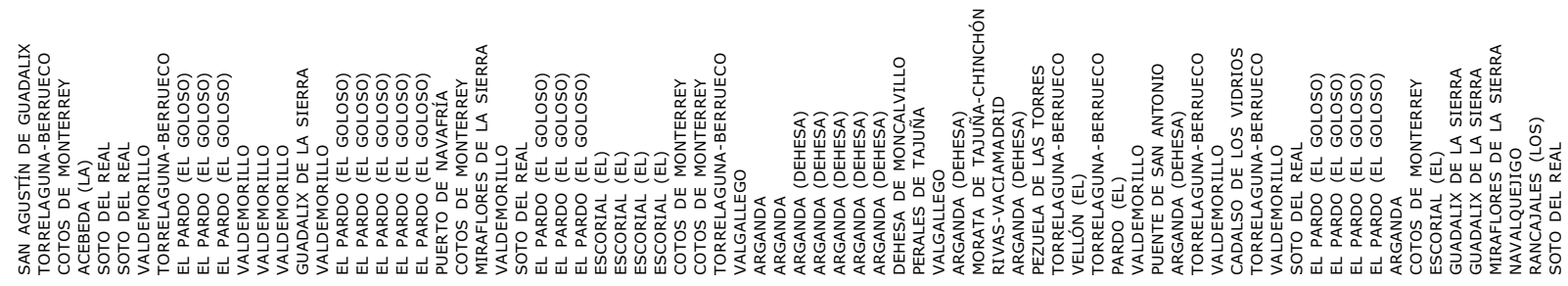

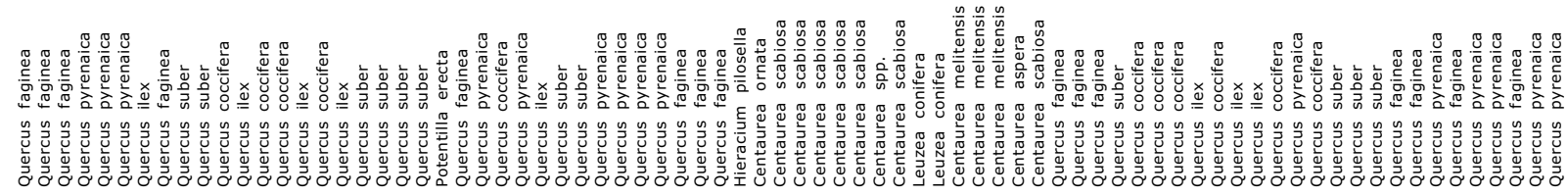

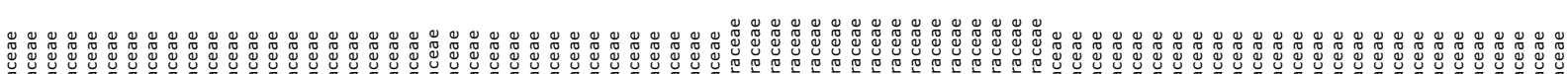
D.
D.

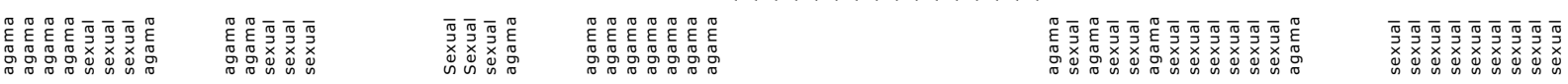

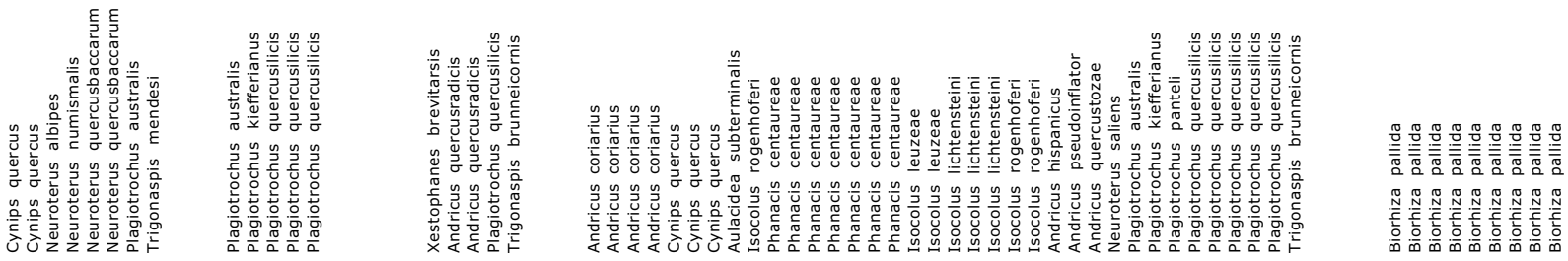

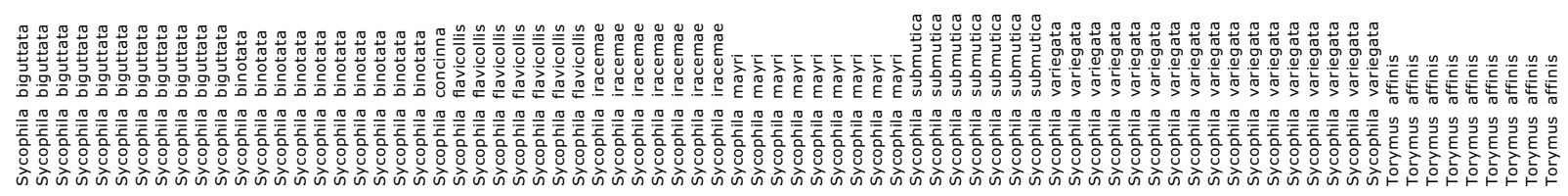




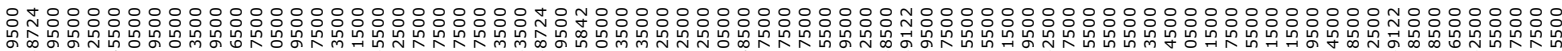

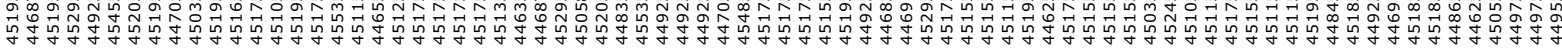

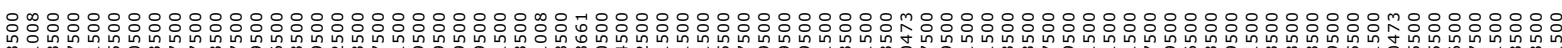

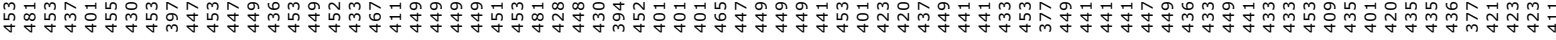

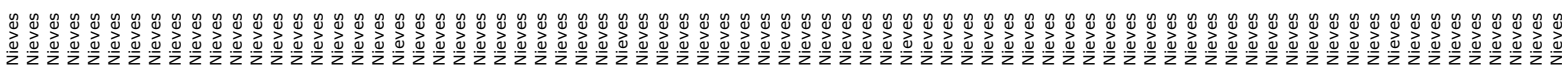

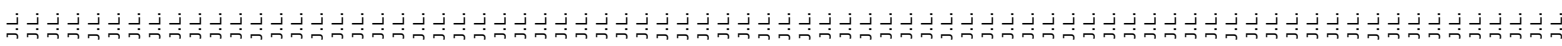

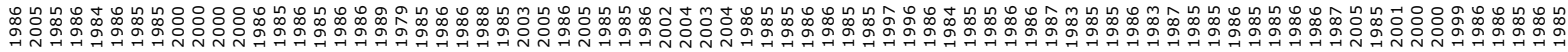

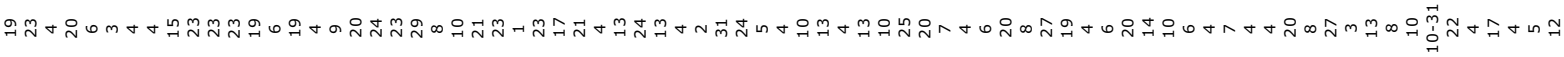

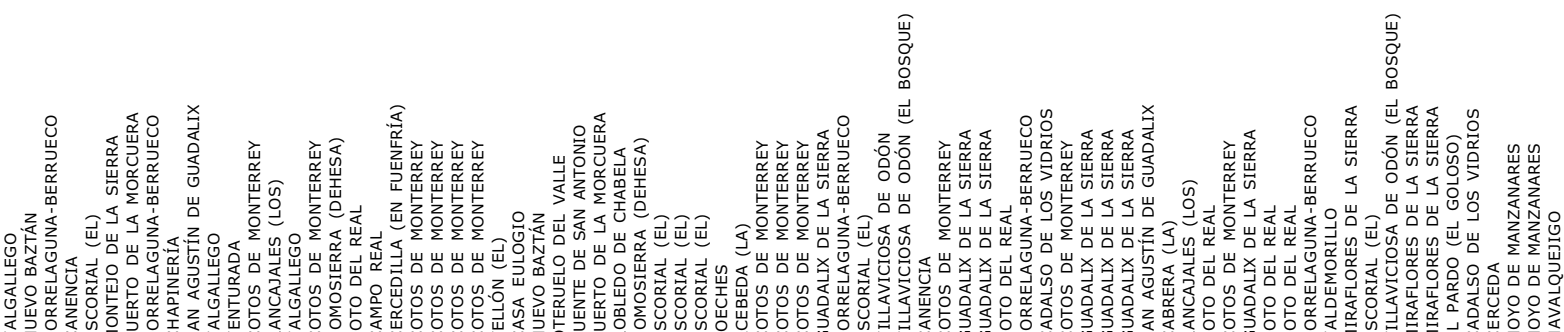

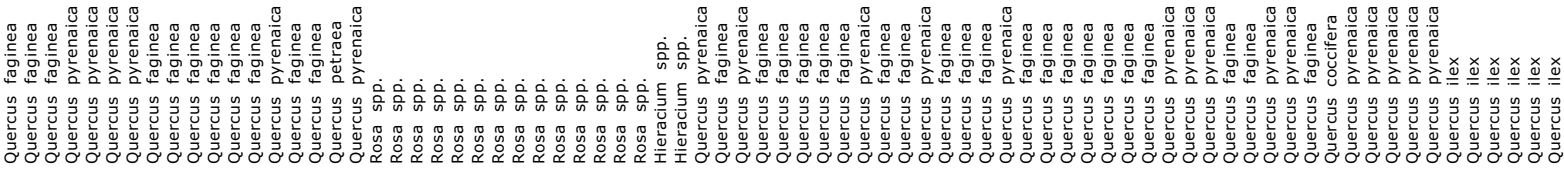

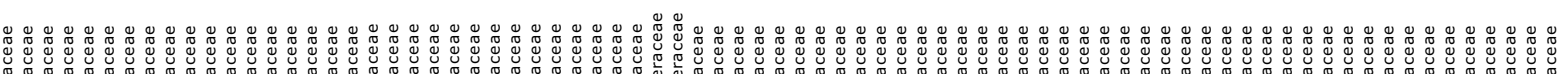
D.
D.

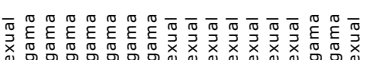

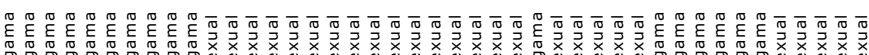

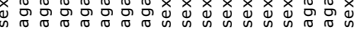

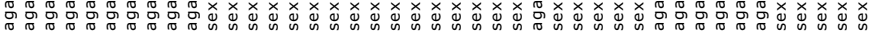

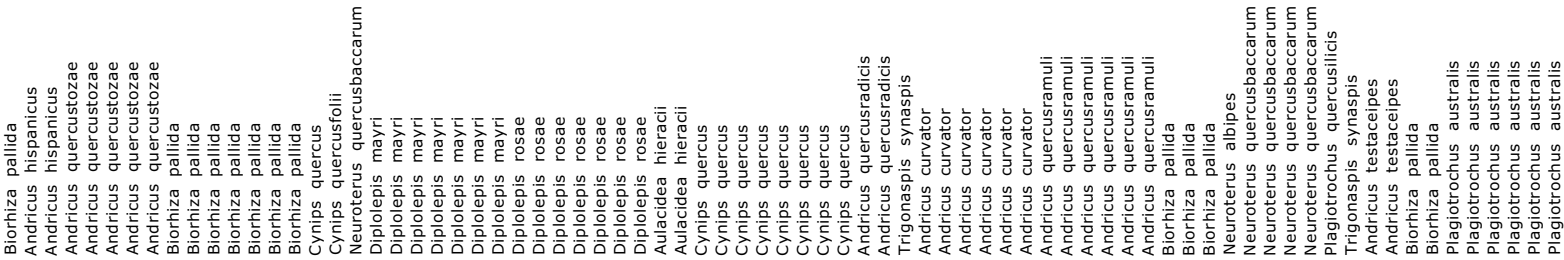

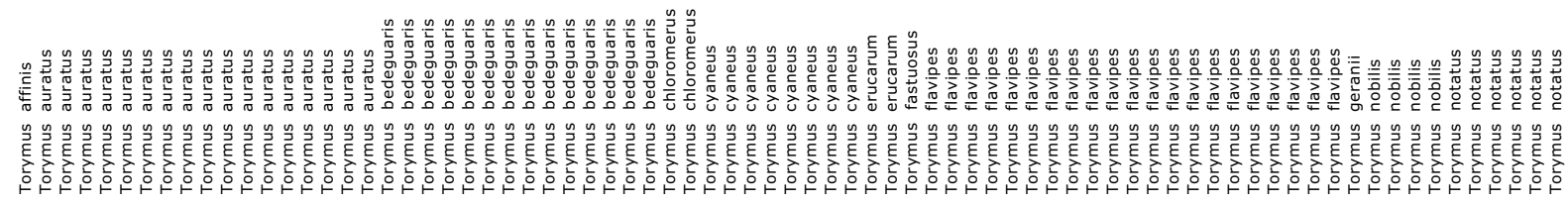




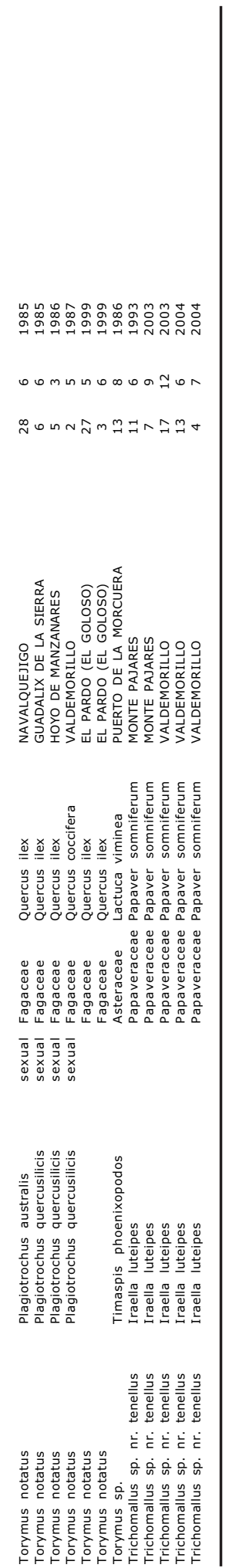

